\title{
Understanding the psychology of positive psychotic symptoms : an epidemiological and momentary assessment approach
}

Citation for published version (APA):

Thewissen, V. H. M. (2007). Understanding the psychology of positive psychotic symptoms : an epidemiological and momentary assessment approach. [Doctoral Thesis, Maastricht University]. Datawyse / Universitaire Pers Maastricht. https://doi.org/10.26481/dis.20071108vt

Document status and date:

Published: 01/01/2007

DOI:

10.26481/dis.20071108vt

Document Version:

Publisher's PDF, also known as Version of record

Please check the document version of this publication:

- A submitted manuscript is the version of the article upon submission and before peer-review. There can be important differences between the submitted version and the official published version of record.

People interested in the research are advised to contact the author for the final version of the publication, or visit the DOI to the publisher's website.

- The final author version and the galley proof are versions of the publication after peer review.

- The final published version features the final layout of the paper including the volume, issue and page numbers.

Link to publication

\footnotetext{
General rights rights.

- You may freely distribute the URL identifying the publication in the public portal. please follow below link for the End User Agreement:

www.umlib.nl/taverne-license

Take down policy

If you believe that this document breaches copyright please contact us at:

repository@maastrichtuniversity.nl

providing details and we will investigate your claim.
}

Copyright and moral rights for the publications made accessible in the public portal are retained by the authors and/or other copyright owners and it is a condition of accessing publications that users recognise and abide by the legal requirements associated with these

- Users may download and print one copy of any publication from the public portal for the purpose of private study or research.

- You may not further distribute the material or use it for any profit-making activity or commercial gain

If the publication is distributed under the terms of Article $25 \mathrm{fa}$ of the Dutch Copyright Act, indicated by the "Taverne" license above, 


\title{
Understanding the psychology of positive psychotic symptoms
}

\author{
An epidemiological and momentary \\ assessment approach
}


Cover design

Print
Sandra Daems, Annette Bouwels-Hermens

Datawyse, Maastricht

Universitaire Pers Maastricht

ISBN 978-90-5278-660-5

Copyright $\odot 2007$ VHM Thewissen, Maastricht

All rights reserved. No part of this thesis may be reproduced, stored or transmitted in any way or by any means without the prior permission of the author or, when appropriate, from the publishers of the publications. 


\title{
Understanding the psychology of positive psychotic symptoms
}

\author{
An epidemiological and momentary \\ assessment approach
}

PROEFSCHRIFT

ter verkrijging van de graad doctor aan de Universiteit Maastricht, op gezag van de Rector Magnificus, Prof. mr. G.P.M.F. Mols, volgens het besluit van het College van Decanen, in het openbaar te verdedigen op 8 november 2007 om 14:00u

door

Viviane Hubertine Marie Thewissen geboren op 20 maart 1980 te Heerlen 


\section{Promotoren}

Prof. dr. J. van Os

Prof. dr. R. P. Bentall (University of Manchester, UK)

\section{Copromotor}

Dr. I. Myin-Germeys

\section{Beoordelingscommissie}

Prof. dr. M. de Vries, voorzitter

Prof. dr. A. Aleman (Rijksuniversiteit Groningen)

Dr. D. Freeman (Institute of Psychiatry, London, UK)

Prof. dr. H. Merckelbach

Prof. dr. R. Wiers

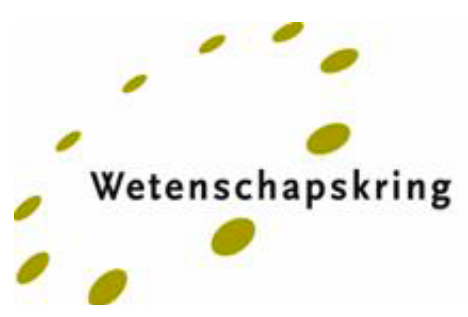

South Limburg Mental Health Research and Teaching Network, PhD Series

The research presented in this thesis was conducted at the Maastricht Brain \& Behaviour Institute and the Department of Psychiatry and Neuropsychology of Maastricht University, psychiatric hospital Vijverdal and Mondriaan Zorggroep.

The publication of this thesis was financially supported by: AstraZeneca B.V., BristolMyers Squibb B.V., Eli Lilly Nederland B.V., GlaxoSmithKline B.V., Janssen-Cilag B.V., Lundbeck B.V., Organon Nederland B.V., Servier Nederland Farma B.V., Wyeth Pharmaceuticals B.V. 
Aan mijn ouders

"When you want something, all the universe conspires in helping you to achieve it"

Paulo Coelho | The Alchemist 


\section{Paranimfen}

Nicole Gunther

Anne-Claire Schrijnemaekers 


\section{Contents}

$\begin{array}{lll}\text { Chapter } 1 & \text { Introduction } & 9\end{array}$

\section{Part 1}

Chapter 2 Instability in self-esteem and paranoia in a general population sample

Chapter 3 Fluctuations in self-esteem and paranoia in the context of daily life

Chapter 4 Emotional changes and paranoia: An experience sampling study

\section{Part 2}

Chapter $5 \quad$ Hearing impairment and psychosis revisited

Chapter 6 Hearing impairment and psychosis: A replication in a cohort of young adults

Chapter $7 \quad$ Epilogue

Summary

Samenvatting

Dankwoord

Curriculum vitae 



\section{Chapter 1}

INTRODUCTION 


\section{Phenomenology AND The CONCEPT OF PSYChOSIS}

Psychosis refers to a mental state in which there is a loss of contact with reality. Individuals who regularly experience a psychotic episode or psychotic symptoms are most frequently diagnosed as suffering from schizophrenia or bipolar disorder. Schizophrenia is one of the most chronic and disabling conditions of all major mental disorders and has a very heterogeneous symptom profile. According to the fourth edition of the Diagnostic and Statistical Manual of Mental Disorders (DSM-IV; American Psychiatric Association, 1994), the hallmark characteristics of schizophrenia are delusions, hallucinations, disorganised speech, chaotic or catatonic behaviour and negative symptoms (e.g. flat affect, poverty of thoughts or speech and apathy). Negative symptoms tend to be chronic, while positive symptoms (e.g. hallucinations, delusions and disorganised speech) are more transient in nature (Liddle, 2000). Schizophrenia has a profound negative impact on the affected person's quality of life as well as on the lives of key relatives (Moller-Leimkuhler, 2005) and has substantial economic impact on health care (Andlin-Sobocki \& Rossler, 2005). These are significant reasons for a considerable increase in research in this field over the past few decades. The lifetime prevalence of schizophrenia generally ranges between 0.5 and 1 percent (American Psychiatric Association, 1994), although a recent systematic review suggests prevalence rates of schizophrenia have generally been overestimated with the lifetime prevalence being closer to 0.4 percent (Saha, Chant, Welham, \& McGrath, 2005). This means in the Netherlands, between 65,600 and 164,000 people are likely to be diagnosed with schizophrenia at some point in their life.

Psychotic symptoms have traditionally been considered as features of "mental illness", which are either present or absent. This dichotomy is inherent in the categorical diagnostic systems used today, but really developed over a century ago by the German psychiatrist Emil Kraepelin (1896). Although this dichotomous, categorical representation of psychosis is convenient for professional communication and clinical decision-making, it may not be an accurate reflection of the psychosis phenotype in nature (Verdoux \& van Os, 2002). There is mounting evidence that psychotic symptoms are not only present in individuals identified as "cases of psychosis" but also occur in a proportion of individuals from the general population (Claridge, 1997; Peters, Joseph, \& Garety, 1999). For instance, 17.5 percent of the Dutch general population has reported positive psychosis-like experiences which resemble the clinical concept of psychosis (van Os, Hanssen, Bijl, \& Ravelli, 2000). Psychosis may therefore exist as a continuous 
trait or phenotype in nature, ranging from "normality" through clinical cases of psychosis (Johns \& van Os, 2001; Stefanis et al., 2002; Verdoux \& van Os, 2002). Published studies suggest that individuals with subclinical psychotic symptoms are at increased risk of making the transition to a clinical psychotic disorder (e.g. Poulton et al., 2000). In recent years, increasing attention has been given to early detection and intervention of psychosis in order to prevent individuals from making transitions from non-clinical to clinical psychosis. Biological, social and psychological factors are important in determining whether an individual will shift along the continuum, as well as in determining the position a person is going to occupy on the hypothesised continuum (van Os \& Verdoux, 2003). The studies described in this current thesis will focus on the psychological aspects underlying the psychosis phenotype.

Psychosis-like experiences in the general population show risk factor profiles similar to those in clinical psychosis (van Os, Hanssen, Bijl, \& Ravelli, 2000). Therefore the psychological mechanisms associated with psychotic disorders may also operate in these subclinical manifestations of psychosis, so investigating psychotic-like symptoms in individuals who do not meet the criteria for clinical psychosis is likely to constitute an attractive approach to elucidating the underlying mechanisms of risk. The strategy of investigating individuals at a lower level of the continuum is advantageous as it avoids potential confounds inherent to clinical patients, such as institutionalisation and side effects of medication (Claridge, 1994). In addition, since the prevalence of psychotic-like symptoms is much higher than the prevalence of the clinical disorder, it is easier to discover variability in subtle processes underlying the psychosis phenotype.

The continuum view of psychosis strongly fits with a dimensional approach in which psychotic symptoms are considered to vary in degree along several dimensions of psychopathology. Factor analytical studies of psychosis have yielded various symptom dimensions, such as the clinically valid four-factor solution with dimensions of positive, negative, depressive and manic symptoms (McGorry, Bell, Dudgeon, \& Jackson, 1998; van Os et al., 1999). Research into the aetiology and psychological mechanisms of psychosis has gradually shifted from a purely categorical syndrome-oriented approach to a dimensional, and even more specific, symptom-oriented approach (Bentall, 2006; Berner, 1997; Costello, 1992; van Os et al., 1999). A symptom-oriented approach to psychosis has the advantage that it offers a way to investigate the concept without accepting the traditional Kraepelian model (Bentall, 1990). Over the last two decades, this approach has facilitated greater theoretical understanding of the underlying 
psychological mechanisms responsible for psychotic symptoms, especially the aetiology of paranoia.

\section{THE CONCEPT OF PARANOIA}

Paranoid or persecutory delusions are the commonest and most frequently studied subtype of abnormal belief (Garety \& Hemsley, 1987; Jorgensen \& Jensen, 1994; Ndetei \& Vadher, 1984). Paranoia, paranoid or persecutory delusions refer to the experience in which an individual feels himself being the victim of some kind of malevolent plot (Bentall, 2003). A comprehensible personal account of paranoia has been written by Peter Chadwick, a British psychologist who has suffered from psychosis:

"A powerful idea of reference also overcame me from a television episode of Colombo and impulsively I decided to write letters to friends and colleagues about "this terrible persecution." It was a deadly mistake. After a few replies of the "we've not heard anything" variety, my subsequent (increasingly overwrought) letters, all of them long, were not answered. But nothing stimulates paranoia better than no feedback, and once you have conceived a delusion, something is bound to happen to confirm it. When phrases from the radio echoed phrases I had used in those very letters, it was "obvious" that the communications had been passed on to radio and then television personnel with the intent of influencing and mocking me. After all betrayal was what I was used to, why should not it be carrying on now? It seemed sensible. So much for my bonding with society. It was totally gone. I was alone and now trusted no one."

(Chadwick, 2007, p. 169)

In order to make a clearer distinction with delusions or ideas of reference (in which a person may, for example, have the experience of being watched or talked about), Freeman and Garety (2000) have offered a more narrow and detailed definition of persecutory delusions. They argue that the imagined perpetrator must clearly have 
the intention to cause harm specifically directed at the patient, at present or in the future. Throughout this thesis, however, the terms 'paranoia', 'paranoid' and 'persecutory' will be used interchangeably. Paranoia also refers to ordinary suspiciousness, found in individuals who do not meet the clinical criteria for psychosis. For many people, suspicions about the intentions of certain colleagues, neighbours or acquaintances appears to be a common experience. A conservative estimate of approximately 10 to 15 percent of the general population regularly experience paranoid or suspicious thoughts (Freeman \& Garety, 2006). Lack of control and feelings of hopelessness are associated with the frequency of these thoughts (Freeman et al., 2005).

The present interest in preventing individuals from making transitions from non-clinical to clinical psychosis (Johns \& van Os, 2001), makes the study of psychological mechanisms of paranoia especially important. A psychological account of paranoia which has received much attention is the psychosis as defence account (Bentall, 1994; Bentall, Corcoran, Howard, Blackwood, \& Kinderman, 2001).

\section{A PSYCHOLOGICAL PERSPECTIVE ON PARANOIA}

Over the last few years, considerable progress has been made in identifying cognitive psychological mechanisms underlying persecutory delusions, such as deficits in the ability to interpret other people's mental states, commonly known as 'theory of mind' (Corcoran, 2000; Corcoran, Cahill, \& Frith, 1997; Frith, 1992), biases in attention (Bentall \& Kaney, 1989; Fear, Sharp, \& Healy, 1996), reasoning (Garety et al., 2005; Garety, Hemsley, \& Wessely, 1991) and attributional style, which is the specific way of reasoning about the causes of events (Bentall, 1994; Bentall, Kaney, \& Dewey, 1991; Kinderman \& Bentall, 1997).

Bentall and colleagues (2001) have described a psychodynamically inflected model that integrates this available psychological research on paranoid delusions; the 'attribution - self-representation model' (Bentall, Corcoran, Howard, Blackwood, \& Kinderman, 2001). According to this model persecutory delusions have a defensive function and are the consequence of a coherent set of cognitive biases that serve to maintain the self-concept. Paranoid patients have latent negative beliefs about the self that are vulnerable to activation by negative events (Bentall \& Kaney, 2005). Patients with persecutory delusions attempt to avoid the activation of negative beliefs about the self by attributing threatening events to the actions of other people, with the adverse 
consequence of obtaining a negative world-view (Bentall, Kinderman, \& Kaney, 1994; Kaney \& Bentall, 1989). These external-personal attributions are an exaggerated form of the self-serving bias observed in persons from the general population (Lee, Randall, Beattie, \& Bentall, 2004). The 'attribution - self-representation model' emphasises the dynamic relationship between attributions and self-representations. Individuals generate causal attributions on the basis of current beliefs about the self and stimuli in the environment. The model proposes that the kind of attribution made at any point in time influences subsequent beliefs about the self, so that self-esteem and attributional style are coupled in a mutually inter-dependent system. One prediction from this model is that self-esteem will be highly unstable (fluctuating) in paranoid patients, since the attempts to avoid the activation of negative beliefs about the self are often dysfunctional. This particular prediction made by the model will be addressed in the chapters 2 and 3 of current thesis.

Freeman and colleagues (2002) take a different view on the development and maintenance of persecutory delusions. Given the multidimensional nature of paranoia, they have proposed a multifactorial model in which persecutory delusions are hypothesised to arise from an interaction between several factors (Freeman \& Garety, 2004a; Freeman \& Garety, 2004b; Freeman, Garety, Kuipers, Fowler, \& Bebbington, 2002). In this model, paranoia is conceptualised as an attempt to explain internal unusual or anomalous experiences (e.g. being aroused or experiencing intrusive sounds or hallucinations). Explanations are influenced by several factors, including pre-existing beliefs (e.g. seeing the self as vulnerable, others as potentially dangerous and the world as bad), personality, cognitive biases (e.g. externalising attributional biases and theory of mind difficulties) and emotional processes. Cognitive biases are important in determining whether a paranoid belief is more likely to become of a delusional intensity (Freeman \& Garety, 2004a). Emotions have a central role in this model, since persecutory delusions are a development of emotional concerns. Especially anxiety is postulated as being important in the generation of a persecutory delusion, since both anxiety and paranoia involve the anticipation of danger. The role of emotional processes in the development of daily life paranoia will be addressed in chapter 4 . 


\section{INVESTIGATING PARANOIA IN DAILY LIFE: THE EXPERIENCE SAMPLING METHOD}

The presence and degree of psychotic symptoms are highly dependent on the context. Previous research has demonstrated that daily life circumstances, such as the presence of other people, can influence the occurrence of delusions. Delusional experiences may therefore fluctuate within a very short time (Myin-Germeys, Nicolson, \& Delespaul, 2001). Investigating the dynamic mechanisms underlying paranoia requires a research method which allows the study of variability and interaction between psychotic symptoms, emotional experience, cognition and context. The Experience Sampling Method (ESM; Csikszentmihalyi \& Larson, 1987), a structured self-assessment diary technique, is pre-eminently appropriate for investigating these dynamic processes. In the studies described in chapters 3 and 4, subjects received a pre-programmed digital wristwatch and a set of paper-and-pencil assessment forms. Ten times a day on six consecutive days, the watch emitted a signal at randomized moments between 7.30 a.m. and 10.30 p.m. After every signal, reports of current context, mood, self-esteem and paranoid symptoms were collected.

ESM has several advantages as opposed to conventional research methods in the field of psychopathology. First, ESM allows to study individuals in their own real-life environment rather than the laboratory. Second, ESM yields momentary self-reported experiences. Retrospective self-reported experiences, on the other hand, may be affected by a memory bias. Third, ESM data collection results in multiple assessments over time, thereby offering greater statistical power. And finally, ESM allows the evaluation of the context in which symptoms appear. The feasibility, validity and reliability of ESM has been fully demonstrated in the field of psychopathology (e.g. Delespaul, 1995; deVries, 1992; Myin-Germeys, van Os, Schwartz, Stone, \& Delespaul, 2001).

\section{RISK FACTORS FOR PSYCHOSIS}

Data from epidemiological, twin and adoption studies (e.g. Gottesman \& Bertelsen, 1989; Tienari et al., 2004; van Os, Pedersen, \& Mortensen, 2004) show that both genes and environmental factors have joint effects on the liability to psychosis. Between 83 and 87 percent of the vulnerability to a psychotic disorder is genetically determined (Cardno et al., 1999). These genetic factors moderate the vulnerability to environmental factors, experienced by the individual from the moment of conception, through 
development, birth and maturation (Tsuang, Stone, \& Faraone, 2001). Over the past few years the following environmental risk factors have been described extensively: complications during pregnancy and birth (e.g. Marcelis et al., 1998), urban birth and upbringing (e.g. Spauwen, Krabbendam, Lieb, Wittchen, \& van Os, 2004), social adversities such as childhood trauma, migration and discrimination (e.g. Cantor-Graae \& Selten, 2005; Janssen et al., 2003; Read, van Os, Morrison, \& Ross, 2005), the use of cannabis (e.g. Henquet, Murray, Linszen, \& van Os, 2005) and stressful life events or daily life stress (e.g. Myin-Germeys, van Os, Schwartz, Stone, \& Delespaul, 2001; Norman \& Malla, 1993).

The impact of environmental factors on psychosis risk may be mediated by social cognitive and psychological mechanisms, including source monitoring (the capacity to discriminate between mental events and events in the world), theory of mind and attributional style. Childhood trauma or discrimination, for example, may lead to negative beliefs about the self, others and the world. Victimisation, even exposure in the form of childhood bullying, can therefore induce a paranoid attributional style (Janssen et al., 2003; Lataster et al., 2006; Read, van Os, Morrison, \& Ross, 2005). A risk factor for psychosis which has recently received renewed attention is the presence of deafness or hearing impairment. Problems in the domain of hearing may constitute a vulnerability to psychosis by impacting on social cognitive and psychological mechanisms.

\section{HEARING IMPAIRMENT AS A RISK FACTOR FOR PSYCHOSIS}

"Blindness cuts you off from things, while deafness cuts you off from people". This famous quote by Helen Keller (1880-1968), a deafblind woman, demonstrates that hearing defects can have a profound social and psychological impact on the affected individuals. Deafness is a comprehensive term including all types of hearing difficulty (Cooper, 1976). Because of its profound social and psychological influence, many studies have focussed on the relationship between deafness or hearing impairment and mental health. The findings of these studies, however, are divergent. A number of studies have shown a clear relationship between hearing impairment and depression (e.g. Strawbridge, Wallhagen, Shema, \& Kaplan, 2000), although other investigations have failed to support these findings (e.g. Bailly, de Chouly de Lenclave, \& Lauwerier, 2003). Similar findings apply to the relationship with psychotic symptoms. 
A series of studies by Cooper and colleagues in the mid-seventies demonstrated an association between deafness and paranoid psychosis in middle-aged and elderly individuals (Cooper \& Curry, 1976; Cooper, Curry, Kay, Garside, \& Roth, 1974; Kay, Cooper, Garside, \& Roth, 1976). The relationship has later also been demonstrated in younger individuals. David and colleagues (1995) investigated a large cohort of 18-yearold male Swedish conscripts and found a significant association between severe hearing loss and later schizophrenia. Du Feu and Fergusson (2003) however, claim that the incidence of schizophrenia in deaf individuals is similar to individuals from the general population.

Individuals with hearing problems may be at risk of social isolation and often experience social stigmatisation. It has been hypothesised that a long-term experience of subordinate position or outsider status, also known as 'social defeat', may increase the risk of schizophrenia (Selten \& Cantor-Graae, 2005, 2007). It may be clear that hearing impairment has a profound influence on interaction with the social environment. In line with Zimbardo, Andersen and Kabat (1981), we suggest that deafness may lead to psychosis by a possible social cognitive mechanism. As mentioned earlier in this introduction, it has been demonstrated that biases in social cognitive processes play a central role in the development of positive psychotic symptoms (e.g. Bentall, 2001; Bentall, Corcoran, Howard, Blackwood, \& Kinderman, 2001; Garety, Kuipers, Fowler, Freeman, \& Bebbington, 2001). Theory of mind and source monitoring are social cognitive processes which are most clearly related to the interaction with the world. It can therefore be hypothesised that when social interaction is impeded because of deafness or hearing impairment, it may well be possible that individuals will experience difficulties in inferring other people's mental states. Furthermore, when the auditory context disappears, individuals may experience difficulties with monitoring the source of information. Chapter 5 will focus on deafness or hearing impairment as a risk factor for psychosis. Age of onset and duration of hearing impairment are important predictors of possible consequences of deafness (Cooper, 1976; Cooper \& Curry, 1976). Chapter 6 will focus on early onset and duration of hearing impairment on the one hand and psychosis on the other. 


\section{AIMS AND OUTLINE OF THE THESIS}

The aims of current thesis are twofold. In part 1, the aim is to investigate the underlying psychological mechanisms responsible for paranoid symptoms. In part 2, the aim is to investigate a specific factor, deafness or hearing impairment, which can impact on the social cognitive and psychological mechanisms responsible for positive psychotic symptoms.

\section{Part 1}

In chapter 2, an epidemiological approach will be used to investigate whether paranoia is associated with (long-term) unstable self-esteem, as predicted by the abovementioned 'attribution - self-representation model'. Investigating a large sample of individuals from the general population can be useful in setting a theoretical framework for a better understanding of psychological models underlying psychosis. This 'cognitive epidemiology' approach is a valuable foundation on which to develop hypotheses regarding underlying mechanisms, which can subsequently be further investigated in smaller samples.

In chapter 3, the relationship between paranoia and self-esteem will be further investigated using a more refined methodology; the Experience Sampling Method. Whereas in the previous chapter, the relationship between paranoia and long-term selfesteem fluctuations was investigated, in current chapter short-term fluctuations in selfesteem are investigated in the context of daily life. This is important, since self-esteem may be highly dependent on contextual factors. The goal of the study described in this chapter was twofold. First, level and instability of self-esteem were investigated in the daily life of individuals who range across the psychosis continuum in level of paranoia. Second, the temporal relationship between changes in self-esteem and momentary paranoia were investigated in the daily life of these individuals.

Chapter 4 will address the role of emotional processes in the development of paranoid beliefs. Although previous studies have consistently shown an association between negative emotions and paranoia, a major shortcoming of these studies is that they only document cross-sectional associations which limits the interpretation of direction of causality. In the study described in this chapter, the Experience Sampling Method was 
used to investigate the dynamic relationship between daily life paranoia and several aspects of emotional experience in a sample of patients with positive psychotic symptoms. The study not only focussed on the cross-sectional association, but also on the temporal relationship between emotional states and paranoia. It was examined whether specific negative emotional states contribute to the development of paranoia or rather result from paranoid experiences.

\section{Part 2}

In Chapter 5, the presence of deafness or hearing impairment as a risk factor for psychosis will be investigated using an epidemiological approach. Previous studies on the association between hearing impairment and psychosis show inconsistent results. In addition, most of these studies have been confined to clinical populations. As lined out in the first part of the introduction, psychosis-like experiences in the general population show risk factor continuities with clinically relevant psychosis. In the study described in this chapter, the association between subjectively reported hearing impairment and the psychosis phenotype was investigated prospectively in an adult general population sample.

Chapter 6 will elaborate on the findings described in previous chapter. The study presented in current chapter aimed to replicate the findings of a relationship between hearing impairment and psychosis in a cohort of young adults from the general population. In addition, it was investigated to what degree any association was conditional on the duration of hearing problems as longer duration may be associated with stronger risk.

In chapter 7 , a short summary and integrative overview of the presented studies will be given. The results will be discussed and important implications for clinical practice as well as directions for further research will be mentioned. 


\section{References}

Andlin-Sobocki, P., \& Rossler, W. (2005). Cost of psychotic disorders in Europe. European Journal of Neurology, 12(Suppl 1), 74-77.

APA. (1994). DSM-IV: Diagnostic and Statistical Manual of Mental Disorders Washington, DC: APA.

Bailly, D., de Chouly de Lenclave, M. B., \& Lauwerier, L. (2003). [Hearing impairment and psychopathological disorders in children and adolescents. Review of the recent literature]. Encephale, 29(4 Pt 1), 329337.

Bentall, R. (2006). Madness explained: Why we must reject the Kraepelinian paradigm and replace it with a 'complaint-orientated' approach to understanding mental illness. Medical Hypotheses, 66(2), 220233.

Bentall, R. P. (1990). Reconstructing schizophrenia. London ; New York: Routledge.

Bentall, R. P. (1994). Cognitive biases and abnormal beliefs: Towards a model of persecutory delusions. In A. David \& J. Cutting (Eds.), The neuropsychology of schizophrenia (pp. 337-360). London: Erlbaum.

Bentall, R. P. (2001). Social cognition and delusional beliefs. In D. Penn \& P. Corrigan (Eds.), Social cognition and schizophrenia. Washington: American Psychological Associaton.

Bentall, R. P. (2003). Madness explained: psychosis and human nature. London: Penguin.

Bentall, R. P., Corcoran, R., Howard, R., Blackwood, N., \& Kinderman, P. (2001). Persecutory delusions: a review and theoretical integration. Clinical Psychology Review, 21(8), 1143-1192.

Bentall, R. P., \& Kaney, S. (1989). Content specific information processing and persecutory delusions: an investigation using the emotional Stroop test. British Journal of Medical Psychology, 62(Pt 4), $355-$ 364.

Bentall, R. P., \& Kaney, S. (2005). Attributional lability in depression and paranoia. British Journal of Clinical Psychology, 44(Pt 4), 475-488.

Bentall, R. P., Kaney, S., \& Dewey, M. E. (1991). Paranoia and social reasoning: an attribution theory analysis. British Journal of Clinical Psychology, 30(Pt 1), 13-23.

Bentall, R. P., Kinderman, P., \& Kaney, S. (1994). The self, atrributional processes and abnormal beliefs: Towards a model of persecutory delusions. Behavior Research and Therapy, 32(3), 331-341.

Berner, P. (1997). Conceptualization of schizophrenia: the symptom-oriented approach. Psychopathology, 30(5), 251-256.

Cantor-Graae, E., \& Selten, J. P. (2005). Schizophrenia and migration: a meta-analysis and review. American Journal of Psychiatry, 162(1), 12-24.

Cardno, A. G., Marshall, E. J., Coid, B., Macdonald, A. M., Ribchester, T. R., Davies, N. J., et al. (1999). Heritability estimates for psychotic disorders: the Maudsley twin psychosis series. Archives of General Psychiatry, 56(2), 162-168. 
Chadwick, P. K. (2007). Peer-professional first-person account: schizophrenia from the inside-phenomenology and the integration of causes and meanings. Schizophrenia Bulletin, 33(1), 166173.

Claridge, G. (1994). Single indicator of risk for schizophrenia: probable fact or likely myth? Schizophrenia Bulletin, 20(1), 151-168.

Claridge, G. (1997). Schizotypy : implications for illness and health. Oxford ; New York: Oxford University Press.

Cooper, A. F. (1976). Deafness and psychiatric illness. British Journal of Psychiatry, 129, 216-226.

Cooper, A. F., \& Curry, A. R. (1976). The pathology of deafness in the paranoid and affective psychoses of later life. Journal of Psychosomatic Research, 20(2), 97-105.

Cooper, A. F., Curry, A. R., Kay, D. W., Garside, R. F., \& Roth, M. (1974). Hearing loss in paranoid and affective psychoses of the elderly. Lancet, 2(7885), 851-854.

Corcoran, R. (2000). Theory of mind in other clinical conditions: is a selective 'theory of mind' deficit exclusive to autism? In S. Baron-Cohen, H. Tager-Flusberg \& D. J. Cohen (Eds.), Understanding other minds: perspectives from developmental cognitive neuroscience (2nd ed., pp. 391-421). Oxford ; New York: Oxford University Press.

Corcoran, R., Cahill, C., \& Frith, C. D. (1997). The appreciation of visual jokes in people with schizophrenia: a study of 'mentalizing' ability. Schizophrenia Research, 24(3), 319-327.

Costello, C. G. (1992). Research on symptoms versus research on syndromes. Arguments in favour of allocating more research time to the study of symptoms. British Journal of Psychiatry, 160, 304-308.

Csikszentmihalyi, M., \& Larson, R. (1987). Validity and reliability of the Experience-Sampling Method. Journal of Nervous and Mental Disease, 175(9), 526-536.

David, A., Malmberg, A., Lewis, G., Brandt, L., \& Allebeck, P. (1995). Are there neurological and sensory risk factors for schizophrenia? Schizophrenia Research, 14(3), 247-251.

Delespaul, P. (1995). Assessing Schizophrenia in Daily Life. Maastricht, The Netherlands: Universitaire Pers Maastricht.

deVries, M. W. (1992). The Experience of psychopathology : investigating mental disorders in their natural settings. Cambridge ; New York: Cambridge University Press.

du Feu, M., \& Fergusson, K. (2003). Sensory impairment and mental health. Advances in Psychiatric Treatment, 9, 95-103.

Fear, C., Sharp, H., \& Healy, D. (1996). Cognitive processes in delusional disorders. British Journal of Psychiatry, 168(1), 61-67.

Freeman, D., \& Garety, P. (2004a). Bats among birds. The Psychologist, 17(11), 642-645.

Freeman, D., \& Garety, P. (2006). Helping patients with paranoid and suspicious thoughts: a cognitivebehavioural approach. Advances in Psychiatric Treatment, 12, 404-415. 
Freeman, D., \& Garety, P. A. (2000). Comments on the content of persecutory delusions: does the definition need clarification? British Journal of Clinical Psychology, 39(Pt 4), 407-414.

Freeman, D., \& Garety, P. A. (2004b). Paranoia : the psychology of persecutory delusions (1st ed.). Hove, East Sussex ; New York: Psychology Press.

Freeman, D., Garety, P. A., Bebbington, P. E., Smith, B., Rollinson, R., Fowler, D., et al. (2005). Psychological investigation of the structure of paranoia in a non-clinical population. British Journal of Psychiatry, $186,427-435$.

Freeman, D., Garety, P. A., Kuipers, E., Fowler, D., \& Bebbington, P. E. (2002). A cognitive model of persecutory delusions. British Journal of Clinical Psychology, 41(Pt 4), 331-347.

Frith, C. D. (1992). The Cognitive Neuropsychology of Schizophrenia. Hove: Lawrence Erlbaum Associates.

Garety, P. A., Freeman, D., Jolley, S., Dunn, G., Bebbington, P. E., Fowler, D. G., et al. (2005). Reasoning, emotions, and delusional conviction in psychosis. Journal of Abnormal Psychology, 114(3), 373-384.

Garety, P. A., \& Hemsley, D. R. (1987). Characteristics of delusional experience. European Archives of Psychiatry and Neurological Sciences, 236(5), 294-298.

Garety, P. A., Hemsley, D. R., \& Wessely, S. (1991). Reasoning in deluded schizophrenic and paranoid patients. Biases in performance on a probabilistic inference task. Journal of Nervous and Mental Disease, 179(4), 194-201.

Garety, P. A., Kuipers, E., Fowler, D., Freeman, D., \& Bebbington, P. E. (2001). A cognitive model of the positive symptoms of psychosis. Psychological Medicine, 31(2), 189-195.

Gottesman, II, \& Bertelsen, A. (1989). Confirming unexpressed genotypes for schizophrenia. Risks in the offspring of Fischer's Danish identical and fraternal discordant twins. Archives of General Psychiatry, 46(10), 867-872.

Henquet, C., Murray, R., Linszen, D., \& van Os, J. (2005). The environment and schizophrenia: the role of cannabis use. Schizophrenia Bulletin, 31(3), 608-612.

Janssen, I., Hanssen, M., Bak, M., Bijl, R. V., de Graaf, R., Vollebergh, W., et al. (2003). Discrimination and delusional ideation. British Journal of Psychiatry, 182, 71-76.

Johns, L. C., \& van Os, J. (2001). The continuity of psychotic experiences in the general population. Clinical Psychology Review, 21(8), 1125-1141.

Jorgensen, P., \& Jensen, J. (1994). Delusional beliefs in first admitters. A clinical description. Psychopathology, 27(1-2), 100-112.

Kaney, S., \& Bentall, R. P. (1989). Persecutory delusions and attributional style. British Journal of Medical Psychology, 62(Pt 2), 191-198.

Kay, D. W., Cooper, A. F., Garside, R. F., \& Roth, M. (1976). The differentiation of paranoid from affective psychoses by patients' premorbid characteristics. British Journal of Psychiatry, 129, 207-215. 
Kinderman, P., \& Bentall, R. P. (1997). Causal attributions in paranoia and depression: internal, personal, and situational attributions for negative events. Journal of Abnormal Psychology, 106(2), 341-345.

Kraepelin, E. (1896). Ein Lehrbuch für Studierende und Ärzte (5 ed.). Leipzig: Barth.

Lataster, T., van Os, J., Drukker, M., Henquet, C., Feron, F., Gunther, N., et al. (2006). Childhood victimisation and developmental expression of non-clinical delusional ideation and hallucinatory experiences: victimisation and non-clinical psychotic experiences. Social Psychiatry and Psychiatric Epidemiology, 41(6), 423-428.

Lee, D. A., Randall, F., Beattie, G., \& Bentall, R. P. (2004). Delusional discourse: an investigation comparing the spontaneous causal attributions of paranoid and non-paranoid individuals. Psychology and Psychotherapy, 77(Pt 4), 525-540.

Liddle, P. F. (2000). Schizophrenia and acute transient psychotic disorders. In M. G. Gelder, J. J. Lopez-Ibor \& N. Andreasen (Eds.), New Oxford Textbook of Psychiatry (1st ed., Vol. 1). Oxford: Oxford University Press.

Marcelis, M., van Os, J., Sham, P., Jones, P., Gilvarry, C., Cannon, M., et al. (1998). Obstetric complications and familial morbid risk of psychiatric disorders. American Journal of Medical Genetics, 81(1), 2936.

McGorry, P. D., Bell, R. C., Dudgeon, P. L., \& Jackson, H. J. (1998). The dimensional structure of first episode psychosis: an exploratory factor analysis. Psychological Medicine, 28(4), 935-947.

Moller-Leimkuhler, A. M. (2005). Burden of relatives and predictors of burden. Baseline results from the Munich 5-year-follow-up study on relatives of first hospitalized patients with schizophrenia or depression. European Archives of Psychiatry and Clinical Neuroscience, 255(4), 223-231.

Myin-Germeys, I., Nicolson, N. A., \& Delespaul, P. A. (2001). The context of delusional experiences in the daily life of patients with schizophrenia. Psychological Medicine, 31(3), 489-498.

Myin-Germeys, I., van Os, J., Schwartz, J. E., Stone, A. A., \& Delespaul, P. A. (2001). Emotional reactivity to daily life stress in psychosis. Archives of General Psychiatry, 58(12), 1137-1144.

Ndetei, D. M., \& Vadher, A. (1984). Frequency and clinical significance of delusions across cultures. Acta Psychiatrica Scandinavica, 70(1), 73-76.

Norman, R. M., \& Malla, A. K. (1993). Stressful life events and schizophrenia. I: A review of the research. British Journal of Psychiatry, 162, 161-166.

Peters, E. R., Joseph, S. A., \& Garety, P. A. (1999). Measurement of delusional ideation in the normal population: introducing the PDI (Peters et al. Delusions Inventory). Schizophrenia Bulletin, 25(3), 553-576.

Poulton, R., Caspi, A., Moffitt, T. E., Cannon, M., Murray, R., \& Harrington, H. (2000). Children's selfreported psychotic symptoms and adult schizophreniform disorder: a 15-year longitudinal study. Archives of General Psychiatry, 57(11), 1053-1058. 
Read, J., van Os, J., Morrison, A. P., \& Ross, C. A. (2005). Childhood trauma, psychosis and schizophrenia: a literature review with theoretical and clinical implications. Acta Psychiatrica Scandinavica, 112(5), 330-350.

Saha, S., Chant, D., Welham, J., \& McGrath, J. (2005). A systematic review of the prevalence of schizophrenia. PLoS Medicine, 2(5), e141.

Selten, J. P., \& Cantor-Graae, E. (2005). Social defeat: risk factor for schizophrenia? British Journal of Psychiatry, 187, 101-102.

Selten, J. P., \& Cantor-Graae, E. (2007). Hypothesis: social defeat is a risk factor for schizophrenia. British Journal of Psychiatry Suppl, in press.

Spauwen, J., Krabbendam, L., Lieb, R., Wittchen, H. U., \& van Os, J. (2004). Does urbanicity shift the population expression of psychosis? Journal of Psychiatric Research, 38(6), 613-618.

Stefanis, N. C., Hanssen, M., Smirnis, N. K., Avramopoulos, D. A., Evdokimidis, I. K., Stefanis, C. N., et al. (2002). Evidence that three dimensions of psychosis have a distribution in the general population. Psychological Medicine, 32(2), 347-358.

Strawbridge, W. J., Wallhagen, M. I., Shema, S. J., \& Kaplan, G. A. (2000). Negative consequences of hearing impairment in old age: a longitudinal analysis. Gerontologist, 40(3), 320-326.

Tienari, P., Wynne, L. C., Sorri, A., Lahti, I., Laksy, K., Moring, J., et al. (2004). Genotype-environment interaction in schizophrenia-spectrum disorder. Long-term follow-up study of Finnish adoptees. British Journal of Psychiatry, 184, 216-222.

Tsuang, M. T., Stone, W. S., \& Faraone, S. V. (2001). Genes, environment and schizophrenia. British Journal of Psychiatry Suppl, 40, s18-24.

van Os, J., Gilvarry, C., Bale, R., Van Horn, E., Tattan, T., White, I., et al. (1999). A comparison of the utility of dimensional and categorical representations of psychosis. UK700 Group. Psychological Medicine, 29(3), 595-606.

van Os, J., Hanssen, M., Bijl, R. V., \& Ravelli, A. (2000). Strauss (1969) revisited: a psychosis continuum in the general population? Schizophrenia Research, 45(1-2), 11-20.

van Os, J., Pedersen, C. B., \& Mortensen, P. B. (2004). Confirmation of synergy between urbanicity and familial liability in the causation of psychosis. Am J Psychiatry, 161(12), 2312-2314.

van Os, J., \& Verdoux, H. (2003). Diagnosis and classification of schizophrenia: categories versus dimensions, distributions versus disease. In R. M. Murray, P. B. Jones, E. Susser, J. van Os \& M. Cannon (Eds.), The Epidemiology of Schizophrenia (pp. 364-410). Cambridge, UK: Cambridge University Press.

Verdoux, H., \& van Os, J. (2002). Psychotic symptoms in non-clinical populations and the continuum of psychosis. Schizophrenia Research, 54(1-2), 59-65.

Zimbardo, P. G., Andersen, S. M., \& Kabat, L. G. (1981). Induced hearing deficit generates experimental paranoia. Science, 212(4502), 1529-1531. 


\section{Chapter 2}

\section{INSTABILITY IN SELF-ESTEEM AND PARANOIA IN A GENERAL POPULATION SAMPLE}

This chapter was published as:

Viviane Thewissen, Inez Myin-Germeys, Richard Bentall ${ }^{\mathrm{a}}$, Ron de Graaf ${ }^{\mathrm{b}}$, Wilma

Vollebergh $^{\mathrm{b}}$ and Jim van Os. (2007). Instability in self-esteem and paranoia in a general population sample. Social Psychiatry and Psychiatric Epidemiology, 42(1), 1-5.

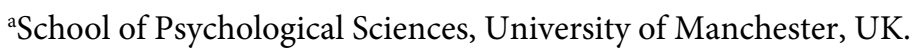

'The Netherlands Institute of Mental Health and Addiction, Trimbos Institute, Utrecht, The Netherlands. 


\section{ABSTRACT}

Research on the association between paranoia and self-esteem has yielded inconsistent findings. Some studies have indicated an association between paranoia and low selfesteem, while other studies have shown an association with high self-esteem. A plausible explanation for these inconsistencies is that self-esteem is unstable in paranoid individuals. The association between instability in self-esteem and paranoia was assessed in a general population risk set of 4636 individuals using logistic regression analysis. Self-esteem instability was significantly associated with the presence of paranoid symptoms (OR 1.27 95\% CI 1.12-1.45) and not with other positive psychotic symptoms (OR 1.09 95\% CI 0.96-1.23), adjusted for a range of a priori selected confounders. The finding of a specific association between unstable self-esteem and paranoia is in line with a recent psychological model suggesting that paranoid beliefs arise partly as a consequence of dysfunctional efforts to regulate self-esteem. 


\section{INTRODUCTION}

Self-esteem is the focus of much research in contemporary psychology and has become an important focus of study in the context of psychological models of psychosis (Barrowclough et al., 2003). It can be described as a favourable or unfavourable attitude toward the self (Rosenberg, 1965). Low levels of self-esteem have been associated with a number of psychiatric disorders, such as major depression, borderline personality disorder and schizophrenia (Guillon, Crocq, \& Bailey, 2003; Silverstone, 1991). Selfesteem has also been hypothesized to play a causal and maintaining role in persecutory delusions (Bentall, Corcoran, Howard, Blackwood, \& Kinderman, 2001; Freeman et al., 1998; Krabbendam et al., 2002).

Studies which have investigated the specific association between self-esteem and paranoid delusions show inconsistent results. Whereas low levels of self-esteem have been associated with paranoid ideation, both in patients with psychosis (Drake et al., 2004; Freeman et al., 1998) and in non-clinical samples (Combs \& Penn, 2004; Ellett, Lopes, \& Chadwick, 2003; Martin \& Penn, 2001), a number of other studies demonstrated relatively high or even normal self-esteem in paranoid patients (Candido \& Romney, 1990; Lyon, Kaney, \& Bentall, 1994). Candido and Romney (1990) assessed global self-esteem in a group of paranoid patients, a group of depressed patients, and a group of patients who were both paranoid and depressed. They demonstrated high selfesteem in the paranoid group, low self-esteem in the depressed group and intermediate scores in the group of patients who were both paranoid and depressed.

The above mentioned studies illustrate that self-esteem is widely assumed to be a trait, suggesting that self-esteem is either high or low, but essentially stable. Some researchers, however, have suggested that self-esteem may vary dynamically across time (Kernis, 2005; Kernis, Cornell, Sun, Berry, \& Harlow, 1993; Kernis \& Goldman, 2003; Leary \& Tangney, 2003). The simple distinction of high versus low self-esteem does not sufficiently capture the role of self-esteem in psychological processes. A more valid way of investigating self-esteem, therefore, may be to include not only the level of selfesteem, but also self-esteem instability. Self-esteem level represents the person's general or typical feelings of global self-worth and self-liking, whereas self-esteem instability reflects the magnitude of fluctuations that people experience in their immediate feelings of self-worth (Greenier et al., 1999; Kernis, 2005). Individuals with unstable self-esteem are found to be more emotionally reactive to everyday events (Kernis, 1993), react more strongly to self-esteem threats (Kernis, Grannemann, \& Barclay, 1989), experience more 
depression when faced with daily hassles (Kernis et al., 1998), and show problems in psychological functioning (Paradise \& Kernis, 2002). Individuals with high, but highly fluctuating, self-esteem have an excessive tendency to attribute negative experiences to external causes (Kernis, 1993). This last finding is interesting, because this particular attribution style resembles the abnormal style of reasoning about the cause of events in individuals with paranoid delusions (Bentall, Corcoran, Howard, Blackwood, \& Kinderman, 2001; Fear, Sharp, \& Healy, 1996; Kaney \& Bentall, 1989, 1992; Lee \& Won, 1998; Sharp, 1997). It is therefore attractive to hypothesize that self-esteem instability may be associated with paranoid thinking.

Paranoid ideation as well as other psychotic symptoms are not only present in individuals diagnosed with a psychotic disorder but also in a proportion of non-ill individuals from the general population (Fenigstein \& Vanable, 1992). Psychosis may exist as a continuous trait or phenotype in nature, ranging from "normality" to clinical cases of psychosis (Johns \& van Os, 2001; Stefanis et al., 2002; Verdoux \& van Os, 2002). Investigating psychosis-like experiences in non-clinical populations may constitute an interesting approach to elucidate psychological mechanisms underlying the psychosis phenotype in large scale samples (Bak et al., 2003; Krabbendam et al., 2004). This "cognitive epidemiology" approach may form the foundation of a theoretical framework resulting in more detailed hypotheses that can be investigated in smaller samples. In the current study, a general population sample was investigated at three points in time (baseline, one year later and three years later). If self-esteem instability truly is associated with paranoia, one would expect larger changes in self-esteem in subjects with subclinical experiences of paranoia.

\section{Methods}

\section{Sample}

Data are derived from the Netherlands Mental Health Survey and Incidence study (NEMESIS), a longitudinal study of the prevalence, incidence, course, and consequences of psychiatric disorders in the Dutch general population. Subjects were interviewed on three measurement occasions: in $1996\left(\mathrm{~T}_{0}\right)$, in $1997\left(\mathrm{~T}_{1}\right)$ and in $1999\left(\mathrm{~T}_{2}\right)$. A comprehensive description of the project's objectives, sample procedure, response, diagnostic instruments, quality control procedures and analyses is provided in previous publications (Bijl, Ravelli, \& van Zessen, 1998; Bijl, van Zessen, Ravelli, de Rijk, \& 
Langendoen, 1998). NEMESIS is based on a multi-stage, stratified, random sampling procedure in which 90 Dutch municipalities, a sample of private households within the selected municipalities, and members with the most recent birthday within each household were selected. Subjects were aged between 18-64 years and sufficiently fluent in Dutch to be interviewed. A total of 7076 individuals provided informed consent and were interviewed at $\mathrm{T}_{0}$ (response rate $=69.7 \%$ ). At $\mathrm{T}_{1}, 5618$ subjects participated for the second time; at $\mathrm{T}_{2}, 4848$ subjects participated for the third time.

\section{CIDI interviews and assessment of symptoms}

Subjects were interviewed at home using the Composite International Diagnostic Interview (CIDI), version 1.1 (computerised version) for all three measurements (Smeets \& Dingemans, 1993; WHO, 1990). The CIDI generates DSM-III-R diagnoses. It is designed for trained interviewers who are not clinicians and has been found to have high inter-rater reliability (Wittchen et al., 1991) and high test-retest reliability (Semler, von Cranach, \& Wittchen, 1987; Wacker, Battegay, Mullejans, \& Schlosser, 1990). The CIDI psychosis section (G) consists of 17 core psychosis items on delusions (13 items) and hallucinations (4 items): items G1-G13, G15, G16, G20 and G21. These items concern classic psychotic symptoms, for example persecution, thought interference, auditory hallucinations and passivity phenomena. All these items can be rated in six ways: "1" - no symptom; "2" - symptom present, but not clinically relevant (not bothered by it and not seeking help for it); " 3 " - symptom is the result of drug use; " 4 " symptom is the result of somatic disease; " 5 " - true psychiatric symptom; " 6 " - symptom is not really a symptom because there appears to be a plausible explanation for it. At $\mathrm{T}_{0}$, lifetime prevalence of psychosis was assessed. At $\mathrm{T}_{1}$ and $\mathrm{T}_{2}$, new symptoms occurring between $T_{0}$ and $T_{1}$ and between $T_{1}$ and $T_{2}$ were assessed.

Paranoid symptoms were narrowly defined as a CIDI rating of 5 on any of the following four CIDI psychosis items: G1 "Have you ever (since the last interview) been convinced that people were spying on you?", G2 "Has there ever (since the last interview) been a period in which you were convinced that you were persecuted by people?", G3 "Have you ever (since the last interview) been convinced that you were secretly tested on or that experiments were carried out on you?", G4 "Have you ever (since the last interview) been convinced that someone was conspiring against you, wanted to cause you harm or poisoning you?". Paranoid symptom outcome was dichotomously defined as the presence (" 1 ”) or absence (“0”) of paranoid symptom(s) at $\mathrm{T}_{0}$ and/or $\mathrm{T}_{1}$ and/or $\mathrm{T}_{2}$. 
Other positive psychotic symptoms were also narrowly defined as a CIDI rating of 5 on any of the CIDI psychosis items, excluding the four paranoid items. Other positive psychotic symptom outcome was dichotomously defined as the presence (" 1 ”) or absence (" 0 ") of symptom(s) at $\mathrm{T}_{0}$ and/or $\mathrm{T}_{1}$ and/or $\mathrm{T}_{2}$.

\section{Assessment of self-esteem}

At baseline, $T_{1}$ and $T_{2}$, subjects were asked to fill in the Rosenberg Self-Esteem Scale (RSE) (Rosenberg, 1965). The RSE consists of 10 items rated on a 4-point Likert scale (ranging from " 1 " strongly agree to " 4 " strongly disagree) and measures overt (explicit) global self-esteem. A high total score indicates high self-esteem. The RSE has demonstrated acceptable consistency and test-retest reliability (Blascovich \& Tomaka, 1991). The Dutch version of the RSE is considered as one of the best measures of global self-esteem (Helbing, 1982) and has a high internal reliability $(\alpha=0.87)$ (Schmitt \& Allik, 2005). Guided by previous research in the field (Greenier et al., 1999; Kernis, Cornell, Sun, Berry, \& Harlow, 1993; Kernis \& Goldman, 2003), self-esteem instability was defined for each participant as the standard deviation of total scores across the three self-esteem assessments.

\section{Statistical analyses}

In order to examine the association between self-esteem instability and paranoid symptoms, a logistic regression model yielding odds ratios was estimated including selfesteem instability as the independent variable and paranoid symptoms as the dependent variable. As mentioned earlier, the dependent variable was dichotomously defined as the presence or absence of paranoid symptom(s) at T0 and/or T1 and/or T2 (i.e. prevalence of symptoms over the three assessments).

The following a priori selected covariates were included in the model: age (five 10-year age groups), sex, education (four levels), presence of any baseline DSM-III-R psychiatric disorder, as well as other possible confounding factors that are known to influence the risk for psychosis: childhood trauma (0, never, once or sometimes experience of emotional, physical, psychological or sexual abuse before age 16 years; 1 , regular, often or very often experience of abuse), experience of discrimination (four levels), urbanicity (level of population density of area of residence; three levels), lifetime drug use ( 0 , no drug use; 1 , any drug use more than five times), single marital status, employment status (unemployed vs other) and ethnic group (white vs other). The confounding effect of depression (standard deviation) was included in the model as self- 
esteem is highly correlated with depression (Barrowclough et al., 2003; Drake et al., 2004; Rosenberg, Schoenbach, Schooler, \& Rosenberg, 1995). Since self-esteem instability may be confounded by self-esteem level, we also included general level of selfesteem as a covariate in the model (mean self-esteem level across the three measure moments).

In order to examine the specificity of the association between self-esteem instability and paranoid symptoms, we further examined whether there was an association between self-esteem instability and other positive psychotic symptoms (excluding paranoid symptoms). The association was assessed using logistic regression analysis and was adjusted for the same covariates as mentioned before. All statistical analyses were conducted using STATA version 9.0 (StataCorp, 2005).

\section{Risk set}

The analyses were conducted in two risk sets. All individuals with no missing values on self-esteem level or self-esteem instability and paranoid symptoms constituted the risk set ( $n=4636 ; 46.7 \%$ male) for examining the association between self-esteem instability and paranoia. In a second risk set, all individuals with paranoid symptoms were excluded ( $\mathrm{n}=4581 ; 46.7 \%$ male). This risk set consisted of all individuals with no missing values on self-esteem level or self-esteem instability and other positive psychotic symptoms.

\section{RESULTS}

\section{Sample}

The mean age of both risk sets was 41.0 years $(\mathrm{SD}=11.8)$ at $\mathrm{T}_{0}$. Paranoid symptoms were present (at least on one assessment) in fifty-one individuals (1.1\%), other positive psychotic symptoms were present (at least on one assessment) in 113 individuals (2.5\%).

\section{Self-esteem, paranoia and positive psychotic symptoms}

Mean self-esteem level in the whole sample was $32.9(\mathrm{SD}=3.5)$. Subjects with paranoid symptoms showed a mean self-esteem level of $30.0(\mathrm{SD}=5.3)$, which was significantly lower than subjects with other positive psychotic symptoms (excluding paranoid symptoms) $(\mathrm{M}=31.8, \mathrm{SD}=4.5)$ and subjects with no positive psychotic symptoms at all $(\mathrm{M}=33.0, \mathrm{SD}=3.4)(\mathrm{F}=24.73, \mathrm{df}=2,4633, \mathrm{p}<0.000)$. 
Logistic regression analyses revealed that self-esteem instability was significantly associated with the presence of paranoid symptoms (OR=1.37; 95\% CI 1.22-1.54). The association remained significant after adjustment for self-esteem level and the remaining abovementioned confounders ( $\mathrm{OR}=1.27$; 95\% CI 1.12-1.45). A significant association was found between self-esteem instability and positive psychotic symptoms in general (excluding paranoid symptoms) at $\mathrm{T}_{1}, \mathrm{~T}_{2}$ and $\mathrm{T}_{3}(\mathrm{OR}=1.17 ; 95 \% \mathrm{CI}$ 1.05-1.31). However, the association lost significance after adjustment for self-esteem level and the other abovementioned confounders (OR=1.09; 95\% CI 0.96-1.23).

\section{Discussion}

The findings indicate that self-esteem instability is specifically associated with paranoid symptoms and not with positive psychotic symptoms in general. These results are in line with previous research suggesting that self-esteem is important in the onset and maintenance of paranoid ideation (Bentall, Corcoran, Howard, Blackwood, \& Kinderman, 2001; Freeman et al., 1998; Lyon, Kaney, \& Bentall, 1994). The current data suggest that, besides self-esteem level, self-esteem instability is also important in relation to paranoid delusions. The unstable nature of self-esteem may be a plausible explanation for the inconsistent findings of the relationship between self-esteem level and paranoia mentioned earlier. The present findings also show that individuals with paranoid symptoms have a significantly lower mean self-esteem level than individuals with other positive psychotic symptoms. These results are compatible with the findings from Kernis and Waschull (1995) showing that more unstable self-esteem is associated with a small reduction in general level of self-esteem.

The present results provide support for a recent psychological model of paranoia (Bentall, Corcoran, Howard, Blackwood, \& Kinderman, 2001), which describes the development of persecutory delusions as a dynamic process in which abnormal beliefs about the self interact with an abnormal attributional style. Patients with persecutory delusions are characterised by an abnormal attributional style in which they make 'external, global and stable' attributions for negative events (i.e. they judge the cause of those events to be external to themselves, affecting all areas of their lives and beyond their control) and excessively internal attributions for positive events (Bentall, Corcoran, Howard, Blackwood, \& Kinderman, 2001; Fear, Sharp, \& Healy, 1996; Kaney \& Bentall, 1989, 1992; Lee \& Won, 1998; Sharp, 1997). The assumed causes of negative 
events involve the deliberate actions and intentions of other people rather than situational factors. The avoidance of internal attributions for negative events is believed to reflect attempts to maintain positive beliefs about the self despite implicit negative self-schemas. Persecutory delusions are therefore suggested to serve a defensive function by blaming others for negative events and thereby avoiding the experience of low selfesteem (Bentall, Corcoran, Howard, Blackwood, \& Kinderman, 2001; Kinderman, Kaney, Morley, \& Bentall, 1992; Lyon, Kaney, \& Bentall, 1994), although this remains controversial (Freeman et al., 1998). According to this defence account of paranoia, covert self-esteem will be lower than overt self-esteem in paranoid individuals.

The efforts to regulate overt self-esteem, however, are not always self-serving. Circumstantial factors may affect the specific attributions generated at any point in time. For example, attributions may temporarily be more pessimistic under circumstances in which underlying negative self-schemas are activated. In a recent experiment, Bentall and Kaney (2005) observed an internalising shift for negative events in paranoid patients following a contrived failure experience. According to the theory, one consequence of these dysfunctional efforts are fluctuations in overt self-esteem. The findings from the present study are therefore consistent with the predictions made from the attributional model.

The results of this study should be interpreted in the light of several limitations. Firstly, self-esteem was measured at three distant points in time. One could argue that the dynamic nature of self-esteem could not sufficiently be captured by three isolated measure moments. However, if self-esteem is truly fluctuating, this should be reflected in changes over time (i.e. larger SD), yet more research is necessary to capture the nature of the instability. Ideally this research should focus on multiple assessments, which enables us to explore the temporal relationship and dynamic patterns between the concepts of interest. Secondly, self-esteem instability was measured by means of the Rosenberg Self-Esteem Scale (Rosenberg, 1965). Originally, this scale was designed to assess global trait self-esteem. However, since it is assumed that global self-esteem might change over time and since the current study investigated subjects at distant points in time (one and two years apart), the Rosenberg Self-Esteem Scale was suitable. Indeed, changes in Rosenberg scores have been used as a measure of self-esteem fluctuation in previous research (Kernis, Cornell, Sun, Berry, \& Harlow, 1993). Thirdly, the study included individuals with prevalent positive psychotic symptoms on at least one of the measure moments, because of a limited number of individuals with prevalent symptoms at all three measure moments together. However, we do not think this is a significant 
limitation of the study, since it is likely that underlying psychological mechanisms responsible for paranoid symptoms are associated with a liability to develop psychosis. Finally, the data of the current study do not allow inferring a causal relationship between self-esteem instability and paranoid symptoms, but merely show an association. Instability in self-esteem can therefore be conceived as an expression of psychosis liability.

\section{References}

Bak, M., Myin-Germeys, I., Hanssen, M., Bijl, R., Vollebergh, W., Delespaul, P., et al. (2003). When does experience of psychosis result in a need for care? A prospective general population study. Schizophrenia Bulletin, 29(2), 349-358.

Barrowclough, C., Tarrier, N., Humphreys, L., Ward, J., Gregg, L., \& Andrews, B. (2003). Self-esteem in schizophrenia: relationships between self-evaluation, family attitudes, and symptomatology. Journal of Abnormal Psychology, 112(1), 92-99.

Bentall, R. P., Corcoran, R., Howard, R., Blackwood, N., \& Kinderman, P. (2001). Persecutory delusions: a review and theoretical integration. Clinical Psychology Review, 21(8), 1143-1192.

Bentall, R. P., \& Kaney, S. (2005). Attributional lability in depression and paranoia. British Journal of Clinical Psychology, 44(Pt 4), 475-488.

Bijl, R. V., Ravelli, A., \& van Zessen, G. (1998). Prevalence of psychiatric disorder in the general population: results of The Netherlands Mental Health Survey and Incidence Study (NEMESIS). Social Psychiatry and Psychiatric Epidemiology, 33(12), 587-595.

Bijl, R. V., van Zessen, G., Ravelli, A., de Rijk, C., \& Langendoen, Y. (1998). The Netherlands Mental Health Survey and Incidence Study (NEMESIS): objectives and design. Social Psychiatry and Psychiatric Epidemiology, 33(12), 581-586.

Blascovich, J., \& Tomaka, J. (1991). Measures of self-esteem. In J. P. Robinson, P. R. Shaver, L. S. Wrightsman \& F. M. Andrews (Eds.), Measures of personality and social psychological attitudes (pp. 115-160). San Diego: Academic Press.

Candido, C. L., \& Romney, D. M. (1990). Attributional style in paranoid vs. depressed patients. British Journal of Medical Psychology, 63(Pt 4), 355-363.

Combs, D. R., \& Penn, D. L. (2004). The role of subclinical paranoia on social perception and behavior. Schizophrenia Research, 69(1), 93-104. 
Drake, R. J., Pickles, A., Bentall, R. P., Kinderman, P., Haddock, G., Tarrier, N., et al. (2004). The evolution of insight, paranoia and depression during early schizophrenia. Psychological Medicine, 34(2), 285292.

Ellett, L., Lopes, B., \& Chadwick, P. (2003). Paranoia in a nonclinical population of college students. Journal of Nervous and Mental Disease, 191(7), 425-430.

Fear, C., Sharp, H., \& Healy, D. (1996). Cognitive processes in delusional disorders. British Journal of Psychiatry, 168(1), 61-67.

Fenigstein, A., \& Vanable, P. A. (1992). Paranoia and self-consciousness. Journal of Personality and Social Psychology, 62(1), 129-138.

Freeman, D., Garety, P., Fowler, D., Kuipers, E., Dunn, G., Bebbington, P., et al. (1998). The London-East Anglia randomized controlled trial of cognitive-behaviour therapy for psychosis. IV: Self-esteem and persecutory delusions. British Journal of Clinical Psychology, 37(Pt 4), 415-430.

Greenier, K. D., Kernis, M. H., McNamara, C. W., Waschull, S. B., Berry, A. J., Herlocker, C. E., et al. (1999). Individual differences in reactivity to daily events: examining the roles of stability and level of selfesteem. Journal of Personality, 67(1), 185-208.

Guillon, M. S., Crocq, M. A., \& Bailey, P. E. (2003). The relationship between self-esteem and psychiatric disorders in adolescents. European Psychiatry, 18(2), 59-62.

Helbing, J. C. (1982). Zelfwaardering: Meting en validiteit. Nederlands Tijdschrift voor Psychologie, 37, $257-$ 277.

Johns, L. C., \& van Os, J. (2001). The continuity of psychotic experiences in the general population. Clinical Psychology Review, 21(8), 1125-1141.

Kaney, S., \& Bentall, R. P. (1989). Persecutory delusions and attributional style. British Journal of Medical Psychology, 62 ( Pt 2), 191-198.

Kaney, S., \& Bentall, R. P. (1992). Persecutory delusions and the self-serving bias. Evidence from a contingency judgment task. Journal of Nervous and Mental Disease, 180(12), 773-780.

Kernis, M. H. (1993). The role of stability and level of self-esteem in psychological functioning. In R. F. Baumeister (Ed.), Self-esteem: the puzzle of low self-regard (pp. 167-182). New York: Plenum Press.

Kernis, M. H. (2005). Measuring self-esteem in context: the importance of stability of self-esteem in psychological functioning. Journal of Personality, 73(6), 1569-1605.

Kernis, M. H., Cornell, D. P., Sun, C. R., Berry, A., \& Harlow, T. (1993). There's more to self-esteem than whether it is high or low: the importance of stability of self-esteem. Journal of Personality and Social Psychology, 65(6), 1190-1204.

Kernis, M. H., \& Goldman, B. M. (2003). Stability and variability in self-concept en self-esteem. In M. Leary \& J. Tangney (Eds.), Handbook of self and identity (pp. 106-152). New York: The Guilford Press. 
Kernis, M. H., Grannemann, B. D., \& Barclay, L. C. (1989). Stability and level of self-esteem as predictors of anger arousal and hostility. Journal of Personality and Social Psychology, 56(6), 1013-1022.

Kernis, M. H., \& Waschull, S. B. (1995). The interactive roles of stability and level of self-esteem: Research and theory. In M. P. Zanna (Ed.), Advances in experimental social psychology (Vol. 27, pp. 93-141). San Diego: Academic Press.

Kernis, M. H., Whisenhunt, C. R., Waschull, S. B., Greenier, K. D., Berry, A. J., Herlocker, C. E., et al. (1998). Multiple facets of self-esteem and their relations to depressive symptoms. Personality and Social Psychology Bulletin, 24, 657-668.

Kinderman, P., Kaney, S., Morley, S., \& Bentall, R. P. (1992). Paranoia and the defensive attributional style: deluded and depressed patients' attributions about their own attributions. British Journal of Medical Psychology, 65 ( Pt 4), 371-383.

Krabbendam, L., Janssen, I., Bak, M., Bijl, R. V., de Graaf, R., \& van Os, J. (2002). Neuroticism and low selfesteem as risk factors for psychosis. Social Psychiatry and Psychiatric Epidemiology, 37(1), 1-6.

Krabbendam, L., Myin-Germeys, I., Hanssen, M., Bijl, R. V., de Graaf, R., Vollebergh, W., et al. (2004). Hallucinatory experiences and onset of psychotic disorder: evidence that the risk is mediated by delusion formation. Acta Psychiatrica Scandinavica, 110(4), 264-272.

Leary, M. R., \& Tangney, J. P. (2003). Handbook of self and identity. New York: Guilford Press.

Lee, H. J., \& Won, H. T. (1998). The self-concepts, the other-concepts, and attributional style in paranoia and depression. Korean Journal of Clinical Psychology, 17, 105-125.

Lyon, H. M., Kaney, S., \& Bentall, R. P. (1994). The defensive function of persecutory delusions. Evidence from attribution tasks. British Journal of Psychiatry, 164(5), 637-646.

Martin, J. A., \& Penn, D. L. (2001). Social cognition and subclinical paranoid ideation. British Journal of Clinical Psychology, 40(Pt 3), 261-265.

Paradise, A. W., \& Kernis, M. H. (2002). Self-esteem and psychological well-being: implications of fragile selfesteem. Journal of Social and Clinical Psychology, 21(4), 345-361.

Rosenberg, M. (1965). Society and the adolescent self-image. Princeton, NJ: Princeton University Press.

Rosenberg, M., Schoenbach, C., Schooler, C., \& Rosenberg, F. (1995). Global self-esteem and specific selfesteem: Different concepts, different outcomes. American Sociological Review, 60(2), 141-156.

Schmitt, D. P., \& Allik, J. (2005). Simultaneous administration of the Rosenberg Self-Esteem Scale in 53 nations: exploring the universal and culture-specific features of global self-esteem. Journal of Personality and Social Psychology, 89(4), 623-642.

Semler, G., von Cranach, M., \& Wittchen, H. U. (1987). Comparison between the Composite International Diagnostic Interview and the Present State Examination: Report to the WHO/ADAMHA Task Force on Instrument Development. Geneva, Switzerland: World Health Organization. 
Sharp, H. M., Fear, C. F., \& Healy, D. (1997). Attributional style and delusions: an investigation based ondelusional content. European Psychiatry, 12, 1-7.

Silverstone, P. H. (1991). Low self-esteem in different psychiatric conditions. British Journal of Clinical Psychology, 30(Pt 2), 185-188.

Smeets, R. M. W., \& Dingemans, P. M. A. J. (1993). Composite International Diagnostic Interview (CIDI) Version 1.1. Geneva, Switzerland: World Health Organisation.

StataCorp. (2005). Stata Statistical Software: Release 9.0. TX: Stata Corporation, College Station.

Stefanis, N. C., Hanssen, M., Smirnis, N. K., Avramopoulos, D. A., Evdokimidis, I. K., Stefanis, C. N., et al. (2002). Evidence that three dimensions of psychosis have a distribution in the general population. Psychological Medicine, 32(2), 347-358.

Verdoux, H., \& van Os, J. (2002). Psychotic symptoms in non-clinical populations and the continuum of psychosis. Schizophrenia Research, 54(1-2), 59-65.

Wacker, H. R., Battegay, R., Mullejans, R., \& Schlosser, C. (1990). Using the CIDI in the general population. In C. N. Stefanis, A. D. Rabavilas \& C. R. Soldatos (Eds.), Psychiatry: a world perspective (pp. 138-143). Amsterdam: Elsevier Science Publishers.

WHO. (1990). Composite International Diagnostic Interview (CIDI) Version 1.0. Geneva: Switzerland: World Health Organisation.

Wittchen, H. U., Robins, L. N., Cottler, L. B., Sartorius, N., Burke, J. D., \& Regier, D. (1991). Cross-cultural feasibility, reliability and sources of variance of the Composite International Diagnostic Interview (CIDI). The Multicentre WHO/ADAMHA Field Trials. British Journal of Psychiatry, 159, 645-653. 


\section{Chapter 3}

\section{FLUCTUATIONS IN SELF-ESTEEM AND PARANOIA IN THE CONTEXT OF DAILY LIFE}

This chapter will be published as:

Viviane Thewissen, Richard Bentalla, Tania Lecomte ${ }^{\mathrm{b}}$, Jim van Os and Inez MyinGermeys. (in press). Fluctuations in self-esteem and paranoia in the context of daily life. Journal of Abnormal Psychology.

a School of Psychological Sciences, University of Manchester, UK.

${ }^{\mathrm{b}}$ Department of Psychiatry, University of British Columbia, Vancouver, BC, Canada. 


\section{ABStRACT}

Studies investigating the relationship between self-esteem and paranoia have specifically focused on self-esteem level, but have neglected the dynamic aspects of self-esteem. In the present paper, we investigated the relationship between self-esteem and paranoia in two different ways. First, a sample of individuals $(n=154)$ who ranged across the continuum in level of paranoia was studied with the Experience Sampling Method (ESM; a structured self-assessment diary technique) in order to assess the association between trait paranoia and level and fluctuation of self-esteem in daily life. Results showed that trait paranoia was associated with both a lower level and higher instability of self-esteem. Second, the temporal relationship between momentary (state) paranoia and self-esteem was investigated in the daily life of these individuals. Results showed that a decrease in self-esteem was associated with an immediate increase in paranoia. The findings indicate that paranoid individuals are not only characterised by a lower level of self-esteem, but also by more fluctuations in their self-esteem and that fluctuations in self-esteem predict the degree of subsequent paranoia. These results are consistent with the hypothesis that paranoia is associated with dysfunctional strategies of self-esteem regulation. 


\section{INTRODUCTION}

Persecutory delusions are the most common abnormal beliefs found in patients with psychosis, both in Western countries (Garety \& Hemsley, 1987; Jorgensen \& Jensen, 1994) and in other parts of the world (Ndetei \& Vadher, 1984). They are often highly distressing and also the most likely delusions to be acted upon (Wessely et al., 1993). There is therefore a need for an explanatory account of this symptom, which identifies causal factors and which can guide the development of novel therapeutic interventions (Blackwood, Howard, Bentall, \& Murray, 2001). It has long been argued that self-esteem is implicated in the formation of paranoid beliefs (Colby, 1975, 1977; Meissner, 1981; Schwartz, 1963). According to a recent psychological model (Bentall, Corcoran, Howard, Blackwood, \& Kinderman, 2001), persecutory delusions are the consequence of a coherent set of cognitive biases that develop in individuals with low self-esteem and which serve the function of protecting the individual from negative thoughts and feelings about the self. Since the attempts to avoid negative thoughts are often dysfunctional, it is predicted by the model that self-esteem will be highly unstable (fluctuating) in paranoid patients.

Studies investigating the relationship between paranoia and self-esteem have mainly focussed on level of self-esteem and have yielded inconsistent results. In a large sample of individuals with drug-resistant psychosis taking part in a cognitive-behaviour therapy trial, low self-esteem was found to be a prominent feature in the majority of patients with persecutory delusions (Freeman et al., 1998). Low levels of self-esteem have also been found in non-clinical samples reporting paranoid beliefs (Combs \& Penn, 2004; Ellett, Lopes, \& Chadwick, 2003; Martin \& Penn, 2001). Combs and Penn (2004) compared a sample of students who scored high and low on a questionnaire that measures subclinical levels of paranoia. They found that persons high in subclinical paranoia had lower self-esteem relative to persons low in subclinical paranoia. Other studies, however, have reported relatively high or normal self-esteem in paranoid patients (Candido \& Romney, 1990; Krstev, Jackson, \& Maude, 1999; Lyon, Kaney, \& Bentall, 1994). For example, Candido and Romney (1990) assessed global self-esteem in paranoid patients, depressed patients, and patients who were both paranoid and depressed. They demonstrated high self-esteem in the paranoid patients, low self-esteem in the depressed patients and intermediate scores in patients who were both paranoid and depressed. 
A number of studies, mainly by Kernis and colleagues (Kernis, 2005; Kernis, Cornell, Sun, Berry, \& Harlow, 1993; Kernis \& Goldman, 2003), indicate that, besides self-esteem level, it is important to take into account the dynamic aspects of self-esteem when investigating psychological mechanisms. In a recent large scale epidemiological study (Thewissen et al., 2007), we have demonstrated that individuals with paranoid symptoms had a significantly lower mean self-esteem level compared to individuals with other positive psychotic symptoms. More importantly, the study showed a specific association between long-term fluctuations in self-esteem and paranoia. However, since it is known that fluctuations in self-esteem may result from a variety of contextual factors, such as evaluative feedback (Kernis \& Johnson, 1990; Markus \& Kunda, 1986), it is useful to investigate self-esteem instability in the context of daily life.

Fluctuations in self-esteem over the short-term can be measured by asking participants to rate themselves on a self-esteem questionnaire several times a day for a number of days (Greenier et al., 1999; Kernis et al., 1993), preferably at random moments (Delespaul, 1995; deVries, 1992; Oosterwegel, Field, Hart, \& Anderson, 2001). In the present paper, the Experience Sampling Method (ESM) was used to investigate self-esteem and paranoid ideation in the context of daily life. ESM (Csikszentmihalyi \& Larson, 1987) is a random time sampling self-assessment diary technique for assessing mental state and the context in which it is embedded in the natural flow of daily life. The feasibility, validity and reliability of ESM has been demonstrated in a wide range of populations (e.g. Jacobs et al., 2005), including in individuals with schizophrenia (Delespaul, 1995; Myin-Germeys, Delespaul, \& van Os, 2005; Myin-Germeys, van Os, Schwartz, Stone, \& Delespaul, 2001) and other psychiatric disorders (deVries, 1992). For example, Myin-Germeys, Delespaul, \& deVries (2000) have demonstrated that this time sampling technique is a suitable method for investigating the variability and intensity of affective experiences in individuals with schizophrenia.

Paranoia may exist as a continuous trait or phenotype in nature and is thought to be expressed also at levels well below psychotic illness (Combs, Michael, \& Penn, 2006; Freeman et al., 2005), in which case it is usually referred to as psychosis proneness, schizotypy or at-risk mental state (Hanssen, Krabbendam, Vollema, Delespaul, \& Van Os, 2006; Johns \& van Os, 2001; van Os, Hanssen, Bijl, \& Vollebergh, 2001). Psychological mechanisms associated with paranoid symptoms are also likely to operate in individuals who have an at-risk mental state. In the current study, subjects ranging across the paranoia continuum were investigated. 
The goal of this current study is twofold. First, we sought to study the level and instability of self-esteem as trait characteristics in individuals who ranged across the paranoia continuum. Level of self-esteem was assessed with a self-esteem questionnaire (the Self-esteem Rating Scale; Nugent \& Thomas, 1993), and, in addition, ESM was used to assess global level of self-esteem in daily life. Experience Sampling data were used to define instability of self-esteem. The rationale for this was that by definition, multiple measurement points are necessary to define instability. Instability was thus defined as 1) standard deviation of self-esteem over 60 Experience Sampling reports for each person, and 2) average moment-to-moment change in self-esteem. It was hypothesised, in accordance with previous findings (Thewissen et al., 2007), that individuals at higher positions on the paranoia continuum - thus reporting higher levels of trait paranoia would show a lower general level of self-esteem. In addition, guided by previous findings (Thewissen et al., 2007) and predictions by the aforementioned psychological model (Bentall et al., 2001), it was hypothesized that individuals with higher levels of trait paranoia would show more fluctuations in self-esteem compared to individuals at lower positions on the continuum.

A second purpose of this study was to examine the temporal relationship between changes in self-esteem and momentary paranoid experiences in individuals who ranged across the paranoia continuum. Previously, it was shown that delusional experiences may fluctuate within days and hours (Myin-Germeys, Nicolson, \& Delespaul, 2001). This study will investigate whether momentary or state paranoia is preceded by changes in momentary self-esteem. It was hypothesised, as predicted by the aforementioned model (Bentall et al., 2001), that a decrease in state self-esteem would lead to an increase in state paranoia.

\section{Methods}

\section{Sample}

In order to obtain a sample that ranged across the continuum of paranoia, we included the following individuals who differed in level of current paranoid symptomatology: i) patients diagnosed with a psychotic disorder who currently present paranoid psychotic symptoms, defined as having a score of $>$ ' 3 ' on item P6 (suspiciousness) of the Positive and Negative Syndromes Scale (PANSS; see Instruments section); ii) patients diagnosed with a psychotic disorder who currently have other positive psychotic symptoms, 
defined as having a score of $<$ ' 4 ' on the PANSS items P6 (suspiciousness) AND having a score of $>$ ' 3 ' on at least one of the PANSS items P1 (delusions), P3 (hallucinatory behaviour), P5 (grandiosity) and G9 (unusual thought content); iii) patients diagnosed with a psychotic disorder who currently report remitted psychotic symptoms, defined as having a score of < ' 4 ' on all the aforementioned PANSS items; iv) individuals with no diagnosis of psychotic disorder who present a psychometric at risk mental state for paranoid psychosis (hereafter 'high schizotypy participants'), defined operationally as scoring high $\left(>90^{\text {th }}\right.$ percentile) on the paranoid items of a questionnaire measuring psychosis-proneness (Community Assessment of Psychic Experiences, CAPE; see Instruments section); and v) 'healthy' control participants defined in terms of scoring in the average range (between $45^{\text {th }}-55^{\text {th }}$ percentile) on all three symptom dimensions of the CAPE, and not scoring high ( $>90^{\text {th }}$ percentile) on the paranoid items.

The inclusion criteria for all participants were signed informed consent, age 18 to 65 years and sufficient command of the Dutch language to understand and fill out the questionnaires. Patients were recruited from clinical and ambulatory mental health facilities in the cities Heerlen and Maastricht, the Netherlands. They were extensively screened for psychiatric symptoms using diagnostic interviews including the Positive and Negative Syndrome Scale (Kay, Fiszbein, \& Opler, 1987) and the Life Chart (Susser et al., 2000). Interview data and, when necessary, clinical record data were used to yield ICD-10 diagnoses by the OPCRIT computer program (McGuffin, Farmer, \& Harvey, 1991). High schizotypy participants and healthy controls were recruited from an earlier longitudinal family study in the general population conducted in the city of Sittard, the Netherlands (Continuum of Mental Disorders study, COMED) (Hanssen et al., 2003). Residents of the municipality of Sittard, aged 36-65 years, were randomly selected and sent a letter in which they were asked to participate. The mailing frame comprised 4589 participants (2287 females and 2302 males). Additionally, a snowball sampling procedure was used: participants who had responded to the mail survey were asked to invite their family members to participate in the study. The total general population sample comprised 768 individuals, aged 17 to 77 years, from 116 families. All participants filled in the extended, 42 -item CAPE. Participants with a high score $\left(>90^{\text {th }}\right.$ percentile) on the paranoid items of the CAPE (see Instruments section) and those with an overall CAPE score close to the mean (i.e. scores between $45^{\text {th }}-55^{\text {th }}$ percentile) were invited to take part in the current study. 


\section{Instruments}

\section{CAPE}

The Community Assessment of Psychic Experiences (CAPE; Hanssen et al., 2003; Konings, Bak, Hanssen, van Os, \& Krabbendam, 2006; Stefanis et al., 2002) is a selfreport instrument which measures frequency of attenuated psychotic experiences in the affective and non-affective domains, as well as distress associated with these experiences. The extended, 42-item instrument is mainly based on the 21-item Peters et al. Delusions Inventory (PDI-21; (Peters, Joseph, \& Garety, 1999). The frequency score is measured on a four-point scale from 0 "never", 1 "sometimes", 2 "often" to 3 "nearly always". The degree of distress is measured on a four-point scale from 0 "not distressed", 1 "a bit distressed", 2 "quite distressed" to 3 "very distressed". As mentioned above, the CAPE was used to select individuals with an at risk mental state for paranoid psychosis. The frequency scores of the following two paranoia-items were used: "Do you ever feel as if you are being persecuted in some way?" (item 7) and "Do you ever feel as if there is a conspiracy against you?" (item 10). The CAPE has demonstrated good test-retest reliability and cross-validity in a general population sample (Konings et al., 2006) and discriminative validity between individuals from the general population and patients with schizophrenia, affective and anxiety disorders (Hanssen et al., 2003).

\section{PANSS}

Within a week after the sampling period, a trained research assistant assessed all participants (including the control participants) with the Positive and Negative Syndromes Scale (PANSS; Kay et al., 1987), a semi-structured interview for rating positive, negative and other symptom dimensions in schizophrenia. The PANSS consists of 30 items: 7 items relating to the positive dimension, 7 items relating to the negative dimension and 16 items relating to general psychopathology. Each item is assessed over the past fortnight and scored on a 7-point scale, ranging from 1 "absent" to 7 "extreme". The item G6 "depression" was used in the analyses as a covariate. The PANSS has demonstrated good evidence of reliability, criterion-related validity and construct validity (Kay, Opler, \& Lindenmayer, 1988).

\section{Paranoia Scale}

In order to assess trait paranoia, participants were asked to complete the Paranoia Scale (PS; Fenigstein \& Vanable, 1992). The PS was designed specifically to measure the incidence of paranoia in a college population (Fenigstein \& Vanable, 1992), but has also 
been validated as a measure of current paranoid ideation in individuals with schizophrenia (Smári, Stefánsson, \& Thorgilsson, 1994). The scale consists of 20 items, which can be scored on a 5-point scale, ranging from 1 "not at all applicable to me" to 5 "extremely applicable to me". The scale is derived from the Minnesota Multiphasic Personality Inventory, which was intended primarily for a clinical population (Dahlstrom, Welsh, \& Dahlstrom, 1975). The following aspects of paranoia are measured on the scale: the belief that other people or forces are trying to influence one's behaviour or control one's thinking; the belief that other people are against the person; the belief of being watched or talked about; suspicion or mistrust of others' motives; and feelings of resentment, bitterness or ill will (Fenigstein \& Vanable, 1992). The PS is the most widely used dimensional measure of paranoia (Freeman et al., 2005) and has been found to have a substantial degree of internal consistency $(\alpha=0.84)$, good test-retest reliability and good construct validity (Fenigstein \& Vanable, 1992).

\section{Self-esteem Rating Scale}

In order to obtain a global measure of trait self-esteem, participants were asked to complete the Self-Esteem Rating Scale (SERS; Nugent \& Thomas, 1993). The SERS is a clinical measure designed to measure not only problematic aspects of self-esteem but also positive non-problematic aspects of self-esteem. The SERS is partially based on Hudson's Index of Self-Esteem (Hudson, 1982) and taps into a variety of areas of selfevaluation, including overall self-worth, social competence, problem-solving ability, intellectual ability, self-competence, and worth relative to others. It consists of 40 items, which can be scored on a 7-point Likert scale, ranging from 1 "never" to 7 "always". Twenty of the items are scored negatively and the remaining items are scored positively. The items are summed to produce a total score that can range from -120 to +120 . Positive scores indicate higher levels of self-esteem while negative scores indicate lower levels of self-esteem. The SERS has a high internal consistency $(\alpha=0.98)$ and good construct validity (Nugent \& Thomas, 1993).

\section{ESM procedure}

The Experience Sampling Method (ESM; Csikszentmihalyi \& Larson, 1987) is a structured self-assessment technique. Participants received a pre-programmed digital wristwatch and 10 identical pocket size assessment forms collated in a booklet for each day. Ten times a day on 6 consecutive days, the watch emitted a signal at unpredictable moments between 7.30 a.m. and 10.30 p.m. After every 'beep', reports of current 
context, mood and self-esteem were collected. All self-assessments were rated on 7point Likert scales.

The ESM procedure was explained to the participants during an initial briefing session and a practice form was completed to confirm that they were able to understand the 7-point Likert scale format. Participants were instructed to complete their reports immediately after the 'beep' to minimize memory distortions. They were also instructed to register the time at which they completed the questionnaire. During the actual sampling period, research staff contacted participants frequently by phone or, when necessary, visited them to assess whether they were complying with the instructions. During a debriefing session, the participants were interviewed extensively to be sure that they complied with the instructions. Based on the times participants indicated they had completed the reports, all reports completed more than 15 minutes after the signal were excluded from the analyses. Previous work (Delespaul, 1995) has shown that reports completed after this time interval are less reliable and consequently less valid. Participants with less than 20 valid reports were excluded from the analyses.

\section{ESM variables}

The ESM assessment forms contained questions regarding momentary self-esteem and momentary paranoia.

\section{State paranoia}

State paranoia was defined as the mean score of the following four items: "I feel that others dislike me", "I feel that others might hurt me", "I feel suspicious", and "I feel safe" (reversed scale). Factor (principal component) analysis on the raw within-participants scores identified one factor according to the Kaiser criterion (eigenvalue $>1$ ), explaining $75 \%$ of the total variance. The items had a strong loading on the factor (negative statements < -.84; positive statement $>.80$ ) and high internal consistency (Cronbach's a $=0.89)$. State paranoia is significantly correlated with total score on the Paranoia Scale (Pearson bivariate correlation $\mathrm{r}=0.42, \mathrm{p}<.001$ ) and the PANSS item P6 paranoia/persecution (Pearson bivariate correlation $\mathrm{r}=0.58, \mathrm{p}<.001$ ).

\section{State self-esteem}

The ESM assessment forms contained four self-esteem items: "I am a failure", "I am ashamed of myself", "I like myself", and "I am a good person". The items were rated on 7-point Likert scales, ranging from 1 "not at all" to 7 "very". Factor (principal 
component) analysis on the raw within-participant scores identified one factor according to the Kaiser criterion (eigenvalue $>1$ ), accounting for $68 \%$ of the total variance. The four items had a strong loading on the factor (negative statements <-0.76; positive statements $>0.80$ ) and high internal consistency (Cronbach's $\alpha=0.84$ ). State self-esteem was defined as the mean score of the four items (scales of the two negative statements were reversed).

\section{Change in state self-esteem}

Change in state self-esteem was defined as the difference in self-esteem between two succeeding reports: the self-esteem score on the previous moment $(\mathrm{t}-1$, roughly 90 minutes earlier) minus the self-esteem score on the target moment $(\mathrm{t})$. The difference score ranges from -6 to +6 and high scores reflect decreases.

\section{Statistical analyses}

i) Is self-esteem level and instability associated with trait paranoia?

The first set of analyses aimed to investigate the association between level and instability of self-esteem as person characteristics and trait paranoia. Trait paranoia was defined as the mean score on the Paranoia Scale. Level of self-esteem was defined as 1) the sum score of the SERS questionnaire and 2) as the mean of the ESM momentary self-esteem reports for each individual (mean over 60 reports). In order to examine the association between self-esteem level and paranoia, two separate linear regression models were estimated with the two self-esteem levels as the dependent variable and trait paranoia as the independent variable. Self-esteem instability was defined as 1) the standard deviation of the ESM momentary self-esteem reports over 60 beeps per subject and 2) the mean absolute ESM momentary self-esteem change score for each individual over 60 reports (indicating the mean change in self-esteem from moment-to-moment). Again, two separate linear regression models were estimated with the two self-esteem instability measures as dependent variable and trait paranoia as the independent variable. Data were analysed with the REG module in STATA/SE version 9.2 (StataCorp, 2006).

Each abovementioned analysis was repeated to investigate a dose-response relationship between trait paranoia and self-esteem level or self-esteem instability. Participants were therefore divided into tertiles based on their total score on the PS (T1 = low paranoia, $\mathrm{T} 2=$ medium paranoia, $\mathrm{T} 3=$ high paranoia). Trait self-esteem level or 
self-esteem instability were treated as dependent variables and paranoia (divided into tertiles) as the independent variable.

The following a priori selected confounders were included in the regression models: depression (PANSS item G6) and sex. Depression was included as a confounder in the model as self-esteem is highly correlated with depression (Barrowclough et al., 2003; Rosenberg, Schoenbach, Schooler, \& Rosenberg, 1995).

\section{ii) Is trait self-esteem instability stronger associated with trait paranoia than self-esteem level?}

First, it was investigated whether self-esteem instability (defined as standard deviation of all momentary self-esteem scores of a person) was associated with self-esteem level (defined as the average of the momentary self-esteem scores for each person) using linear regression analyses. If they are indeed associated, self-esteem level will be added as a confounder to the models predicting self-esteem instability, and self-esteem instability will be added as a confounder to the models predicting self-esteem level.

\section{iii) Are momentary changes in state self-esteem associated with state paranoia?}

In order to examine the temporal relationship between changes in self-esteem and state paranoid experiences, multilevel linear random regression models were estimated. Multilevel or hierarchical linear modelling techniques are a variant of the more often used unilevel linear regression analyses and are ideally suited for the analysis of hierarchical or clustered data (Schwartz \& Stone, 1998). ESM data have a hierarchical structure in which repeated momentary observations are clustered within participants (beeps within participants). Since - in ESM - observations from the same participants are more similar than observations from different participants, the residuals are not independent. Conventional regression techniques do not take into account the variance components at two levels. Data were analysed with the XTREG module in STATA/SE version 9.2 (StataCorp, 2006). The $B$ is the fixed regression coefficient of the predictor and can be interpreted identically to the estimate in a unilevel linear regression model. The individual intercepts $(\alpha)$ of the multilevel model are treated as a random factor.

In order to examine the relationship between momentary changes in selfesteem and state paranoid experiences, a multilevel linear random regression model was estimated with change in momentary self-esteem between the previous moment and the target moment as the independent variable and state paranoia at the target moment as the dependent variable (Figure 3.1). The multilevel model was corrected for the a priori 
selected confounders sex and depressive mood. Depressive mood was assessed using the momentary mood item "I feel down" at the target moment. In addition, the model was adjusted for paranoia at previous moments $(\mathrm{t}-1)$.

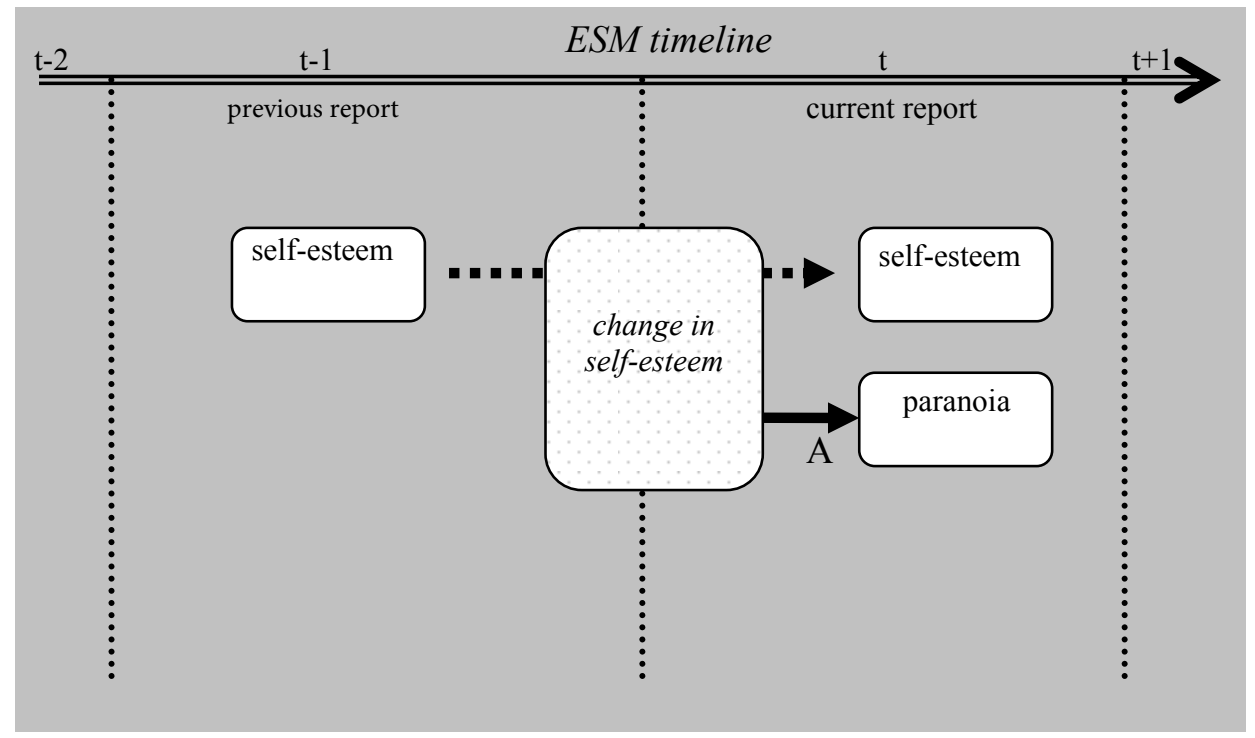

Figure 3.1 Longitudinal association between changes in self-esteem and paranoia

Note. A; Multilevel linear regression analysis to investigate whether a change in self-esteem (selfesteem $t$ - 1 minus self-esteem $t$ ) (independent variable) longitudinally influences paranoia ( $\mathrm{t}$ ) (dependent variable), with sex, depressive mood $(\mathrm{t})$ and paranoia $(\mathrm{t}-1)$ as confounding factors.

\section{RESULTS}

\section{Sample and descriptive statistics}

Of the 183 participants who entered the study, some individuals were recruited from clinical or ambulatory mental health facilities and others were recruited from the general population. Of these 183 participants, 29 (15.8\%) individuals were excluded from the analyses. Twenty-two participants terminated the study before the end of the six-day sampling period, due to severity of psychotic symptoms $(n=11)$, cognitive incapability $(n=5)$ or lack of cooperation $(n=6)$. Although finishing the study, three individuals were excluded because of an insufficient number $(<20)$ of valid ESM observations, one individual because of missing data on the Paranoia Scale, one 
individual because of missing data on the PANSS and two individuals had missing data on both the Paranoia Scale and the PANSS. Of the 29 individuals who were excluded from the analyses, 24 were patients, 3 were high-schizotypy participants and 2 were healthy controls. The final study sample therefore comprised 154 participants. These participants had each completed an average of 44 valid ESM reports $(S D=10)$. Additional information regarding number of valid reports, sociodemographic and clinical characteristics of the participants are summarized in Table 3.1. In the patient group with current paranoid psychotic symptoms, 9 patients had a score of ' 4 ' on the PANSS, 10 patients had a score of ' 5 ', 5 patients had a score of ' 6 ' and 6 patients had a score of ' 7 '. In the current study, trait paranoia is included as a continuous variable, based on the mean score on the Paranoia Scale. However, in order to investigate doseresponse relationships, the participants were divided into three tertiles. The composition of the paranoia tertile groups is presented in Table 3.2. Mean scores of the independent and dependent variables by tertile group are presented in Table 3.3.

Table 3.2 Composition of the paranoia tertiles

\begin{tabular}{llll}
\hline $\begin{array}{l}\text { Study sample } \\
(n=154)\end{array}$ & $\begin{array}{l}\text { T1 } \\
\text { Low } \\
\text { paranoia } \\
(n=47)\end{array}$ & $\begin{array}{l}\text { T2 } \\
\text { Medium } \\
\text { paranoia } \\
(n=51)\end{array}$ & $\begin{array}{l}\text { T3 } \\
\text { High } \\
\text { paranoia } \\
(n=56)\end{array}$ \\
\hline & & & \\
Current paranoid patients, $\%$ & $0 \%$ & $23 \%$ & $77 \%$ \\
& $(n=0)$ & $(n=7)$ & $(n=23)$ \\
Current non-paranoid patients, $\%$ & $15 \%$ & $26 \%$ & $59 \%$ \\
& $(n=5)$ & $(n=9)$ & $(n=20)$ \\
Remitted patients, \% & $20 \%$ & $33 \%$ & $47 \%$ \\
& $(n=3)$ & $(n=5)$ & $(n=7)$ \\
High schizotypy participants, \%* & $32 \%$ & $53 \%$ & $16 \%$ \\
& $(n=12)$ & $(n=20)$ & $(n=6)$ \\
Healthy controls, \% & $73 \%$ & $27 \%$ & $0 \%$ \\
& $(n=27)$ & $(n=10)$ & $(n=0)$ \\
\hline
\end{tabular}

* Due to rounding, percentages may not add exactly to $100 \%$. 
Table 3.1 Descriptive characteristics of the participants

\begin{tabular}{|c|c|c|c|c|c|}
\hline & $\begin{array}{l}\text { Current } \\
\text { paranoid } \\
\text { patients } \\
(n=30) \\
\end{array}$ & $\begin{array}{l}\text { Current } \\
\text { non- } \\
\text { paranoid } \\
\text { patients } \\
(n=34) \\
\end{array}$ & $\begin{array}{l}\text { Remitted } \\
\text { patients } \\
(n=15) \\
\end{array}$ & $\begin{array}{l}\text { High } \\
\text { schizotypy } \\
\text { participants } \\
(n=38)\end{array}$ & $\begin{array}{l}\text { Healthy } \\
\text { controls } \\
(n=37)\end{array}$ \\
\hline $\begin{array}{l}\text { Number of valid reports, } \\
\text { (SD), } \\
\text { [range] }\end{array}$ & $\begin{array}{l}37(10) \\
{[20 ; 59]}\end{array}$ & $\begin{array}{l}38(10) \\
{[21 ; 58]}\end{array}$ & $\begin{array}{l}42(9) \\
{[20 ; 55]}\end{array}$ & $\begin{array}{l}49(6) \\
{[32 ; 59]}\end{array}$ & $\begin{array}{l}49(6) \\
{[37 ; 59]}\end{array}$ \\
\hline Sociodemographic variables & & & & & \\
\hline $\begin{array}{l}\text { Age, mean (SD), } \\
\text { [range], y }\end{array}$ & $\begin{array}{l}38.1(10.7) \\
{[19 ; 57]}\end{array}$ & $\begin{array}{l}36.0(11.6) \\
{[18 ; 63]}\end{array}$ & $\begin{array}{l}32.5(12.3) \\
{[18 ; 59]}\end{array}$ & $\begin{array}{l}47.3(10.3) \\
{[23 ; 60]}\end{array}$ & $\begin{array}{l}48.7(9.2), \\
{[23 ; 59]}\end{array}$ \\
\hline $\begin{array}{l}\text { Sex, male/female ratio, } \\
\text { No. }(\%)\end{array}$ & $\begin{array}{l}26 / 4 \\
(87 / 13)\end{array}$ & $\begin{array}{l}26 / 8 \\
(76 / 24)\end{array}$ & $\begin{array}{l}14 / 1 \\
(93 / 7)\end{array}$ & $\begin{array}{l}13 / 25 \\
(34 / 66)\end{array}$ & $\begin{array}{l}14 / 23 \\
(38 / 62)\end{array}$ \\
\hline $\begin{array}{l}\text { Education, No. }(\%)^{*} \\
\text { Elementary school } \\
\text { Secondary school } \\
\text { Higher education }\end{array}$ & $\begin{array}{l}3(10) \\
25(83) \\
2(7)\end{array}$ & $\begin{array}{l}6(18) \\
22(65) \\
6(18)\end{array}$ & $\begin{array}{l}1(7) \\
14(93) \\
0(0)\end{array}$ & $\begin{array}{l}2(5) \\
23(61) \\
13(34)\end{array}$ & $\begin{array}{l}1(3) \\
14(38) \\
22(59)\end{array}$ \\
\hline $\begin{array}{l}\text { Marital status, No. }(\%)^{*} \\
\text { Married or living together } \\
\text { Divorced } \\
\text { Widowed } \\
\text { Never married }\end{array}$ & $\begin{array}{l}3(10) \\
6(20) \\
0(0) \\
21(70)\end{array}$ & $\begin{array}{l}2(6) \\
5(15) \\
1(3) \\
26(76)\end{array}$ & $\begin{array}{l}1(7) \\
1(7) \\
0(0) \\
13(87)\end{array}$ & $\begin{array}{l}29(76) \\
4(11) \\
0(0) \\
5(13)\end{array}$ & $\begin{array}{l}32(86) \\
4(11) \\
0(0) \\
1(3)\end{array}$ \\
\hline $\begin{array}{l}\text { Work situation, No. }(\%)^{*} \\
\text { Working / fulltime } \\
\text { household / studying } \\
\text { Protected work } \\
\text { Incapable of work } \\
\text { Unemployed } \\
\text { Retired }\end{array}$ & $\begin{array}{l}1(3) \\
0(0) \\
24(80) \\
5(17) \\
0(0)\end{array}$ & $\begin{array}{l}2(6) \\
2(6) \\
26(76) \\
4(12) \\
0(0)\end{array}$ & $\begin{array}{l}2(13) \\
1(7) \\
9(60) \\
3(20) \\
0(0)\end{array}$ & $\begin{array}{l}24(63) \\
0(0) \\
6(16) \\
7(18) \\
1(3)\end{array}$ & $\begin{array}{l}33(89) \\
0(0) \\
2(5) \\
1(3) \\
1(3)\end{array}$ \\
\hline Clinical variables & & & & & \\
\hline $\begin{array}{l}\text { OPCRIT(McGuffin et al., } \\
\text { 1991) lifetime ICD10 } \\
\text { diagnosis, } \\
\text { No. }(\%)^{*} \\
\text { Schizophrenia / psychotic } \\
\text { disorder } \\
\text { Schizoaffective disorder } \\
\text { Mild / moderate depression }\end{array}$ & $\begin{array}{l}28(93) \\
2(7) \\
0(0)\end{array}$ & $\begin{array}{l}28(82) \\
6(18) \\
0(0)\end{array}$ & $\begin{array}{l}14(93) \\
1(7) \\
0(0)\end{array}$ & $\begin{array}{l}0(0) \\
0(0) \\
4(11)\end{array}$ & $\begin{array}{l}0(0) \\
0(0) \\
6(16)\end{array}$ \\
\hline
\end{tabular}


Table 3.1 - continued Descriptive characteristics of the participants

\begin{tabular}{|c|c|c|c|c|c|}
\hline & $\begin{array}{l}\text { Current } \\
\text { paranoid } \\
\text { patients } \\
(n=30)\end{array}$ & $\begin{array}{l}\text { Current } \\
\text { non- } \\
\text { paranoid } \\
\text { patients } \\
(n=34)\end{array}$ & $\begin{array}{l}\text { Remitted } \\
\text { patients } \\
(n=15)\end{array}$ & $\begin{array}{l}\text { High } \\
\text { schizotypy } \\
\text { participants } \\
(n=38)\end{array}$ & $\begin{array}{l}\text { Healthy } \\
\text { controls } \\
(n=37)\end{array}$ \\
\hline \multicolumn{6}{|l|}{ Clinical variables } \\
\hline $\begin{array}{l}\text { PANSS } † \text { score }(\mathrm{SD}), \\
\text { [range] }\end{array}$ & $\begin{array}{l}71.4(13.7) \\
{[47 ; 103]}\end{array}$ & $\begin{array}{l}60.5(9.7) \\
{[41 ; 79]}\end{array}$ & $\begin{array}{l}44.3(8.5) \\
{[32 ; 60]}\end{array}$ & $\begin{array}{l}36(4.5) \\
{[31 ; 50]}\end{array}$ & $\begin{array}{l}33.7(2.9), \\
{[30 ; 44]}\end{array}$ \\
\hline $\begin{array}{l}\text { PANSS suspiciousness/ } \\
\text { persecution } \ddagger \\
\text { (SD), [range] }\end{array}$ & $\begin{array}{l}5.3(1.1) \\
{[4 ; 7]}\end{array}$ & $\begin{array}{l}2.3(0.9) \\
{[1 ; 3]}\end{array}$ & $\begin{array}{l}1.7(0.9) \\
{[1 ; 3]}\end{array}$ & $\begin{array}{l}1.6(0.7) \\
{[1 ; 3]}\end{array}$ & $\begin{array}{l}1.2(0.4) \\
{[1 ; 2]}\end{array}$ \\
\hline $\begin{array}{l}\text { ESM momentary paranoia, } \\
\text { (SD), [range] }\end{array}$ & $\begin{array}{l}3.0(1.6) \\
{[1 ; 7]}\end{array}$ & $\begin{array}{l}2.1(1.1) \\
{[1 ; 7]}\end{array}$ & $\begin{array}{l}1.7(0.8) \\
{[1 ; 4.8]}\end{array}$ & $\begin{array}{l}1.6(0.7) \\
{[1 ; 5.5]}\end{array}$ & $\begin{array}{l}1.3(0.4) \\
{[1 ; 4.5]}\end{array}$ \\
\hline $\begin{array}{l}\text { Mean age of first psychotic } \\
\text { episode (SD), [range], y } ₫\end{array}$ & $\begin{array}{l}22.8(8.2) \\
{[13 ; 45]}\end{array}$ & $\begin{array}{l}23.1(7.3) \\
{[13 ; 43]}\end{array}$ & $\begin{array}{l}22.1(6.3) \\
{[12 ; 35]}\end{array}$ & - & - \\
\hline $\begin{array}{l}\text { Mean age of first contact } \\
\text { with psychiatric service due } \\
\text { to psychotic symptoms } \\
\text { (SD), [range], y }\end{array}$ & $\begin{array}{l}26.9(8.8) \\
{[16 ; 49]}\end{array}$ & $\begin{array}{l}24.5(7.7) \\
{[15 ; 44]}\end{array}$ & $\begin{array}{l}22.5(6.0) \\
{[12 ; 35]}\end{array}$ & - & - \\
\hline \multicolumn{6}{|l|}{$\begin{array}{l}\text { Usual symptom severity last } \\
2 \text { years (Life Chart), } \\
\text { No. }(\%)^{*} \dagger \dagger\end{array}$} \\
\hline Severe & $3(10)$ & $1(3)$ & $0(0)$ & - & - \\
\hline Moderate & $14(48)$ & $14(45)$ & $6(46)$ & - & - \\
\hline Mild & $11(38)$ & $15(48)$ & $5(38)$ & - & - \\
\hline Recovered & $1(3)$ & $1(3)$ & $2(15)$ & - & - \\
\hline
\end{tabular}

\footnotetext{
${ }^{\star}$ Due to rounding, percentages may not add exactly to $100 \%$.

$\uparrow$ Total score on the Positive and Negative Syndromes Scale.

$\$$ Mean score on item P6 of the Positive and Negative Syndromes Scale, scale ranges from 1 to 7.

$\$$ Because of missing values, data were only calculated for 26 current paranoid patients, 28 current nonparanoid patients and 14 remitted patients.

g Because of missing values, data were only calculated for 28 current paranoid patients and 32 current nonparanoid patients.

$\dagger \dagger$ Because of missing values, data were only calculated for 29 current paranoid patients, 31 current nonparanoid patients and 13 remitted patients.
}

Depression, as measured with the PANSS, was significantly associated with trait paranoia $(B[S E]=.30[.01], \mathrm{p}<0.001)$. Depression was also correlated with self-esteem level (e.g. ESM self-esteem level: $\mathrm{B}[\mathrm{SE}]=-.24[.05], \mathrm{p}<0.000$ ) and self-esteem variability (e.g self-esteem standard deviation: $\mathrm{B}[\mathrm{SE}]=.09$ [.02], $\mathrm{p}<0.000$ ). It is therefore likely that 
depression confounds the association between paranoia and the self-esteem variables. In order to assess the associations that are specific for paranoia, depression was added as a confounder in the models.

Table 3.3 Independent and dependent variables by tertile group*

\begin{tabular}{|c|c|c|c|c|}
\hline & $\begin{array}{l}\text { T1 } \\
\text { Low } \\
\text { paranoia } \\
(n=47)\end{array}$ & $\begin{array}{l}\text { T2 } \\
\text { Medium } \\
\text { paranoia } \\
(n=51)\end{array}$ & $\begin{array}{l}\text { T3 } \\
\text { High } \\
\text { paranoia } \\
(n=56)\end{array}$ & $\begin{array}{l}\text { Total } \\
\text { sample } \\
(n=154)\end{array}$ \\
\hline \multicolumn{5}{|l|}{ Part 1} \\
\hline $\begin{array}{l}\mathrm{PS} \dagger,(\mathrm{SD}), \\
\text { [range] }\end{array}$ & $\begin{array}{l}1.5(0.2) \\
{[1 ; 1.8]}\end{array}$ & $\begin{array}{l}2.2(0.2) \\
{[1.9 ; 2.6]}\end{array}$ & $\begin{array}{l}3.3(0.5) \\
{[2.6 ; 4.5]}\end{array}$ & $\begin{array}{l}2.4(0.8) \\
{[1 ; 4.5]}\end{array}$ \\
\hline $\begin{array}{l}\text { PANSS depression } \neq \text {, } \\
(S D) \text {, [range] }\end{array}$ & $\begin{array}{l}1.5(1.0) \\
{[1 ; 5]}\end{array}$ & $\begin{array}{l}1.9(1.1) \\
{[1 ; 5]}\end{array}$ & $\begin{array}{l}2.8(1.3) \\
{[1 ; 6]}\end{array}$ & $\begin{array}{l}2.1(1.3) \\
{[1 ; 6]}\end{array}$ \\
\hline \multicolumn{5}{|l|}{ Measures of SE level } \\
\hline $\begin{array}{l}\text { Momentary level\$, }(S D) \text {, } \\
\text { [range] }\end{array}$ & $\begin{array}{l}6.3(0.5) \\
{[3.9 ; 7]}\end{array}$ & $\begin{array}{l}6.0(0.8) \\
{[3.5 ; 7.0]}\end{array}$ & $\begin{array}{l}5.6(1.0) \\
{[2.7 ; 7]}\end{array}$ & $\begin{array}{l}6.0(0.8) \\
{[2.7 ; 7]}\end{array}$ \\
\hline $\begin{array}{l}\text { Participant levelg, }(S D), \\
\text { [range] }\end{array}$ & $\begin{array}{l}56.4(25.1) \\
{[-33 ; 102]}\end{array}$ & $\begin{array}{l}41.8(27.7) \\
{[-9 ; 93.0]}\end{array}$ & $\begin{array}{l}18.8(34.0) \\
{[-53 ; 92]}\end{array}$ & $\begin{array}{l}37.9(33.2) \\
{[-53 ; 102]}\end{array}$ \\
\hline \multicolumn{5}{|l|}{ Measures of SE instability } \\
\hline $\begin{array}{l}\text { Momentary level }{ }^{* *},(S D), \\
\text { [range] }\end{array}$ & $\begin{array}{l}0.2(0.2) \\
{[0 ; 0.8]}\end{array}$ & $\begin{array}{l}0.3(0.3) \\
{[0 ; 1.7]}\end{array}$ & $\begin{array}{l}0.4(0.3) \\
{[0 ; 1.5]}\end{array}$ & $\begin{array}{l}0.3(0.3) \\
{[0 ; 1.7]}\end{array}$ \\
\hline $\begin{array}{l}\text { Participant level } \neq \neq,(S D), \\
\text { [range] }\end{array}$ & $\begin{array}{l}0.3(0.2) \\
{[0 ; 1.0]}\end{array}$ & $\begin{array}{l}0.4(0.3) \\
{[0 ; 1.6]}\end{array}$ & $\begin{array}{l}0.6(0.4) \\
{[0 ; 1.8]}\end{array}$ & $\begin{array}{l}0.4(0.3) \\
{[0 ; 1.8]}\end{array}$ \\
\hline \multicolumn{5}{|l|}{ Part 2} \\
\hline $\begin{array}{l}\text { ESM momentary } \\
\text { paranoia } \$ \$,(S D),[\text { range] }\end{array}$ & $\begin{array}{l}1.3(0.5) \\
{[1 ; 6.3]}\end{array}$ & $\begin{array}{l}1.7(1.0) \\
{[1 ; 7]}\end{array}$ & $\begin{array}{l}2.6(1.3) \\
{[1 ; 7]}\end{array}$ & $\begin{array}{l}1.9(1.1) \\
{[1 ; 7]}\end{array}$ \\
\hline
\end{tabular}

* Separate means were calculated for each participant and subsequently aggregated to obtain group means. $\dagger$ PS indicates mean score on the Paranoia Scale, scale ranges from 1 to 5.

$\$$ PANSS depression indicates mean score on the depression item of the Positive and Negative Syndromes Scale, scale ranges from 1 to 7 .

$\$$ ESM momentary self-esteem assessment, scale ranges from 1 to 7 .

T Total score on the Self-Esteem Rating Scale, scale ranges from -120 to +120 .

** Absolute difference score in self-esteem between two concurrent ESM assessments, minimum possible difference score is 0 and maximum possible difference score is 6 .

末 Standard deviation of all ESM momentary self-esteem assessments.

$\S \S \mathrm{ESM}$ momentary paranoia assessment, scale ranges from 1 to 7 . 


\section{i) Is self-esteem level and instability associated with trait paranoia?}

Trait paranoia was significantly associated with a lower level of trait self-esteem, as consistently shown by lower sum scores on the SERS questionnaire and by lower mean levels of momentary self-esteem assessed in daily life (Table 3.4). High paranoid individuals (highest tertile) showed a significantly lower self-esteem level compared to low paranoid participants (lowest tertile) (Table 3.4). After controlling for the possible confounding effects of sex and depression, paranoia was still significantly associated with a lower level of self-esteem. After subsequently controlling for the constraining effect of self-esteem instability, the effect disappeared at momentary level (Table 3.4).

Table 3.4 Regression estimates $(B)$ for the effect of paranoia on self-esteem level

\begin{tabular}{|c|c|c|c|c|c|c|}
\hline $\begin{array}{l}\text { Self-esteem } \\
\text { level }\end{array}$ & Confounders & $n$ & $B(S E)$ & $\begin{array}{l}p \text { linear } \\
\text { trend }\end{array}$ & $\begin{array}{l}p \\
(\mathrm{~T} 2 \text { vs } \mathrm{T} 1)^{*}\end{array}$ & $\begin{array}{l}p \\
(\mathrm{~T} 3 \text { vs } \mathrm{T} 1)^{*}\end{array}$ \\
\hline \multicolumn{7}{|c|}{$\begin{array}{l}\text { Mean ESM } \\
\text { self-esteem level }\end{array}$} \\
\hline & - & 154 & $-.32(.08)$ & $\mathrm{p}<.001$ & & $* * *$ \\
\hline & $\operatorname{sex}$ & 154 & $-.32(.08)$ & $\mathrm{p}<.001$ & & $* * *$ \\
\hline & sex, depression & 154 & $-.20(.09)$ & $\mathrm{p}=.03$ & & * \\
\hline & $\begin{array}{l}\text { sex, depression, } \\
\text { self-esteem instability }\end{array}$ & 154 & $-.09(.01)$ & n.s. & & \\
\hline \multicolumn{7}{|c|}{$\begin{array}{l}\text { SERS } \\
\text { self-esteem level }\end{array}$} \\
\hline & - & 154 & $-18.93(2.89)$ & $\mathrm{p}<.001$ & * & $* * *$ \\
\hline & sex & 154 & $-20.33(3.09)$ & $\mathrm{p}<.001$ & $* *$ & $* * *$ \\
\hline & sex, depression & 154 & $-16.10(3.30)$ & $\mathrm{p}<.001$ & * & $* * *$ \\
\hline & $\begin{array}{l}\text { sex, depression, } \\
\text { self-esteem instability }\end{array}$ & 154 & $-13.04(3.30)$ & $\mathrm{p}<.001$ & & $* * *$ \\
\hline
\end{tabular}

In addition, trait paranoia was significantly associated with higher fluctuations in selfesteem. Both larger standard deviations and a larger mean change from moment-tomoment measured in daily life, were associated with more trait paranoia, even after controlling for the possible confounding effects of sex and depression (Table 3.5). High 
paranoid individuals (highest tertile) showed significantly more self-esteem fluctuations compared to low paranoid individuals (lowest tertile), even after controlling for all possible confounding effects (Table 3.5).

Table 3.5 Regression estimates $(B)$ for the effect of paranoia on self-esteem instability

\begin{tabular}{|c|c|c|c|c|c|c|}
\hline $\begin{array}{l}\text { Self-esteem } \\
\text { instability }\end{array}$ & Confounders & $n$ & $B(S E)$ & $\begin{array}{l}p \text { linear } \\
\text { trend }\end{array}$ & $\begin{array}{l}p \\
(\mathrm{~T} 2 \text { vs } \mathrm{T} 1)^{*}\end{array}$ & $\begin{array}{l}p \\
(\mathrm{~T} 3 \text { vs T1 })^{*}\end{array}$ \\
\hline \multicolumn{7}{|c|}{$\begin{array}{l}\text { moment-to- } \\
\text { moment change }\end{array}$} \\
\hline & - & 154 & $.11(.03)$ & $\mathrm{p}<.001$ & & $* * *$ \\
\hline & sex & 154 & $.14(.03)$ & $\mathrm{p}<.001$ & * & $* * *$ \\
\hline & sex, depression & 154 & $.09(.03)$ & $\mathrm{p}=.002$ & & $* *$ \\
\hline & $\begin{array}{l}\text { sex, depression, } \\
\text { self-esteem level }\end{array}$ & 154 & $.06(.03)$ & $\mathrm{p}=.02$ & & * \\
\hline \multicolumn{7}{|l|}{ SD } \\
\hline & - & 154 & $.13(.03)$ & $\mathrm{p}<.001$ & & $* * *$ \\
\hline & sex & 154 & $.16(.03)$ & $\mathrm{p}<.001$ & * & $* * *$ \\
\hline & sex, depression & 154 & $.11(.03)$ & $\mathrm{p}=.001$ & & $* * *$ \\
\hline & $\begin{array}{l}\text { sex, depression, } \\
\text { self-esteem level }\end{array}$ & 154 & $.08(.03)$ & $\mathrm{p}=.01$ & & $* *$ \\
\hline
\end{tabular}

\section{ii) Is trait self-esteem instability stronger associated with trait paranoia than self-esteem level?}

Self-esteem level was significantly and linearly associated with self-esteem instability $(\mathrm{B}[\mathrm{SE}]=-.20$ [.03]; $\mathrm{p}<.001)$. Therefore, self-esteem instability was controlled for in the model predicting self-esteem level. As presented in Table 3.4, the effect of trait paranoia on self-esteem level disappeared after controlling for the constraining effects of selfesteem instability. In the model predicting self-esteem instability on the other hand, the effect of trait paranoia remained significant after controlling for self-esteem level (see Table 3.5). Therefore, it seems safe to suggest that self-esteem instability is more strongly related to paranoia than self-esteem level. 


\section{iii) Are momentary changes in state self-esteem associated with state paranoia?}

Multilevel linear regression analysis showed a temporal association between changes in self-esteem and state paranoia. A decrease in self-esteem between two succeeding reports was significantly associated with an increase in subsequent momentary paranoia $(\mathrm{B}[\mathrm{SE}]=.17[.01] ; \mathrm{p}<.001)$. This association remained strong and significant after controlling for sex, current depressive mood and paranoia at the previous beep moment $(\mathrm{B}[\mathrm{SE}]=.17[.01] ; \mathrm{p}<.001)$.

\section{Robustness of the results}

Additional analyses were performed to investigate whether the individuals who were excluded from the analyses were comparable to the study group in terms of their scores on ESM momentary self-esteem. The analyses were performed on the data of 27 individuals, since 2 individuals did not comply with the protocol (one filled out all the booklets on the first day, the other did not report the time on any of the beeps). Factor (principal component) analysis on the raw within-participants ESM self-esteem scores identified one factor, accounting for $68 \%$ of the total variance. The four self-esteem items had a strong loading on the factor (negative statements respectively -0.78 and 0.90; positive statements respectively 0.90 and 0.69 ) and good internal consistency (Cronbach's $a=0.84$ ), which is comparable to that of the study group. The mean ESM momentary self-esteem level of the excluded individuals was $5.1(S D=1.1)$, which was substantially lower than the mean ESM momentary self-esteem level of high paranoid individuals in the highest tertile (Table 3.3). The mean ESM momentary fluctuation, based on only 23 individuals, was $0.7(S D=0.5)$, which was substantially higher than the mean ESM momentary fluctuation of high paranoid individuals in the highest tertile (Table 3.3). These differences will be addressed in the discussion.

\section{Discussion}

The findings support the hypothesis that instability in self-esteem is associated with both trait and state paranoia. The results of part 1 confirm the hypothesis that individuals at higher positions on the paranoia continuum not only show a lower general self-esteem level, but also more fluctuations in their self-esteem. These results are consistent with previous findings of an association between paranoia and low levels of self-esteem, both found in patients with psychosis (Freeman et al., 1998) and in non- 
clinical samples (Combs \& Penn, 2004; Ellett et al., 2003; Martin \& Penn, 2001). The results are also in line with findings of a specific association between paranoia and fluctuations of self-esteem in a general population sample (Thewissen et al., 2007) and extend these findings to the context of daily life in individuals ranging from nonpathological to pathological levels of paranoia. Furthermore, these data suggest that instability of self-esteem plays a more important role in the association with paranoia than level of self-esteem. The second set of analyses aimed to investigate the temporal relationship between momentary self-esteem and state paranoia in the daily life of psychotic patients. The results are in line with the hypothesis that decreases in selfesteem may result in increases in paranoid thinking (Bentall et al., 2001) thus providing evidence for a causal relationship between self-esteem and paranoia.

The relationship between self-esteem and psychosis has been investigated thoroughly (Barrowclough et al., 2003; Bowins \& Shugar, 1998; Freeman et al., 1998; Krabbendam et al., 2002; Lecomte et al., 1999; Nickols, 1966; Silverstone, 1991; Silverstone \& Salsali, 2003). There is a growing consensus that psychotic individuals present with low levels of self-esteem at different phases of the illness (Hall \& Tarrier, 2003), even after symptomatic recovery (Gureje, Harvey, \& Herrman, 2004). Negative evaluations of the self are specifically associated with positive psychotic symptoms in general (Barrowclough et al., 2003), although premorbid feelings of inferiority have been found to be more frequent in paranoid patients than in a comparison group of individuals with schizophrenia (Kendler \& Hays, 1981).

The more specific relationship between self-esteem and paranoia has also been the focus of study for many years (Bentall, 1994; Bentall, Kinderman, \& Kaney, 1994; Colby, 1975; Garety, Kuipers, Fowler, Freeman, \& Bebbington, 2001; Meissner, 1981; Schwartz, 1963). Up to now, most studies had specifically focused on the relationship between levels of self-esteem and paranoia. However, the results of these studies are equivocal, particularly compared to the results of studies investigating the relationship between self-esteem and psychosis in general. Paranoia has been found to be associated with low levels of self-esteem, both in patients (Freeman et al., 1998) and in non-clinical samples (Combs \& Penn, 2004; Ellett et al., 2003; Martin \& Penn, 2001), as well as relatively high or even normal levels of self-esteem in paranoid patients (Candido \& Romney, 1990; Krstev et al., 1999; Lyon et al., 1994). One explanation for these inconsistent findings is that the dynamic aspects of self-esteem were not taken into account. 
The importance of fluctuations in self-esteem has been stressed by a recent explanatory model of paranoia in which the formation of persecutory delusions is suggested to be a complex and dynamic process (Bentall et al., 2001). According to the model, paranoid patients attempt to avoid negative beliefs about the self by assuming that their disappointments in life are caused by intentional actions of other people. These attempts to maintain self-esteem have the unfortunate consequence of obtaining a negative world view. However, as the attempts to avoid negative beliefs are not always effective, it is predicted that self-esteem will be highly unstable in paranoid patients, rather than being a stable trait. The present findings of a strong association between paranoia and higher fluctuations of self-esteem are therefore well in line with this theory and additionally show that self-esteem may fluctuate within a very short period.

The strength of the findings in part 1 is that fluctuations in self-esteem were consistently demonstrated using two different approaches to measure instability of selfesteem. First, at a momentary level, in which fluctuations were identified from moment to moment. And second, as a participant characteristic, in which the fluctuations reflected the variance in self-esteem over the study period. There was evidence for a dose-response relationship, in that the results showed significantly more self-esteem fluctuations in high paranoid individuals compared to low paranoid individuals at all three levels.

The findings of the part 1 also provide evidence for a strong association between paranoia and a lower self-esteem level using two different approaches to measure self-esteem level: global level of self-esteem over the days, and level of selfesteem assessed with a questionnaire. After controlling for self-esteem instability, the association disappeared at momentary level. This may indicate that self-esteem level is strongly constrained by self-esteem instability. On the other hand, self-esteem instability was not found to be confounded by level of self-esteem. This suggests that in the context of daily life, instability of self-esteem plays a more important role in the relationship with paranoia than level of self-esteem, as the latter is reducible to the first but not the other way around.

In part 1 , it was not possible to infer the direction of causality between paranoia and level and fluctuations in self-esteem. Level and fluctuations in self-esteem could merely be interpreted as an expression of psychosis liability. The results of part 2, however, yield evidence of a temporal association between self-esteem and paranoia by showing that a decrease in self-esteem is associated with an immediate increase in paranoia. Although these findings demonstrate that the fluctuation magnitude of self- 
esteem influences the degree of paranoia, it is most likely that a low self-esteem level and high self-esteem instability both act as a vulnerability, maintaining and consequential factor of paranoia (Bentall et al., 2001; Freeman et al., 1998; Krabbendam et al., 2002; Roe, 2003).

The results of both studies should be interpreted in the context of some limitations. First, comparison analyses in part 1 demonstrated that the individuals who had been excluded from the main analyses were different from the study group in terms of mean momentary self-esteem level and fluctuations. The excluded group showed a lower self-esteem level and considerably higher self-esteem fluctuations. However, as most of the excluded individuals were patients who were not able to participate in the study due to severity of their illness, the lower self-esteem level and higher self-esteem fluctuations can be interpreted as expressions of the degree of their illness. Moreover, this observation suggests that, if anything, the current findings may underestimate the association between paranoia and level and fluctuations of self-esteem. Second, it has been argued that the Paranoia Scale might contain some affectively laden or depression items. Therefore, one could argue that current findings of a relationship between selfesteem and paranoia are ambiguous. However, controlling for depression did not change the results, suggesting that it is more the paranoid rather than the depressive content of the Paranoia Scale that is associated with self-esteem. Third, self-esteem was measured in both studies as one single concept. According to some researchers (Barrowclough et al., 2003), it is important to make a distinction between positive and negative components of self-esteem, since individuals may hold both positive and negative views about the self, which may act independently. However, since the current results are consistently found using two different definitions, the results are expected to be reliable. Besides, factor analysis on the positive and negative momentary self-esteem items demonstrated that the items were representative of one single substantive construct. Fourth, there was no distinction made based on content of the paranoid beliefs. It has been argued that there may be two separate types of paranoia which represent beliefs about the deservedness of the persecution. One type is persecution or 'poor me' paranoia and the other type is punishment or 'bad me' paranoia (Chadwick, Trower, Juusti-Butler, \& Maguire, 2005). 'Bad me' paranoia, in which the malevolence of others is conceived as justifiably deserved, is typically characterised by lower selfesteem. Recent evidence shows that these beliefs on deservedness may change or alternate within a person over time, representing separate phases of an unstable phenomenon (Melo, Taylor, \& Bentall, 2006). Therefore, it would be valuable for future 
studies on momentary paranoia to investigate these two types of paranoia separately. Finally, it could be argued that the key issue is not variability in self-esteem but rather a more general emotional vulnerability. Self-esteem variability possibly is a marker for this more general emotional vulnerability. This possibility cannot be ruled out in the current paper.

The current findings have several implications. The finding that not only a low self-esteem level, but also self-esteem fluctuations are a main feature of paranoid patients has an important implication for treatment. Besides targeting improvement of self-esteem (Hall \& Tarrier, 2003; Lecomte et al., 1999), psychological treatments should also focus on regulation of self-esteem. Future explanatory models of paranoia should also take into account the dynamic structure of self-esteem. Other factors, such as mood, which are involved in the complex relationship between self-esteem and paranoia merit further investigation.

\section{References}

Barrowclough, C., Tarrier, N., Humphreys, L., Ward, J., Gregg, L., \& Andrews, B. (2003). Self-esteem in schizophrenia: relationships between self-evaluation, family attitudes, and symptomatology. Journal of Abnormal Psychology, 112(1), 92-99.

Bentall, R. P. (1994). Cognitive biases and abnormal beliefs: Towards a model of persecutory delusions. In A. David \& J. Cutting (Eds.), The neuropsychology of schizophrenia (pp. 337-360). London: Erlbaum.

Bentall, R. P., Corcoran, R., Howard, R., Blackwood, N., \& Kinderman, P. (2001). Persecutory delusions: a review and theoretical integration. Clinical Psychology Review, 21(8), 1143-1192.

Bentall, R. P., Kinderman, P., \& Kaney, S. (1994). The self, atrributional processes and abnormal beliefs: Towards a model of persecutory delusions. Beh Res Therapy, 32(3), 331-341.

Blackwood, N. J., Howard, R. J., Bentall, R. P., \& Murray, R. M. (2001). Cognitive neuropsychiatric models of persecutory delusions. American Journal of Psychiatry, 158(4), 527-539.

Blascovich, J., \& Tomaka, J. (1991). Measures of self-esteem. In J. P. Robinson, P. R. Shaver, L. S. Wrightsman \& F. M. Andrews (Eds.), Measures of personality and social psychological attitudes (pp. 115-160). San Diego: Academic Press.

Bowins, B., \& Shugar, G. (1998). Delusions and self-esteem. Canadian Journal of Psychiatry, 43(2), 154-158.

Candido, C. L., \& Romney, D. M. (1990). Attributional style in paranoid vs. depressed patients. British Journal of Medical Psychology, 63 ( Pt 4), 355-363. 
Chadwick, P. D., Trower, P., Juusti-Butler, T. M., \& Maguire, N. (2005). Phenomenological evidence for two types of paranoia. Psychopathology, 38(6), 327-333.

Colby, K. M. (1975). Artificial paranoia; a computer simulation of paranoid processes. New York: Pergamon Press.

Colby, K. M. (1977). Appraisal of four psychological theories of paranoid phenomena. Journal of Abnormal Psychology, 86(1), 54-59.

Combs, D. R., Michael, C. O., \& Penn, D. L. (2006). Paranoia and emotion perception across the continuum. British Journal of Clinical Psychology, 45(Pt 1), 19-31.

Combs, D. R., \& Penn, D. L. (2004). The role of subclinical paranoia on social perception and behavior. Schizophrenia Research, 69(1), 93-104.

Csikszentmihalyi, M., \& Larson, R. (1987). Validity and reliability of the Experience-Sampling Method. Journal of Nervous and Mental Disease, 175(9), 526-536.

Dahlstrom, W. G., Welsh, G. S., \& Dahlstrom, L. F. (1975). An MMPI handbook (Vol. 2. Research applications). Minneapolis, MN: University of Minnesota Press.

Delespaul, P. (1995). Assessing Schizophrenia in Daily Life. Maastricht, The Netherlands: Universitaire Pers Maastricht.

deVries, M. W. (1992). The Experience of psychopathology : investigating mental disorders in their natural settings. Cambridge; New York: Cambridge University Press.

Ellett, L., Lopes, B., \& Chadwick, P. (2003). Paranoia in a nonclinical population of college students. Journal of Nervous and Mental Disease, 191(7), 425-430.

Fenigstein, A., \& Vanable, P. A. (1992). Paranoia and self-consciousness. Journal of Personality and Social Psychology, 62(1), 129-138.

Freeman, D., Garety, P., Fowler, D., Kuipers, E., Dunn, G., Bebbington, P., et al. (1998). The London-East Anglia randomized controlled trial of cognitive-behaviour therapy for psychosis. IV: Self-esteem and persecutory delusions. British Journal of Clinical Psychology, 37 ( Pt 4), 415-430.

Freeman, D., Garety, P. A., Bebbington, P. E., Smith, B., Rollinson, R., Fowler, D., et al. (2005). Psychological investigation of the structure of paranoia in a non-clinical population. British Journal of Psychiatry, $186,427-435$.

Garety, P. A., \& Hemsley, D. R. (1987). Characteristics of delusional experience. European Archives of Psychiatry and Neurological Sciences, 236(5), 294-298.

Garety, P. A., Kuipers, E., Fowler, D., Freeman, D., \& Bebbington, P. E. (2001). A cognitive model of the positive symptoms of psychosis. Psychological Medicine, 31(2), 189-195.

Greenier, K. D., Kernis, M. H., McNamara, C. W., Waschull, S. B., Berry, A. J., Herlocker, C. E., et al. (1999). Individual differences in reactivity to daily events: examining the roles of stability and level of selfesteem. Journal of Personality, 67(1), 185-208. 
Gureje, O., Harvey, C., \& Herrman, H. (2004). Self-esteem in patients who have recovered from psychosis: profile and relationship to quality of life. Australian and New Zealand Journal of Psychiatry, 38(5), 334-338.

Hall, P. L., \& Tarrier, N. (2003). The cognitive-behavioural treatment of low self-esteem in psychotic patients: a pilot study. Behaviour Research and Therapy, 41(3), 317-332.

Hanssen, M., Krabbendam, L., Vollema, M., Delespaul, P., \& Van Os, J. (2006). Evidence for instrument and family-specific variation of subclinical psychosis dimensions in the general population. Journal of Abnormal Psychology, 115(1), 5-14.

Hanssen, M., Peeters, F., Krabbendam, L., Radstake, S., Verdoux, H., \& van Os, J. (2003). How psychotic are individuals with non-psychotic disorders? Social Psychiatry and Psychiatric Epidemiology, 38(3), 149-154.

Hudson, W. W. (1982). The clinical measurement package : a field manual. Homewood, Ill.: Dorsey Press.

Jacobs, N., Nicolson, N. A., Derom, C., Delespaul, P., van Os, J., \& Myin-Germeys, I. (2005). Electronic monitoring of salivary cortisol sampling compliance in daily life. Life Sciences, 76(21), 2431-2443.

Johns, L. C., \& van Os, J. (2001). The continuity of psychotic experiences in the general population. Clinical Psychology Review, 21(8), 1125-1141.

Jorgensen, P., \& Jensen, J. (1994). Delusional beliefs in first admitters. A clinical description. Psychopathology, 27(1-2), 100-112.

Kay, S. R., Fiszbein, A., \& Opler, L. A. (1987). The positive and negative syndrome scale (PANSS) for schizophrenia. Schizophrenia Bulletin, 13(2), 261-276.

Kay, S. R., Opler, L. A., \& Lindenmayer, J. P. (1988). Reliability and validity of the positive and negative syndrome scale for schizophrenics. Psychiatry Research, 23(1), 99-110.

Kendler, K. S., \& Hays, P. (1981). Paranoid psychosis (delusional disorder) and schizophrenia. A family history study. Archives of General Psychiatry, 38(5), 547-551.

Kernis, M. H. (2005). Measuring self-esteem in context: the importance of stability of self-esteem in psychological functioning. Journal of Personality, 73(6), 1569-1605.

Kernis, M. H., Cornell, D. P., Sun, C. R., Berry, A., \& Harlow, T. (1993). There's more to self-esteem than whether it is high or low: the importance of stability of self-esteem. Journal of Personality and Social Psychology, 65(6), 1190-1204.

Kernis, M. H., \& Goldman, B. M. (2003). Stability and variability in self-concept en self-esteem. In M. Leary \& J. Tangney (Eds.), Handbook of self and identity (pp. 106-152). New York: The Guilford Press.

Kernis, M. H., \& Johnson, E. K. (1990). Current and typical self-appraisals: Differential responsiveness to evaluative feedback and implications for emotions. Journal of Research in Personality, 24, 241-257. 
Konings, M., Bak, M., Hanssen, M., van Os, J., \& Krabbendam, L. (2006). Validity and reliability of the CAPE: a self-report instrument for the measurement of psychotic experiences in the general population. Acta Psychiatrica Scandinavica, 114, 55-61.

Krabbendam, L., Janssen, I., Bak, M., Bijl, R. V., de Graaf, R., \& van Os, J. (2002). Neuroticism and low selfesteem as risk factors for psychosis. Social Psychiatry and Psychiatric Epidemiology, 37(1), 1-6.

Krstev, H., Jackson, H., \& Maude, D. (1999). An investigation of attributional style in first-episode psychosis. British Journal of Clinical Psychology, 38 ( Pt 2), 181-194.

Lecomte, T., Cyr, M., Lesage, A. D., Wilde, J., Leclerc, C., \& Ricard, N. (1999). Efficacy of a self-esteem module in the empowerment of individuals with schizophrenia. Journal of Nervous and Mental Disease, 187(7), 406-413.

Lyon, H. M., Kaney, S., \& Bentall, R. P. (1994). The defensive function of persecutory delusions. Evidence from attribution tasks. British Journal of Psychiatry, 164(5), 637-646.

Markus, H., \& Kunda, Z. (1986). Stability and malleability of the self-concept. Journal of Personality and Social Psychology, 51(4), 858-866.

Martin, J. A., \& Penn, D. L. (2001). Social cognition and subclinical paranoid ideation. British Journal of Clinical Psychology, 40(Pt 3), 261-265.

McGuffin, P., Farmer, A., \& Harvey, I. (1991). A polydiagnostic application of operational criteria in studies of psychotic illness. Development and reliability of the OPCRIT system. Archives of General Psychiatry, 48(8), 764-770.

Meissner, W. W. (1981). The schizophrenic and the paranoid process. Schizophrenia Bulletin, 7(4), 611-631.

Melo, S. S., Taylor, J. L., \& Bentall, R. P. (2006). Poor me versus bad me paranoia and the instability of persecutory ideation. Psychology and Psychotherapy, 79(Pt 2), 271-287.

Myin-Germeys, I., Delespaul, P., \& van Os, J. (2005). Behavioural sensitization to daily life stress in psychosis. Psychological Medicine, 35(5), 733-741.

Myin-Germeys, I., Delespaul, P. A., \& deVries, M. W. (2000). Schizophrenia patients are more emotionally active than is assumed based on their behavior. Schizophrenia Bulletin, 26(4), 847-854.

Myin-Germeys, I., Nicolson, N. A., \& Delespaul, P. A. (2001). The context of delusional experiences in the daily life of patients with schizophrenia. Psychological Medicine, 31(3), 489-498.

Myin-Germeys, I., van Os, J., Schwartz, J. E., Stone, A. A., \& Delespaul, P. A. (2001). Emotional reactivity to daily life stress in psychosis. Archives of General Psychiatry, 58(12), 1137-1144.

Ndetei, D. M., \& Vadher, A. (1984). Frequency and clinical significance of delusions across cultures. Acta Psychiatrica Scandinavica, 70(1), 73-76.

Nickols, J. (1966). Self-image ratings of normal and disturbed subjects. Journal of Health and Human Behavior, 7(1), 28-36. 
Nugent, W. R., \& Thomas, J. W. (1993). Validation of a clinical measure of self-esteem. Research on Social Work Practice, 3(2), 191-207.

Oosterwegel, A., Field, N., Hart, D., \& Anderson, K. (2001). The relation of self-esteem variability to emotion variability, mood, personality traits, and depressive tendencies. Journal of Personality, 69(5), 689708.

Peters, E. R., Joseph, S. A., \& Garety, P. A. (1999). Measurement of delusional ideation in the normal population: introducing the PDI (Peters et al. Delusions Inventory). Schizophrenia Bulletin, 25(3), 553-576.

Roe, D. (2003). A prospective study on the relationship between self-esteem and functioning during the first year after being hospitalized for psychosis. Journal of Nervous and Mental Disease, 191(1), 45-49.

Rosenberg, M. (1965). Society and the adolescent self-image. Princeton, NJ: Princeton University Press.

Rosenberg, M., Schoenbach, C., Schooler, C., \& Rosenberg, F. (1995). Global self-esteem and specific selfesteem: Different concepts, different outcomes. American Sociological Review, 60(2), 141-156.

Schwartz, D. A. (1963). A review of the 'paranoid concept'. Archives of General Psychiatry, 8, 349-361.

Schwartz, J. E., \& Stone, A. A. (1998). Strategies for analyzing ecological momentary assessment data. Health Psychology, 17(1), 6-16.

Silverstone, P. H. (1991). Low self-esteem in different psychiatric conditions. British Journal of Clinical Psychology, 30(Pt 2), 185-188.

Silverstone, P. H., \& Salsali, M. (2003). Low self-esteem and psychiatric patients: Part I - The relationship between low self-esteem and psychiatric diagnosis. Annals of General Hospital Psychiatry, 2(1), 2.

Smári, J., Stefánsson, S., \& Thorgilsson, H. (1994). Paranoia, Self-Consciousness, and Social Cognition in Schizophrenics. Cognitive Therapy and Research, 18(4), 387-399.

StataCorp. (2006). Stata Statistical Software: Release 9.2. TX: Stata Corporation, College Station.

Stefanis, N. C., Hanssen, M., Smirnis, N. K., Avramopoulos, D. A., Evdokimidis, I. K., Stefanis, C. N., et al. (2002). Evidence that three dimensions of psychosis have a distribution in the general population. Psychological Medicine, 32(2), 347-358.

Susser, E., Finnerty, M., Mojtabai, R., Yale, S., Conover, S., Goetz, R., et al. (2000). Reliability of the life chart schedule for assessment of the long-term course of schizophrenia. Schizophrenia Research, 42(1), 67-77.

Thewissen, V., Myin-Germeys, I., Bentall, R., de Graaf, R., Vollebergh, W., \& van Os, J. (2007). Instability in self-esteem and paranoia in a general population sample. Social Psychiatry and Psychiatric Epidemiology, 42(1), 1-5.

van Os, J., Hanssen, M., Bijl, R. V., \& Vollebergh, W. (2001). Prevalence of psychotic disorder and community level of psychotic symptoms: an urban-rural comparison. Archives of General Psychiatry, 58(7), 663-668. 
Wessely, S., Buchanan, A., Reed, A., Cutting, J., Everitt, B., Garety, P., et al. (1993). Acting on delusions. I: Prevalence. British Journal of Psychiatry, 163, 69-76. 


\section{Chapter 4}

\section{EMOTIONAL CHANGES AND PARANOIA: AN EXPERIENCE SAMPLING STUDY}

This chapter has been submitted for publication as:

Viviane Thewissen, Richard P. Bentall ${ }^{\mathrm{a}}$, Joost à Campo ${ }^{\mathrm{b}}$, Thom van Lierop ${ }^{\mathrm{b}}$, Jim van Os and Inez Myin-Germeys. (2007). Emotional changes and paranoia:

An Experience Sampling Study.

a School of Psychological Sciences, University of Manchester, UK.

${ }^{\mathrm{b}}$ Section Social Cognition, Mondriaan Zorggroep, Heerlen, The Netherlands. 


\section{AbStract}

Two contemporary psychological accounts of paranoia suggest a different role for emotional processes in the development of paranoid symptoms: paranoia as a protection against negative emotions and paranoia as a direct reflection of negative emotions, especially anxiety. Studies have mainly investigated the association between negative emotional processes and paranoia using cross-sectional designs, limiting the possibility to infer direction of causality. In the present study, the temporal association between changes in momentary emotional processes and paranoia was investigated in the daily life of patients with positive psychotic symptoms. The Experience Sampling Method (a structured self-assessment diary technique) was used to examine paranoia and changes in three key negative emotional processes including depression, anxiety and anger. Multilevel regression analyses yielded significant cross-sectional associations between paranoia and the above mentioned aspects of emotional experience. Longitudinal analyses showed that paranoid beliefs not only generate, but independently also arise from increases in negative emotional experiences. An increase in anxiety was found to be the strongest predictor of paranoia. It can be concluded that paranoia may be emotion-driven, rather than serving an immediate defensive function against negative emotions. Anxiety in particular is a possible maintaining factor of paranoid beliefs. 


\section{INTRODUCTION}

Research into the etiology and mechanisms of psychosis has gradually shifted from a syndrome-oriented approach to a dimensional, or even more specific, symptomoriented approach (Bentall, 2006; Berner, 1997; Costello, 1992; van Os et al., 1999). The underlying mechanisms of paranoid symptoms in particular have become an important focus of attention (Bentall, Corcoran, Howard, Blackwood, \& Kinderman, 2001; Freeman, Garety, Kuipers, Fowler, \& Bebbington, 2002). Over the last few years, considerable progress has been made in identifying (social) cognitive determinants of persecutory delusions, such as deficits in theory of mind (Corcoran, 2000; Corcoran, Cahill, \& Frith, 1997; Frith, 1992), biases in attention (Bentall \& Kaney, 1989; Fear, Sharp, \& Healy, 1996), reasoning (Garety et al., 2005; Garety, Hemsley, \& Wessely, 1991) and attributional style (Bentall, 1994; Bentall, Kaney, \& Dewey, 1991; Kinderman \& Bentall, 1997). However, less is known about the underlying psychological processes which may interact with these cognitive factors in the development of paranoid beliefs, in particular the contribution of negative emotions.

Emotional processes are considered to play an important role in the generation and maintenance of paranoid symptoms. The role of emotions is incorporated in two main contemporary psychological accounts of persecutory delusions (Bentall, Corcoran, Howard, Blackwood, \& Kinderman, 2001; Freeman, Garety, Kuipers, Fowler, \& Bebbington, 2002). According to one account, persecutory delusions are thought to arise in individuals with deeply rooted low self-esteem. Paranoid individuals attempt to protect their self-esteem and avoid negative beliefs about the self by attributing threatening events to the actions of other people (Bentall, Corcoran, Howard, Blackwood, \& Kinderman, 2001). Emotional processes play an essential theoretical role in this delusion-as-defence account, since it is hypothesised that paranoid beliefs prevent the activation of negative emotions. This account of paranoia is consistent with the suggestion that paranoia is a form of hidden or camouflaged depression (Zigler \& Glick, 1988). Another influential account of persecutory delusions proposes that delusions arise from an interaction between several factors, such as pre-existing negative self schemas and personality, cognitive biases, internal unusual experiences, external events and emotional processes (Freeman, Dunn et al., 2005; Freeman \& Garety, 2004; Freeman, Garety, Kuipers, Fowler, \& Bebbington, 2002). In this model, a more central and direct role is claimed for emotion and self-esteem in the development and maintenance of delusions. The content of delusions may directly reflect the 
emotional state of the individual. Especially anxiety is postulated as being important, since persecutory delusions can be conceptualised as threat beliefs (Freeman \& Garety, 2003; Freeman \& Garety, 2004; Freeman, Garety, \& Kuipers, 2001; Freeman, Garety, Kuipers, Fowler, \& Bebbington, 2002). But also depression, anger, guilt and disgust, or a combination of those, may contribute to the content of persecutory delusions (Freeman \& Garety, 2003).

Although there is increasing evidence for a role of emotional processes in the development and maintenance of psychosis in general (e.g. Häfner et al., 2005; Jones, Rodgers, Murray, \& Marmot, 1994), and more specifically to positive psychotic symptoms (Allen et al., 2005; Krabbendam et al., 2002; Krabbendam \& van Os, 2005; Norman \& Malla, 1994), evidence for a contribution of emotion to paranoia is rather limited. Appelbaum et al. (1999) demonstrated, in a large sample of hospitalised patients, that persecutory delusions were associated with higher levels of negative affect relative to other types of delusions, such as delusions of guilt, somatic or religious delusions. Recently, Smith et al. (2006) have demonstrated a strong association between persecutory delusions and depression, low self-esteem and negative evaluative beliefs in a large sample of individuals who had suffered a recent relapse in psychosis. A study by Green et al. (2006) provides evidence for an association between negative emotions and specific aspects of delusional content in persecutory delusions. Depression and low selfesteem were found to be characteristic for individuals who feel less powerful than their persecutors. Subclinical paranoia has also been found to be associated with negative emotional experiences, such as higher levels of depression, lower self-esteem and greater social anxiety (Combs \& Penn, 2004; Martin \& Penn, 2001). In an experimental study using virtual reality, Freeman et al. (2005) showed that subclinical paranoia was closely related to emotional disturbances as well. Level of anxiety was found to be the strongest predictor of persecutory ideation in a virtual reality controlled environment.

The evidence to date for a contribution of emotion to paranoia is fairly inconclusive due to methodological difficulties. Associations were predominantly investigated using cross-sectional designs, limiting the interpretation of direction of causality. Therefore, it cannot be concluded from these studies that negative emotions trigger or contribute to the maintenance of paranoid symptoms. Furthermore, since emotional changes have been shown to occur within a short-time period (MyinGermeys, Delespaul, \& deVries, 2000; Myin-Germeys, van Os, Schwartz, Stone, \& Delespaul, 2001) and, more importantly, since delusional experiences may fluctuate over periods of months or weeks (Garety \& Hemsley, 1997) or even days and hours 
(Myin-Germeys, Nicolson, \& Delespaul, 2001), it may be worthwhile investigating the temporal association between momentary emotional processes and paranoia in the context of daily life.

Three types of negative emotion - anxiety, anger and depression - are of considerable interest when studying persecutory delusions (Freeman \& Garety, 2004). In the current study, we used the Experience Sampling Method (ESM), a structured selfassessment diary technique, to explore the dynamic relationship between changes in these three types of negative emotional experience and paranoia in the daily life of a sample of psychotic patients. First, the cross-sectional association between changes in emotional states and paranoia was investigated. Second, the temporal relationship between changes in emotional states and paranoia was studied. It was examined whether changes in specific negative emotional states contribute to the development of paranoia or rather result from paranoid experiences.

\section{Methods}

\section{Sample}

In order to obtain a sample of patients who were likely to have fleeting everyday instances of paranoid thinking, individuals with a clinical diagnosis of psychotic disorder were selected. These individuals were derived from a previous study (Thewissen et al., 2007). The following individuals were included in the present study: i) patients with current paranoid psychotic symptoms, defined as having a score of $>3$ on item P6 (suspiciousness) of the Positive and Negative Syndromes Scale (PANSS; see Instruments section); ii) patients with current other positive psychotic symptoms, defined as having a score of $<4$ on the PANSS items P6 (suspiciousness) AND having a score of $>3$ on at least one of the PANSS items P1 (delusions), P3 (hallucinatory behaviour), P5 (grandiosity) and G9 (unusual thought content); iii) patients with remitted psychotic symptoms, defined as having a score of $<4$ on all the aforementioned PANSS items.

Inclusion criteria were 18 to 65 years of age, sufficient command of the Dutch language to understand and fill out the questionnaires, and signed informed consent conforming to the local ethics committee guidelines. Patients were recruited from inpatient and out-patient psychiatric services in the region of South Limburg, the Netherlands. All patients were under current treatment and were extensively screened 
for psychiatric symptoms using diagnostic interviews including the Brief Psychiatric Rating Scale (Overall \& Gorham, 1962), the Positive and Negative Syndrome Scale (Kay, Fiszbein, \& Opler, 1987) and the Life Chart (Susser et al., 2000). Interview data and, when necessary, clinical record data were used to yield ICD-10 diagnoses by the OPCRIT (Operational Criteria Checklist for Psychotic and Affective Illness) computer program version 3.4 (McGuffin, Farmer, \& Harvey, 1991).

\section{Measures}

\section{ESM}

Paranoid symptoms and aspects of emotional experience were assessed using the Experience Sampling Method (ESM; Csikszentmihalyi \& Larson, 1987), a random time sampling self-assessment diary technique to assess mental state in a daily life context. Subjects received a digital wristwatch and ten identical pocket size questionnaires collated in a booklet for each day. Ten times a day on six consecutive days, the watch emitted a signal after which subjects had to rate their current mood, self-esteem and symptoms on a 7-point Likert scale. The watch was programmed to emit a signal at least every 90 minutes at unpredictable moments between 7.30 a.m. and 10.30 p.m. Three different time series were used to prevent participants, some of whom were living in the same sheltered housing, being signalled at precisely the same moment.

During an initial briefing session, the ESM procedure was explained and a practice form was completed to confirm that subjects were able to understand the 7point Likert scale format. Subjects were instructed to complete their reports immediately after the 'beep' to minimize memory distortions and to register the time at which they completed the questionnaire. During the actual sampling period, research staff contacted subjects frequently by phone or, when necessary, visited them to assess whether they were complying with the instructions. During a debriefing session, subjects were interviewed extensively to be sure that they complied with the instructions. Based on the indicated times of completion, all reports completed more than 15 minutes after the signal were excluded from the analysis as previous work (Delespaul, 1995) has shown that reports completed after this time interval are less reliable and consequently less valid. For the same reason, subjects with less than 20 valid reports were excluded from the analyses.

The feasibility, validity and reliability of ESM has been demonstrated in previous research in healthy individuals (Jacobs et al., 2005), but also in individuals with schizophrenia (Delespaul, 1995; Myin-Germeys, Delespaul, \& van Os, 2005; Myin- 
Germeys, van Os, Schwartz, Stone, \& Delespaul, 2001) and other psychiatric disorders (De Vries, 1992).

\section{Assessment of momentary paranoia}

Paranoia was derived from the Experience Sampling reports and defined as the mean score of the items "I feel that others dislike me", "I feel that others might hurt me", "I feel suspicious", and "I feel safe" (reversed scale). The items were rated on 7-point Likert scales, ranging from 1 "not at all" to 7 "very". Principal component factor analysis on the raw within-subjects scores yielded one factor according to the Kaiser criterion (eigenvalue $>1$ ), accounting for $75 \%$ of the total variance. The items had a strong loading on the factor (negative statements $<-.84$; positive statement $>.80$ ) and high internal consistency (Cronbach's $\alpha=0.89$ ).

\section{Assessment of emotional changes}

Emotional experiences were derived from the Experience Sampling reports using the following three negative mood items: "anxious", "angry" and "down". The items were rated on 7-point Likert scales, ranging from 1 "not at all" to 7 "very". Emotional changes were defined as the difference in affect between two succeeding reports (see statistical analyses).

\section{Statistical analyses}

Multilevel linear regression models were estimated to examine the cross-sectional and longitudinal association between emotional processes and paranoia. Multilevel or hierarchical linear modelling techniques are a more advanced variant of unilevel linear regression analyses and are ideally suited for the analysis of hierarchical or clustered data (Schwartz \& Stone, 1998). ESM data have a hierarchical structure, in which repeated momentary observations (level 1) are clustered within subjects (level 2). Multilevel techniques allow the variability of each variable to be analysed at multiple hierarchical levels.

First, the cross-sectional association between emotional experiences on the one hand and paranoia on the other was determined. Separate multilevel linear regression models were estimated with paranoia at the target moment as the dependent variable and "anxiety", "anger" and "depression" at the target moment successively as the independent variables. Subsequently, all mood items were added to the model in order to investigate mutual independence. The multilevel models were corrected for the $a$ 
priori selected confounders sex and age (see arrow A in Figure 4.1).

Second, it was investigated whether paranoia at target moments $(\mathrm{t})$ is predicted by changes in preceding emotional experiences. Emotional changes were defined as the difference (i.e. an increase) in negative mood between two succeeding reports: the score on the mood item at the target moment $(\mathrm{t})$ minus the score on the mood item at the previous moment ( $\mathrm{t}-1$, roughly 90 minutes earlier). The difference score ranges from -6 to +6 and high scores reflect increases. In order to investigate whether paranoia $(t)$ is predicted by emotional changes, separate multilevel linear regression models were estimated with paranoia $(\mathrm{t})$ as the dependent variable and changes in "anxiety", "anger" and "depression" successively as the independent variables. To investigate mutual independence, a multilevel linear regression model was estimated with paranoia $(t)$ as the dependent variable and changes in the three mood items as independent variable. The multilevel models were corrected for the a priori selected confounders sex and age. In addition, the models were adjusted for paranoia on previous moments $(\mathrm{t}-1)$ (see arrow B in Figure 4.1).

Third, in order to investigate whether paranoia predicts changes in emotional experiences, separate multilevel linear regression models were estimated with changes in emotional experiences between the target moment and the following moment as dependent variable and paranoia at the target moment $(t)$ as the independent variable. The multilevel models were corrected for the a priori selected confounders sex and age and for emotional processes at the target moment ( $\mathrm{t}$ ) (see arrow $\mathrm{C}$ in Figure 4.1).

The multilevel regression models were analysed with the XTREG module in STATA/SE version 9.2 (StataCorp, 2006). The $\beta$ is the fixed regression coefficient of the predictor and can be interpreted identically to the estimate in a unilevel regression model. The individual intercepts $(\alpha)$ of the multilevel model are treated as a random factor.

\section{RESULTS}

\section{Sample and descriptive statistics}

Of the 103 patients who entered the study, 24 (23.3\%) subjects were excluded from the analyses. Twenty-one patients terminated the study before the end of the six-day sampling period, due to severity of psychotic symptoms $(n=11)$, cognitive incapability $(n=5)$ or lack of cooperation $(n=5)$. Even though they finished the study, three patients 
were excluded because of an insufficient number $(<20)$ of valid ESM observations. The final study sample therefore comprised 79 patients. The remaining patients had each completed an average of 38 valid reports $(S D=10)$. During the sampling period, the patients showed a mean momentary paranoia score of $2.5(\mathrm{SD}=1.2$; range $1-6.2)$, which is indicative of a sufficient degree of fleeting instances of paranoid thinking. Additional information regarding clinical and sociodemographic characteristics of the sample is summarised in Table 4.1.

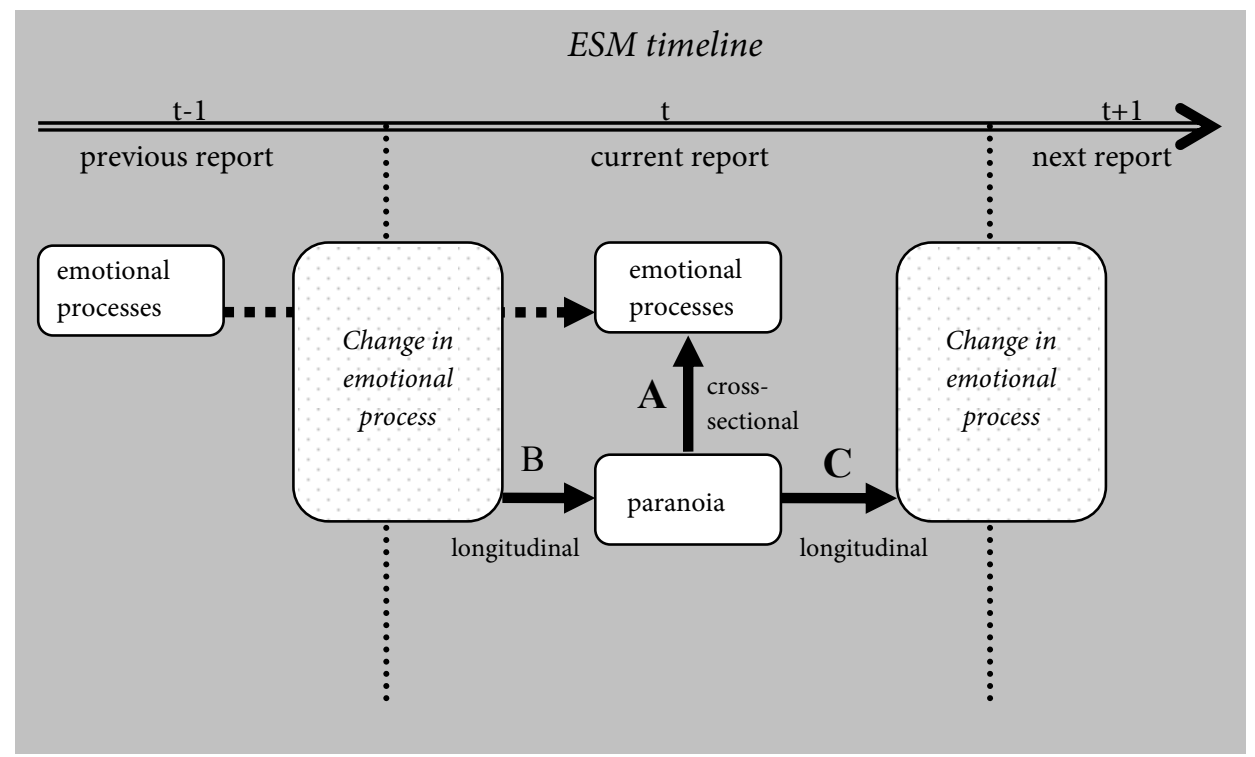

Figure 4.1 Cross-sectional and longitudinal associations between emotional processes and paranoia

Note. A; Multilevel linear regression analysis to investigate cross-sectional association between emotional processes $(\mathrm{t})$ (independent variable) and paranoia $(\mathrm{t})$ (dependent variable), with age and sex as confounding factors.

$\mathrm{B}$; Multilevel linear regression analysis to investigate whether changes in emotional processes (independent variable) longitudinally influence paranoia $(\mathrm{t})$ (dependent variable), with age, sex and paranoia ( $\mathrm{t}-1)$ as confounding factors.

C; Multilevel linear regression analysis to investigate whether paranoia ( $t$ ) (independent variable) longitudinally influences changes in emotional processes (dependent variable), with age, sex and emotional processes $(\mathrm{t})$ as confounding factors. 
Table 4.1 Sociodemographic and clinical details of the participants

\begin{tabular}{|c|c|}
\hline Sociodemographic variables & $\begin{array}{l}\text { Psychotic patients } \\
(\mathrm{n}=79)\end{array}$ \\
\hline Age, mean (SD), [range], y & $36.1(11.4),[18 ; 63]$ \\
\hline Sex, male/female ratio, No. (\%) & $66 / 13(84 / 16)$ \\
\hline \multicolumn{2}{|l|}{ Education, No. $(\%)^{*}$} \\
\hline Elementary school & $10(13)$ \\
\hline Secondary school & $61(77)$ \\
\hline Higher education & $8(10)$ \\
\hline \multicolumn{2}{|l|}{ Marital status, No. $(\%)^{*}$} \\
\hline Married or living together & $6(8)$ \\
\hline Divorced & $12(15)$ \\
\hline Widowed & $1(1)$ \\
\hline Never married & $60(76)$ \\
\hline \multicolumn{2}{|l|}{ Work situation, No. $(\%)^{*}$} \\
\hline Working / fulltime household / studying & $5(6)$ \\
\hline Protected work & $3(4)$ \\
\hline Incapable of work & $59(75)$ \\
\hline Unemployed & $12(15)$ \\
\hline Retired & $0(0)$ \\
\hline \multicolumn{2}{|c|}{$\begin{array}{l}\text { OPCRIT(McGuffin, Farmer, \& Harvey, 1991) lifetime } \\
\text { ICD10 diagnosis, } \\
\text { No. }(\%)^{*}\end{array}$} \\
\hline Schizophrenia / psychotic disorder & $70(89)$ \\
\hline Schizoaffective disorder & $9(11)$ \\
\hline $\begin{array}{l}\text { PANSS } † \text { score }(\mathrm{SD}), \\
\text { [range] }\end{array}$ & $61.6(14.7),[32 ; 103]$ \\
\hline $\begin{array}{l}\text { PANSS suspiciousness/persecution } \neq \text {, } \\
\text { (SD), [range] }\end{array}$ & $3.3(1.9),[1 ; 7]$ \\
\hline $\begin{array}{l}\text { ESM momentary anxiety } \$ \text {, } \\
\text { (SD), [range] }\end{array}$ & $1.9(1.1),[1 ; 5.5]$ \\
\hline $\begin{array}{l}\text { ESM momentary anger } \$ \text {, } \\
\text { (SD), [range] }\end{array}$ & $2.1(1.1),[1 ; 5.1]$ \\
\hline $\begin{array}{l}\text { ESM momentary depression\$, } \\
\text { (SD), [range] }\end{array}$ & $2.1(1.1),[1 ; 4.7]$ \\
\hline
\end{tabular}


Table 4.1 - continued Sociodemographic and clinical details of the participants

Clinical variables

Psychotic patients

$(\mathrm{n}=79)$

Usual symptom severity last 2 years (Life Chart), No.

$(\%)^{\star} \mathbf{g}$

Severe

Moderate

34 (47)

Mild

$31(42)$

Recovered

Patient status, No. (\%)*

Inpatient

41 (52)

Outpatient

38 (48)

${ }^{\star}$ Due to rounding, percentages may not add exactly to $100 \%$

$\dagger$ Mean total score on the Positive and Negative Syndromes Scale

$\$$ Mean score on item P6 of the Positive and Negative Syndromes Scale, scale ranges from 1 to 7

$\$$ Separate means were calculated for each participant and subsequently aggregated to obtain group means.

gecause of missing values, data were only calculated for 73 patients

\section{Association between emotional processes and paranoia}

Cross-sectional multilevel linear regression analyses showed that momentary paranoia was significantly associated with all three momentary mood items ("anxious", "angry" and “down") after controlling for age and sex (Table 4.2).

The regression analysis with all emotional items entered together in the model showed that 'feeling anxious' $(\mathrm{B}[\mathrm{SE}]=.19[.01] ; \mathrm{p}<.01)$, 'feeling angry' $(\mathrm{B}[\mathrm{SE}]=.08[.01]$; $\mathrm{p}<.01)$ and 'feeling down' $(\mathrm{B}[\mathrm{SE}]=.15[.01] ; \mathrm{p}<.01)$, were independently associated with paranoia after controlling for the confounding effects of age and sex. Post-hoc Wald chi square tests, based on the multilevel regression model, were used for pairwise comparisons of the coefficients. 'Feeling anxious' was significantly stronger associated with paranoia compared to 'feeling down' $\left(\chi^{2}(1)=5.05, p=0.02\right)$ and 'feeling angry' $\left(\chi^{2}(1)=40.13, \mathrm{p}<0.001\right)$. 'Feeling down' was significantly more associated with paranoia compared to 'feeling angry' $\left(\chi^{2}(1)=13.76, p<0.001\right)$. 


\section{Changes in emotional processes as a predictor of paranoia}

Longitudinal multilevel linear regression models were estimated to clarify the contribution of changes in emotional processes to the development of subsequent paranoia. Paranoia was significantly associated with changes in negative affect and changes in all three mood items, after controlling for age, sex and paranoia at the previous beep moment (Table 4.2).

Table 4.2 Cross-sectional and longitudinal multilevel regression estimates (B) for emotional processes and paranoia

\begin{tabular}{|c|c|c|c|c|c|c|}
\hline $\begin{array}{l}\text { Dependent } \\
\text { variable }\end{array}$ & $\begin{array}{l}\text { Independent } \\
\text { variable }\end{array}$ & $\mathrm{B}^{*}$ & $(95 \% \mathrm{CI})$ & $\mathrm{p}$ & $\mathrm{N} \dagger$ & Confounders \\
\hline \multicolumn{7}{|c|}{ Cross-sectional (arrow A Figure 1) } \\
\hline Paranoia & Anxious & .26 & $(.24 ; .29)$ & $<.001$ & 3009 & age, sex \\
\hline Paranoia & Angry & .16 & $(.14 ; .18)$ & $<.001$ & 3010 & age, sex \\
\hline Paranoia & Down & .23 & $(.21 ; .25)$ & $<.001$ & 3010 & age, sex \\
\hline \multicolumn{7}{|c|}{ Longitudinal (arrow B Figure 1) } \\
\hline Paranoia & $\begin{array}{l}\text { Change in } \\
\text { feeling anxious }\end{array}$ & .14 & $(.11 ; .16)$ & $<.001$ & 2397 & age, sex, paranoia $(t-1)$ \\
\hline Paranoia & $\begin{array}{l}\text { Change in } \\
\text { feeling angry }\end{array}$ & .08 & $(.06 ; .10)$ & $<.001$ & 2400 & age, sex, paranoia $(\mathrm{t}-1)$ \\
\hline Paranoia & $\begin{array}{l}\text { Change in } \\
\text { feeling down }\end{array}$ & .11 & $(.09 ; .13)$ & $<.001$ & 2400 & age, sex, paranoia $(\mathrm{t}-1)$ \\
\hline \multicolumn{7}{|c|}{ Longitudinal (arrow C Figure 1) } \\
\hline $\begin{array}{l}\text { Change in } \\
\text { feeling anxious }\end{array}$ & Paranoia & .20 & $(.15 ; .26)$ & $<.001$ & 2399 & age, sex, anxious (t) \\
\hline $\begin{array}{l}\text { Change in } \\
\text { feeling angry }\end{array}$ & Paranoia & .15 & $(.09 ; .22)$ & $<.001$ & 2402 & age, sex, angry (t) \\
\hline $\begin{array}{l}\text { Change in } \\
\text { feeling down }\end{array}$ & Paranoia & .18 & $(.11 ; .24)$ & $<.001$ & 2402 & age, sex, down (t) \\
\hline
\end{tabular}

* $\mathrm{B}$ can be interpreted identically to the regression coefficient in a unilevel linear regression model

$\dagger$ Number of momentary assessments 
The regression analysis with all mood item change scores entered together in the model showed that increases in 'feeling anxious' $(\mathrm{B}[\mathrm{SE}]=.11[.01] ; \mathrm{p}<.01)$, 'feeling angry' $(\mathrm{B}[\mathrm{SE}]=.05[.01] ; \mathrm{p}<.01)$ and 'feeling down' $(\mathrm{B}[\mathrm{SE}]=.07[.01] ; \mathrm{p}<.01)$ were independent predictors of paranoia, after controlling for age, sex and the confounding effects of paranoia at the previous beep moment. Post-hoc pairwise Wald chi square tests, based on the multilevel regression model, confirmed that 'feeling anxious' was a significantly stronger predictor of paranoia compared to 'feeling down' $\left(\chi^{2}(1)=6.33, p=0.01\right)$ and 'feeling angry' $\left(\chi^{2}(1)=14.95, \mathrm{p}<0.001\right)$. No significant differences were demonstrated between 'feeling down' and 'feeling angry' $\left(\chi^{2}(1)=1.22, \mathrm{p}=0.27\right)$.

\section{Paranoia as a predictor of emotional processes}

Longitudinal multilevel linear regression analyses showed that momentary paranoia led to a subsequent increase in all three emotional states after controlling for sex, age and emotional processes at the target moment (Table 4.2).

\section{Discussion}

This study examined the relationship between key negative emotional processes and paranoid symptoms in daily life. The findings show that paranoia is independently and significantly cross-sectionally associated with feeling anxious, angry and down. When examining the longitudinal association within subjects, increases in feeling anxious, angry and down were found to be significant and independent short-term predictors of paranoia. Paranoia in its turn was a significant predictor of an increase in all three negative emotional processes, after controlling for sex, age and emotional processes at the target moment. Paranoia showed the strongest association with anxiety, in both cross-sectional and longitudinal relationships.

The established relationship between paranoia and negative emotional experiences adds to the findings of earlier studies which have demonstrated this association at clinical as well as subclinical levels (e.g. Appelbaum, Robbins, \& Roth, 1999; Combs \& Penn, 2004; Freeman, Garety et al., 2005; Martin \& Penn, 2001; Smith et al., 2006).

\section{Paranoia: hidden depression or anxiety-driven?}

The temporal association between the two constructs showed that increases in feeling 
'anxious', 'angry' and 'down' were independent predictors of paranoia, suggesting a causal association between these emotional states and paranoia. An increase in feeling anxious was found to be the strongest predictor of paranoia. This finding supports the idea that anxiety is the most important aspect of emotional experience which immediately leads to the formation of paranoid beliefs (Freeman \& Garety, 2003; Freeman \& Garety, 2004; Freeman, Garety, \& Kuipers, 2001; Freeman, Garety, Kuipers, Fowler, \& Bebbington, 2002). In addition, the results showed that paranoia significantly predicted a subsequent increase in all three key negative emotions. Current findings imply that paranoid beliefs both generate and arise from changes in negative emotional experiences. It therefore seems that paranoid beliefs do not serve an immediate defensive function against depressive or other negative emotions (Bentall, Corcoran, Howard, Blackwood, \& Kinderman, 2001; Zigler \& Glick, 1988), at least in the shortterm. The present findings demonstrate that increases in negative emotional states (especially anxiety) predict immediate paranoid symptoms, however interestingly paranoia also predicts subsequent increases in negative emotional states. It is therefore plausible that emotional processes, and anxiety in particular, are an important maintaining factor of paranoid beliefs.

\section{Limitations of the study}

A few limitations need to be taken into account when interpreting the study findings. First, the findings were based on subjective reports using a paper-and-pencil diary method. Some concern has been raised about the reliability of subjective reports, since for instance each individual can interpret the same question in a different way. However, subjective reports can be valid whereas when using objective measures, the validity should not be taken for granted (Strauss, 1994). In addition, the use of a paperand-pencil diary method has been questioned as it may lead to poor participant compliance. However, recent studies have demonstrated that the traditional paper-andpencil diary methods are not inferior to electronic diary methods with regard to compliance rates (e.g. Bolger, Shrout, Green, Rafaeli, \& Reis, 2006; Green, Rafaeli, Bolger, Shrout, \& Reis, 2006). The validity of self-report data has further been supported by a recent study, which demonstrated acceptable compliance with random ESM sampling procedures (Jacobs et al., 2005). A second limitation of the study is that there was no distinction made based on content of the paranoid beliefs. It has been argued that there may be two separate types of paranoia, namely persecution or 'poor me' paranoia and punishment or 'bad me' paranoia, representing beliefs about the 
deservedness of the persecution (Chadwick, Trower, Juusti-Butler, \& Maguire, 2005). 'Bad me' paranoia, in which the malevolence of others is conceived as justifiably deserved, is characterised by lower self-esteem and higher depression and anxiety. Recent evidence shows that these beliefs on deservedness may change or alternate within a person over time (Melo, Taylor, \& Bentall, 2006), which suggests that the beliefs are strongly related to state emotional experiences. Emotional processes and content of paranoid experiences may therefore be an important line of further investigation.

\section{Implications for treatment}

Current findings have important implications for clinical practice. Single-symptom research contributes to more targeted treatment interventions. Cognitive-behavioral therapy (CBT) has proven to be successful in reducing psychotic symptoms and the concomitant emotional distress by primarily addressing dysfunctional thoughts and beliefs (Turkington, Dudley, Warman, \& Beck, 2004). However, it is important to recognise the primacy of emotions in psychological treatments of psychosis. Current results suggest that emotional disturbances may precede paranoid symptoms in daily life. Anxiety in particular appears to be an initiating and maintaining factor of paranoid beliefs. Campbell and Morrison (2007) suggest that any treatment package offered to individuals with paranoid delusions should incorporate anxiety management techniques. Anxiety should be specifically targeted complementary to the primary focus on dysfunctional cognitions. In fact, Birchwood and Trower (2006) state that "the next generation of therapy needs to focus on theory-driven studies of emotional dysfunction (...) including treatment studies which are themselves effective in ameliorating distress, but which may also have a secondary effect on the psychotic phenomena". With the advent of the third generation of cognitive behavioural therapy, the primacy of emotional processes in psychosis is gradually being brought back into the picture.

\section{References}

Allen, P., Freeman, D., McGuire, P., Garety, P., Kuipers, E., Fowler, D., et al. (2005). The prediction of hallucinatory predisposition in non-clinical individuals: examining the contribution of emotion and reasoning. British Journal of Clinical Psychology, 44(Pt 1), 127-132. 
Appelbaum, P. S., Robbins, P. C., \& Roth, L. H. (1999). Dimensional approach to delusions: comparison across types and diagnoses. American Journal of Psychiatry, 156(12), 1938-1943.

Bentall, R. (2006). Madness explained: Why we must reject the Kraepelinian paradigm and replace it with a 'complaint-orientated' approach to understanding mental illness. Medical Hypotheses, 66(2), 220233.

Bentall, R. P. (1994). Cognitive biases and abnormal beliefs: Towards a model of persecutory delusions. In A. David \& J. Cutting (Eds.), The neuropsychology of schizophrenia (pp. 337-360). London: Erlbaum.

Bentall, R. P., Corcoran, R., Howard, R., Blackwood, N., \& Kinderman, P. (2001). Persecutory delusions: a review and theoretical integration. Clinical Psychology Review, 21(8), 1143-1192.

Bentall, R. P., \& Kaney, S. (1989). Content specific information processing and persecutory delusions: an investigation using the emotional Stroop test. British Journal of Medical Psychology, 62 ( Pt 4), 355364.

Bentall, R. P., Kaney, S., \& Dewey, M. E. (1991). Paranoia and social reasoning: an attribution theory analysis. British Journal of Clinical Psychology, 30 ( Pt 1), 13-23.

Berner, P. (1997). Conceptualization of schizophrenia: the symptom-oriented approach. Psychopathology, 30(5), 251-256.

Birchwood, M., \& Trower, P. (2006). The future of cognitive-behavioural therapy for psychosis: not a quasineuroleptic. British Journal of Psychiatry, 188, 107-108.

Bolger, N., Shrout, P. E., Green, A. S., Rafaeli, E., \& Reis, H. T. (2006). Paper or plastic revisited: Let's keep them both - Reply to Broderick and Stone (2006); Tennen, Affleck, Coyne, Larsen, and DeLongis (2006); and Takarangi, Garry, and Loftus (2006). Psychological Methods, 11(1), 123-125.

Campbell, M. L. C., \& Morrison, A. P. (2007). The subjective experience of paranoia: Comparing the experiences of patients with psychosis and individuals with no psychiatric history. Clinical Psychology and Psychotherapy, 14, 63-77.

Chadwick, P. D., Trower, P., Juusti-Butler, T. M., \& Maguire, N. (2005). Phenomenological evidence for two types of paranoia. Psychopathology, 38(6), 327-333.

Combs, D. R., \& Penn, D. L. (2004). The role of subclinical paranoia on social perception and behavior. Schizophrenia Research, 69(1), 93-104.

Corcoran, R. (2000). Theory of mind in other clinical conditions: is a selective 'theory of mind' deficit exclusive to autism? In S. Baron-Cohen, H. Tager-Flusberg \& D. J. Cohen (Eds.), Understanding other minds : perspectives from developmental cognitive neuroscience (2nd ed., pp. 391-421). Oxford ; New York: Oxford University Press.

Corcoran, R., Cahill, C., \& Frith, C. D. (1997). The appreciation of visual jokes in people with schizophrenia: a study of 'mentalizing' ability. Schizophrenia Research, 24(3), 319-327. 
Costello, C. G. (1992). Research on symptoms versus research on syndromes. Arguments in favour of allocating more research time to the study of symptoms. British Journal of Psychiatry, 160, 304-308.

Csikszentmihalyi, M., \& Larson, R. (1987). Validity and reliability of the Experience-Sampling Method. Journal of Nervous and Mental Disease, 175(9), 526-536.

De Vries, M. W. (1992). The Experience of psychopathology : investigating mental disorders in their natural settings. Cambridge; New York: Cambridge University Press.

Delespaul, P. (1995). Assessing Schizophrenia in Daily Life. Maastricht, The Netherlands: Universitaire Pers Maastricht.

Fear, C., Sharp, H., \& Healy, D. (1996). Cognitive processes in delusional disorders. British Journal of Psychiatry, 168(1), 61-67.

Freeman, D., Dunn, G., Garety, P. A., Bebbington, P., Slater, M., Kuipers, E., et al. (2005). The psychology of persecutory ideation I: a questionnaire survey. Journal of Nervous and Mental Disease, 193(5), 302308.

Freeman, D., \& Garety, P. A. (2003). Connecting neurosis and psychosis: the direct influence of emotion on delusions and hallucinations. Behaviour Research and Therapy, 41(8), 923-947.

Freeman, D., \& Garety, P. A. (2004). Paranoia : the psychology of persecutory delusions (1st ed.). Hove, East Sussex; New York: Psychology Press.

Freeman, D., Garety, P. A., Bebbington, P., Slater, M., Kuipers, E., Fowler, D., et al. (2005). The psychology of persecutory ideation II: a virtual reality experimental study. Journal of Nervous and Mental Disease, 193(5), 309-315.

Freeman, D., Garety, P. A., \& Kuipers, E. (2001). Persecutory delusions: developing the understanding of belief maintenance and emotional distress. Psychological Medicine, 31(7), 1293-1306.

Freeman, D., Garety, P. A., Kuipers, E., Fowler, D., \& Bebbington, P. E. (2002). A cognitive model of persecutory delusions. British Journal of Clinical Psychology, 41(Pt 4), 331-347.

Frith, C. D. (1992). The Cognitive Neuropsychology of Schizophrenia. Hove: Lawrence Erlbaum Associates.

Garety, P. A., Freeman, D., Jolley, S., Dunn, G., Bebbington, P. E., Fowler, D. G., et al. (2005). Reasoning, emotions, and delusional conviction in psychosis. Journal of Abnormal Psychology, 114(3), 373-384.

Garety, P. A., \& Hemsley, D. R. (1997). Delusions : investigations into the psychology of delusional reasoning. Hove, East Sussex, UK: Psychology Press.

Garety, P. A., Hemsley, D. R., \& Wessely, S. (1991). Reasoning in deluded schizophrenic and paranoid patients. Biases in performance on a probabilistic inference task. Journal of Nervous and Mental Disease, 179(4), 194-201.

Green, A. S., Rafaeli, E., Bolger, N., Shrout, P. E., \& Reis, H. T. (2006). Paper or plastic? Data equivalence in paper and electronic diaries. Psychological Methods, 11(1), 87-105. 
Green, C., Garety, P. A., Freeman, D., Fowler, D., Bebbington, P., Dunn, G., et al. (2006). Content and affect in persecutory delusions. British Journal of Clinical Psychology, 45(Pt 4), 561-577.

Häfner, H., Maurer, K., Trendler, G., an der Heiden, W., Schmidt, M., \& Konnecke, R. (2005). Schizophrenia and depression: challenging the paradigm of two separate diseases--a controlled study of schizophrenia, depression and healthy controls. Schizophrenia Research, 77(1), 11-24.

Jacobs, N., Nicolson, N. A., Derom, C., Delespaul, P., van Os, J., \& Myin-Germeys, I. (2005). Electronic monitoring of salivary cortisol sampling compliance in daily life. Life Sciences, 76(21), 2431-2443.

Jones, P., Rodgers, B., Murray, R., \& Marmot, M. (1994). Child development risk factors for adult schizophrenia in the British 1946 birth cohort. Lancet, 344(8934), 1398-1402.

Kay, S. R., Fiszbein, A., \& Opler, L. A. (1987). The positive and negative syndrome scale (PANSS) for schizophrenia. Schizophrenia Bulletin, 13(2), 261-276.

Kinderman, P., \& Bentall, R. P. (1997). Causal attributions in paranoia and depression: internal, personal, and situational attributions for negative events. Journal of Abnormal Psychology, 106(2), 341-345.

Krabbendam, L., Janssen, I., Bak, M., Bijl, R. V., de Graaf, R., \& van Os, J. (2002). Neuroticism and low selfesteem as risk factors for psychosis. Social Psychiatry and Psychiatric Epidemiology, 37(1), 1-6.

Krabbendam, L., \& van Os, J. (2005). Affective processes in the onset and persistence of psychosis. European Archives of Psychiatry and Clinical Neuroscience, 255(3), 185-189.

Martin, J. A., \& Penn, D. L. (2001). Social cognition and subclinical paranoid ideation. British Journal of Clinical Psychology, 40(Pt 3), 261-265.

McGuffin, P., Farmer, A., \& Harvey, I. (1991). A polydiagnostic application of operational criteria in studies of psychotic illness. Development and reliability of the OPCRIT system. Archives of General Psychiatry, 48(8), 764-770.

Melo, S. S., Taylor, J. L., \& Bentall, R. P. (2006). Poor me versus bad me paranoia and the instability of persecutory ideation. Psychology and Psychotherapy, 79(Pt 2), 271-287.

Myin-Germeys, I., Delespaul, P., \& van Os, J. (2005). Behavioural sensitization to daily life stress in psychosis. Psychological Medicine, 35(5), 733-741.

Myin-Germeys, I., Delespaul, P. A., \& deVries, M. W. (2000). Schizophrenia patients are more emotionally active than is assumed based on their behavior. Schizophrenia Bulletin, 26(4), 847-854.

Myin-Germeys, I., Nicolson, N. A., \& Delespaul, P. A. (2001). The context of delusional experiences in the daily life of patients with schizophrenia. Psychological Medicine, 31(3), 489-498.

Myin-Germeys, I., van Os, J., Schwartz, J. E., Stone, A. A., \& Delespaul, P. A. (2001). Emotional reactivity to daily life stress in psychosis. Archives of General Psychiatry, 58(12), 1137-1144.

Norman, R. M., \& Malla, A. K. (1994). Correlations over time between dysphoric mood and symptomatology in schizophrenia. Comprehensive Psychiatry, 35(1), 34-38.

Overall, J. E., \& Gorham, D. R. (1962). The Brief Psychiatric Rating Scale. Psychological Report, 10, 779-812. 
Schwartz, J. E., \& Stone, A. A. (1998). Strategies for analyzing ecological momentary assessment data. Health Psychology, 17(1), 6-16.

Smith, B., Fowler, D. G., Freeman, D., Bebbington, P., Bashforth, H., Garety, P., et al. (2006). Emotion and psychosis: links between depression, self-esteem, negative schematic beliefs and delusions and hallucinations. Schizophrenia Research, 86(1-3), 181-188.

StataCorp. (2006). Stata Statistical Software: Release 9.2. TX: Stata Corporation, College Station.

Strauss, J. S. (1994). The person with schizophrenia as a person. II: Approaches to the subjective and complex. British Journal of Psychiatry, Supplement(23), 103-107.

Susser, E., Finnerty, M., Mojtabai, R., Yale, S., Conover, S., Goetz, R., et al. (2000). Reliability of the life chart schedule for assessment of the long-term course of schizophrenia. Schizophrenia Research, 42(1), $67-77$.

Thewissen, V., Bentall, R., Lecomte, T., van Os, J., \& Myin-Germeys, I. (2007). Fluctuations in self-steem and paranoia in the context of daily life. Journal of Abnormal Psychology, in press.

Turkington, D., Dudley, R., Warman, D. M., \& Beck, A. T. (2004). Cognitive-behavioral therapy for schizophrenia: a review. Journal of Psychiatry Practice, 10(1), 5-16.

van Os, J., Gilvarry, C., Bale, R., Van Horn, E., Tattan, T., White, I., et al. (1999). A comparison of the utility of dimensional and categorical representations of psychosis. UK700 Group. Psychological Medicine, 29(3), 595-606.

Zigler, E., \& Glick, M. (1988). Is paranoid schizophrenia really camouflaged depression? American Psychology, 43(4), 284-290. 


\section{Chapter 5}

\section{HEARING IMPAIRMENT AND PSYCHOSIS \\ REVISITED}

This chapter was published as:

Viviane Thewissen, Inez Myin-Germeys, Richard Bentalla, Ron de Graaf ${ }^{\mathrm{b}}$, Wilma Vollebergh $^{\mathrm{b}}$ and Jim van Os. (2005). Hearing impairment and psychosis revisited. Schizophrenia Research, 76, 99-103.

a School of Psychological Sciences, University of Manchester, UK.

$\mathrm{b}$ The Netherlands Institute of Mental Health and Addiction, Trimbos Institute, Utrecht, The Netherlands. 


\section{AbStract}

The previously reported but still poorly investigated link between deafness or hearing impairment (DHI) and the onset of positive psychotic experiences was investigated prospectively in a general population sample. Of the 109 DHI subjects at baseline, 11 (10.1\%) displayed psychotic experiences at T2 versus 137 (2.9\%) of the non-DHI subjects ( $\mathrm{OR}=3.8,95 \% \mathrm{CI}: 2.0,7.2)$. This effect size was only slightly attenuated after adjustment for baseline psychotic experiences (OR=3.2, 95\% CI: 1.6, 6.5) and after adjustment for T0 psychotic experiences and a range of other confounders $(\mathrm{OR}=3.0$, 95\% CI: 1.4, 6.2) These results confirm previous findings of an association between hearing impairments and psychosis and show that this association can also be found prospectively in a nonclinical population. 


\section{INTRODUCTION}

Ever since Kraepelin (1915) reported the occurrence of persecutory delusions in individuals with a hearing impairment, several studies have investigated the alleged association, primarily in elderly populations. While some studies failed to show an association between deafness or hearing impairment (DHI) and paranoid illness (e.g., Moore, 1981 and Watt, 1985), others reported that chronic deafness may constitute an important aetiological factor in the development of paranoid psychosis in later life (Cooper et al., 1974, Cooper, 1976, Cooper and Curry, 1976 and Stein and Thienhaus, 1993). Reports of an association between hearing impairment and psychosis have not been confined to elderly populations only. One study reported that significant hearing impairment at age 18 years was a risk factor for the development of schizophrenia (David et al., 1995). Hearing impairment has even been experimentally associated with the development of paranoid symptoms (Zimbardo et al., 1981). Normal subjects who were made partially deaf by hypnotic suggestion, without awareness of the source of their deafness, became more paranoid than subjects who were aware of the source of their deafness. Almost all of these studies focused on the association between hearing impairment and psychotic illness. However, investigating psychosis-like experiences in nonclinical populations may also constitute a sensitive approach to elucidating risk factors for the psychosis phenotype (Johns and van Os, 2001, van Os et al., 2000 and Verdoux and van Os, 2002). In the current study, therefore, the association between self-reported hearing impairment and psychosis-like experiences was investigated prospectively in a general population cohort of 7076 individuals. Previous research in this cohort demonstrated that nonclinical psychotic experiences were continuous with clinical psychotic symptoms in terms of psychopathology, functional measures and risk factors (van Os et al., 2000), including urbanicity (van Os et al., 2001 and van Os et al., 2003), neuroticism (Krabbendam et al., 2002), cannabis use (van Os et al., 2002), experience of discrimination (Janssen et al., 2003) and childhood trauma (Janssen et al., 2004).

\section{MethodS}

\section{Sample}

The current article is based on data pertaining to the Netherlands Mental Health Survey 
and Incidence study (NEMESIS), a longitudinal study of the prevalence, incidence, course and consequences of psychiatric disorders in the Dutch general population. A comprehensive description of the project's objectives, sample procedure, response, diagnostic instruments, quality control procedures and analyses is provided in previous publications (Bijl et al., 1998a, Bijl et al., 1998b and van Os et al., 2001). At T0 (1996), a total of 7076 individuals (response rate $=69.7 \%$ ) between 18-64 years were interviewed at home using the Composite International Diagnostic Interview (CIDI; Smeets and Dingemans, 1993 and WHO, 1990), assessing the lifetime prevalence of psychotic experiences and symptoms. At T1 (1997), 5618 subjects participated for the second time, and, at T2 (1999), 4848 subjects participated for the third time.

\section{T0 deafness or hearing impairment (DHI)}

Subjects were asked during the face-to-face interview at T0 whether they had experienced deafness or serious hearing impairment in the past 12 months. Ratings were yes (" 1 ") or no ("0"). Individuals could also indicate whether they had received medical treatment for this problem. This group was analysed separately as the additional presence of medical treatment confers a greater level of validation to the exposure.

\section{T2 psychosis}

The psychosis outcome was defined as any positive response on any of the CIDI psychosis items at the end of the study at T2. Ratings concerned the 17 CIDI core psychosis items on delusions (13 items) and hallucinations (4 items) (items G1-G13, G15, G16, G20 and G21). These concern classic psychotic symptoms involving, for example, persecution, thought interference, auditory hallucinations and passivity phenomena. All these items can be rated in six ways: 1-no symptom, 2-symptom present but not clinically relevant (not bothered by it and not seeking help for it), 3symptom result of ingestion of drugs, 4-symptom result of somatic disease, 5symptom present (bothered by it/seeking help for it), 6-symptom may not really be a symptom because there appears to be a plausible explanation for it. T2 psychotic experience was broadly defined as any CIDI rating of 2, 3, 4, 5 or 6 on any fo the CIDI psychosis items. The justification for these broad ratings was derived from a previous study, where it was shown that the five different ratings on the CIDI psychosis items were strongly associated with each other (van Os et al., 2000), and, in addition, the five different ratings independently showed a similar pattern of associations with known risk factors for psychosis (van Os et al., 2000 and van Os et al., 2001). As they therefore 
appear to reflect the same underlying latent dimension of "positive psychosis," they were joined together into one single broad rating of psychosis.

\section{Statistical analyses}

The association between DHI at T0 and the onset of psychotic experiences at T2 was assessed using logistic regression, with DHI at T0 as the exposure and T2 psychosis as the outcome. The following covariates were included in the model: age (five 10-year age groups), sex, education (four levels), presence of any T0 DSM-III-R psychiatric disorder, as well as other potential confounding factors for psychosis that have been identified previously in this cohort: childhood trauma, experience of discrimination (four levels), urbanicity (level of population density of area of residence; three levels), neuroticism, cannabis use ( 0 , no drug use; 1 , drug use more than five times), single marital status, employment status (unemployed vs. other) and ethnic group (white vs. other). Furthermore, we included the confounding factor of presence of psychotic symptoms at T0 in the model to ensure that associations with incident psychotic experiences could be interpreted prospectively. The analyses were conducted using STATA version 8 (StataCorp, 2003).

\section{Results}

\section{Sample}

The sample at T0 consisted of 7076 individuals. 4845 individuals (46.5\% male) with a mean age of 41.2 years (S.D.=11.9) at T0 were included in the analysis with nonmissing data on DHI and T2 psychosis. A total of 109 (2.3\%) individuals reported DHI in the past 12 months at T0, of which $72(66.1 \%)$ had received medical treatment for their DHI. A total of 148 subjects (3.1\%) displayed one or more CIDI psychotic experiences at T2. Of these, 100 (67.6\%) had displayed similar experiences at T0.

\section{TO DHI and 2 psychosis}

Of the 109 T0 DHI subjects, 11 (10.1\%) displayed psychotic experiences at T2 versus 137 (2.9\%) of the non-DHI subjects ( $\mathrm{OR}=3.8,95 \% \mathrm{CI}: 2.0,7.2)$. This effect size was only slightly attenuated after adjustment for T0 psychotic experiences (OR=3.2, 95\% CI: 1.6, 6.5) and after adjustment for T0 psychotic experiences and all other confounders $(\mathrm{OR}=3.0,95 \% \mathrm{CI}: 1.4,6.2)$. Of the 72 T0 DHI subjects who were receiving medical 
treatment for their DHI, nine had T2 psychosis (12.5\%; OR=4.8, 95\% CI: 2.3, 9.8). This estimate was similarly only slightly to moderately reduced after adjustment for T0 psychosis (OR=4.1, 95\% CI: 1.9, 9.1) and additional adjustment for all other confounders (OR=3.6, 95\% CI: 1.6, 8.1).

\section{Discussion}

The findings were that baseline DHI predicted positive psychotic experiences (hallucinations and/or delusional ideation) 3 years later in a general population sample. These results are in line with previous reports associating deafness with psychotic illness (e.g., Cooper et al., 1974, Cooper, 1976, Cooper and Curry, 1976 and Stein and Thienhaus, 1993) and extend these findings to the subclinical expression of psychosis in the general population.

In the current study, DHI was measured subjectively by asking the subjects whether they had experienced DHI in the last year. One could argue that subjective measures of DHI are suspect because the experience of clinical or subclinical psychosis might provoke the idea of being hard of hearing. However, to objectify the DHI, the subjects were additionally asked whether they were under treatment or medical supervision for their hearing problems, and results for this group were similar. Similarly, adjustment for T0 psychosis only reduced the association by a small amount so that it seems safe to suggest that reverse causality (psychosis provokes the idea of DHI) is unlikely to be the sole explanation of the current findings.

An association between DHI and positive psychotic symptoms can be understood in terms of recent psychological models concerning the formation and maintenance of psychotic symptoms. These models focus on cognitive biases as an essential element in the development of psychotic symptoms (Bentall, 2003 and Garety et al., 2001). One model by Frith (1992) states that the development of delusions arises as a result of a 'theory of mind' (ToM) deficit. ToM is the ability to infer the mental states (beliefs, thoughts and intentions) of others in order to predict and explain their behaviour (Premack and Woodruff, 1978). As none of the subjects in the study were born deaf or had had serious hearing deficits since childhood, they had all learned to use all information available to infer the mental states of others. When a large part of this information (i.e., the auditory context) is then lost or reduced, the person will have more difficulties to construct and understand the mental states of others. DHI thus puts 
people at risk of developing deficits in their ToM and therefore at risk of developing psychotic experiences.

A second related model by Maher suggests that delusions may be rational interpretations of anomalous experiences (Maher, 1974, Maher, 1992 and Maher, 1999). It may be hypothesised that individuals who fail to recognize that they are having hearing difficulties may try to explain partial auditory input, for example, as other people whispering or being secretive (Bentall, 2003). Finally, hearing impairments may also impair source monitoring capacities. It has been suggested that hallucinations are the result of a failure in source monitoring, which is the capacity to discriminate between mental events and events in the world. When hallucinating, subjects make an incorrect attribution of internally generated stimuli (especially speech) to an external source. Studies have shown that source monitoring is a skill that requires several sources of information (Johnson et al., 1993 and Bentall, 2003). In the case of DHI, in a person who previously did not have such problems, the person loses an important source of information and becomes less able to tell the difference between internally and externally generated stimuli due to the lack of external information, which increases the risk of source monitoring failures. This fits in with data suggesting that source monitoring failures are more likely to occur during conditions of sensory restriction or meaningless auditory input (Margo et al., 1981 and Gallagher et al., 1994).

\section{REFERENCES}

Bentall, R.P. (2003). Madness Explained: Psychosis and Human Nature. Penguin, London.

Bijl, R.V., Ravelli, A., \& van Zessen, G. (1998a). Prevalence of psychiatric disorder in the general population: results of the Netherlands Mental Health Survey and Incidence Study (NEMESIS). Social Psychiatry and Psychiatric Epidemiology, 33(12), 587-595.

Bijl, R.V., van Zessen, G., Ravelli, A., de Rijk, C., \& Langendoen, Y. (1998b). The Netherlands Mental Health Survey and Incidence Study (NEMESIS): objectives and design. Social Psychiatry and Psychiatric Epidemiology, 33(12), 581-586.

Cooper, A.F. (1976). Deafness and psychiatric illness. British Journal of Psychiatry, 129, 216-226.

Cooper, A.F., \& Curry, A.R. (1976). The pathology of deafness in the paranoid and affective psychoses of later life. Journal of Psychosomatic Research, 20, 97-105.

Cooper, A.F., Curry, A.R., Kay, D.W., Garside, R.F., \& Roth, M. (1974). Hearing loss in paranoid and affective psychoses of the elderly. Lancet, 2, 851-854. 
David, A., Malmberg, A., Lewis, G., Brandt, L., \& Allebeck, P. (1995). Are there neurological and sensory risk factors for schizophrenia? Schizophrenia Research, 14, 247-251.

Frith, C.D. (1992). The Cognitive Neuropsychology of Schizophrenia. Lawrence Erlbaum Associates, Hove.

Gallagher, A.G., Dinan, T.G., \& Baker, L.J. (1994). The effects of varying auditory input on schizophrenic hallucinations: a replication. British Journal of Medical Psychology, 67(Pt 1), 67-75.

Garety, P.A., Kuipers, E., Fowler, D., Freeman, D., \& Bebbington, P.E. (2001). A cognitive model of the positive symptoms of psychosis. Psychological Medicine, 31, 189-195.

Janssen, I., Hanssen, M., Bak, M., Bijl, R.V., de Graaf, R., Vollebergh, W., et al. (2003). Discrimination and delusional ideation. British Journal of Psychiatry, 182, 71-76.

Janssen, I., Krabbendam, L., Bak, M., Hanssen, M., Vollebergh, W., de Graaf, R., et al. (2004). Childhood abuse as a risk factor for psychotic experiences. Acta Psychiatrica Scandinavica, 109, 38-45.

Johns, L.C., \& van Os, J. (2001). The continuity of psychotic experiences in the general population. Clinical Psychology Review, 21, 1125-1141.

Johnson, M.K., Hashtroudi, S., \& Lindsay, D.S. (1993). Source monitoring. Psychological Bulletin, 114, 3-28.

Krabbendam, L., Janssen, I., Bak, M., Bijl, R.V., de Graaf, R., \& van Os, J. (2002). Neuroticism and low selfesteem as risk factors for psychosis. Social Psychiatry and Psychiatric Epidemiology, 37, 1-6.

Kraepelin, E. (1915). Psychiatrie. Barth, Leipzig.

Maher, B.A. (1974). Delusional thinking and perceptual disorder. Journal of Individual Psychology, 30, 98-113.

Maher, B.A. (1992). Models and methods for the study of reasoning in delusions. European Review of Applied Psychology, 42, 97-102.

Maher, B.A. (1999). Anomalous experience in everyday life: its significance for psychopathology. The Monist, $82,547-570$.

Margo, A., Hemsley, D.R., \& Slade, P.D. (1981). The effects of varying auditory input on schizophrenic hallucinations. British Journal of Psychiatry, 139, 122-127.

Moore, N.C. (1981). Is paranoid illness associated with sensory defects in the elderly? Journal of Psychosomatic Research, 25, 69-74.

Premack, D., \& Woodruff, G. (1978). Does the chimpanzee have a theory of mind? Behavioral and Brain Sciences, 4, 515-526.

Smeets, R.M.W., \& Dingemans, P.M.A.J. (1993). Composite International Diagnostic Interview (CIDI) Version 1.1. World Health Organisation, Geneva, Switzerland.

StataCorp (2003). Stata Statistical Software: Release 8.0. Stata, College Station, TX.

Stein, L.M., \& Thienhaus, O.J. (1993). Hearing impairment and psychosis. International Psychogeriatrics, 5, 49-56.

van Os, J., Hanssen, M., Bijl, R.V., \& Ravelli, A. (2000). Strauss (1969) revisited: a psychosis continuum in the general population? Schizophrenia Research, 45, 11-20. 
van Os, J., Hanssen, M., Bijl, R.V., \& Vollebergh, W. (2001). Prevalence of psychotic disorder and community level of psychotic symptoms: an urban-rural comparison. Archives of General Psychiatry, 58, 663668.

van Os, J., Bak, M., Hanssen, M., Bijl, R.V., de Graaf, R., \& Verdoux, H. (2002). Cannabis use and psychosis: a longitudinal population-based study. American Journal of Epidemiology, 156, 319-327.

van Os, J., Hanssen, M., Bak, M., Bijl, R.V., \& Vollebergh, W. (2003). Do urbanicity and familial liability coparticipate in causing psychosis? American Journal of Psychiatry, 160, 477-482.

Verdoux, H., \& van Os, J. (2002). Psychotic symptoms in non-clinical populations and the continuum of psychosis. Schizophrenia Research, 54, 59-65.

Watt, J.A. (1985). Hearing and premorbid personality in paranoid states. American Journal of Psychiatry, 142, 1453-1455.

WHO (1990). Composite International Diagnostic Interview (CIDI) Version 1.0. World Health Organisation, Geneva, Switzerland.

Zimbardo, P.G., Andersen, S.M., \& Kabat, L.G. (1981). Induced hearing deficit generates experimental paranoia. Science, 212, 1529-1531. 


\section{ChAPTER 6}

\section{HEARING IMPAIRMENT AND PSYCHOSIS: A REPLICATION IN A COHORT OF YOUNG ADULTS}

This chapter was published as:

Viviane Thewissen ${ }^{\star}$, Nikos Stefanis $^{a}{ }^{\star}$, Chryssa Bakoula ${ }^{\mathrm{b}}$, Jim van Os, Inez MyinGermeys. (2006). Hearing impairment and psychosis: A replication in a cohort of young adults. Schizophrenia Research, 85(1-3), 266-272.

* Joined first authorship

${ }^{a}$ University Mental Health Research Institute, Athens, Greece.

${ }^{\mathrm{b}}$ First Department of Paediatrics, Athens University Medical School, 'Aghia Sophia' Children's Hospital, Athens, Greece. 


\section{AbStract}

Previous work has demonstrated an association between hearing impairment and psychosis. In the current study, this association was studied in a cohort of young people. In addition, it was studied to what degree duration of hearing problems (i.e. onset earlier in life) impacted on risk. Data were derived from the Greek National Perinatal Survey, a prospective birth cohort study of 11048 neonates at baseline, 6594 7-year olds at T1 and 3500 19-year olds at T2. A significant association was found at age 19 years between the presence of hearing impairment and the presence of self-reported positive psychotic-like experiences $(\beta=0.18 \mathrm{SE}=0.02, \mathrm{p}<0.000)$. In addition, this association was conditional on the duration of hearing problems, in that the association at age 19 years was stronger if hearing impairment had already been reported at age 7 years (test for interaction: $\mathrm{p}=0.022$ ). These results replicate previous findings of an association between hearing impairment and psychosis, extend it to the age range of late adolescence, and suggest that longer duration is associated with stronger risk. 


\section{INTRODUCTION}

Previous work has demonstrated that hearing impairment is a potential risk factor for the development of psychosis or schizophrenia. Whereas the majority of studies have focussed on the relationship between hearing impairment and psychosis in elderly populations (Almeida, Howard, Levy, \& David, 1995; Cooper, 1976; Cooper \& Curry, 1976; Cooper, Curry, Kay, Garside, \& Roth, 1974; Eastwood, Corbin, Reed, Nobbs, \& Kedward, 1985; Rodriguez-Ferrera, Vassilas, \& Haque, 2004; Stein \& Thienhaus, 1993), one study has reported that significant hearing impairment at age 18 years is a risk factor for the development of schizophrenia (David, Malmberg, Lewis, Brandt, \& Allebeck, 1995). The great majority of this earlier work focussed on the association between hearing impairment and established psychotic illness, rather than at risk mental states that frequently precede psychotic illness (Chapman, Chapman, Kwapil, Eckblad, \& Zinser, 1994; Hanssen, Bak, Bijl, Vollebergh, \& van Os, 2005; Johns \& van Os, 2001; McGorry, 2000; Poulton et al., 2000). In a recent study (Thewissen et al., 2005), an association was reported between hearing impairment and expression of psychosis in a non-clinical general population sample between 18 and 64 years of age. Individuals with hearing impairment in the past twelve months had a threefold increased risk to develop positive psychotic experiences. The current study aimed to replicate these results in a general population sample of 3500 young adults aged 19 years. In addition, it was investigated to what degree any association was conditional on the duration of hearing problems, hypothesising that longer duration would be associated with greater risk.

\section{Methods}

\section{Sample}

Data were derived from the Greek National Perinatal Survey, a prospective study of all the 11048 births throughout Greece between April 1 and April 30, 1983 (TzoumakaBakoula, 1987). At T1 (1990), when the children were aged 7 years, attempts were made to identify all children at primary schools throughout Greece. A total of 6594 individuals and their parents completed postal questionnaires, which were subsequently merged successfully with corresponding data collected at T0 (1983). At T2 (2001), when the individuals were in the period of transition from adolescence to adult life, attempts were made again to locate them in order to collect subject and parental postal questionnaires. 
Questions were divided into the following sections: 1. family, friends and school; 2. general and current health; 3 . lifestyle and spare time; 4 . nutrition habits; 5 . other habits; 6. psychic experiences; 7. behaviour; 8. biological measurements. Parents filled in questions about socio-economic factors, family affairs and life-style. Of the 4675 adolescent/parent questionnaires which were sent off at T2, 3016 were returned (response rate $=64.5 \%$ ). In a second round, another 484 completed questionnaires were collected, making a total of 3500 completed questionnaires at age 19 years.

Sensitivity analyses showed that the subsample of 3500 individuals was representative of the original sample at T0 with regard to place of birth (urban, rural), birth weight, length at birth, father's occupation, mother's education, sex of the adolescent, marital status, maternal age and region of adolescent's residence (Stefanis et al., 2004).

\section{T1 and T2 hearing impairment}

The presence of a hearing impairment was determined at age 7 years (T1) and age 19 years (T2). At T1, hearing problems (no problem “0”; problem “1”) were rated by teachers and parents. Hearing problems (HI_7) were rated " 1 ” when both teachers and parents indicated that the child had difficulty with hearing. At T2, participants were asked: "How would you define your hearing?". One of the following possibilities had to be rated separately for each ear: normal (“0”), slightly affected (“1”), clearly impaired (" 2 "), or deaf (" 3 "). Hearing outcome was calculated as the mean of the two ears. For the purpose of the analyses, hearing impairment at age 19 (HI_19) was expressed as a dichotomous outcome measure (mean of the two ears $\leq 0.5=0$; mean of the two ears $>$ $0.5=1$ ). This means that individuals with bilateral normal hearing or slightly unilateral hearing loss were defined as not having hearing problems. Individuals with at least slightly bilateral hearing loss or clearly unilateral hearing loss were defined as having hearing problems.

\section{T2 psychosis}

At T2, adolescents filled in the 40-item Community Assessment of Psychic Experiences (CAPE) (Hanssen et al., 2003; Stefanis et al., 2002), a questionnaire that measures attenuated psychotic experiences in positive, negative and depressive symptom dimensions. It measures frequency of the experience (measured on a four-point scale from "never", "sometimes", "often" to "nearly always", to avoid "ticking the middle box" bias) as well as distress associated with the experience (measured on a four-point scale 
from "not distressed", “a bit distressed", "quite distressed" to "very distressed”). The CAPE is mainly based on the 21-item Peters et al. Delusions Inventory (PDI-21) (Peters, Joseph, \& Garety, 1999). Previous research with the CAPE has shown discriminative validity across groups of individuals with schizophrenia, mood and anxiety disorders and individuals from the general population (Hanssen et al., 2003), and concurrent validity with other scales measuring psychotic experiences (Stefanis et al., 2002). A detailed description of the development of the CAPE is provided in previous publications (Hanssen et al., 2003; Stefanis et al., 2004; Stefanis et al., 2002). In the statistical analyses, psychosis outcome was defined as the mean frequency score on the positive dimension. In the descriptive statistics, psychosis outcome was expressed as a dichotomous outcome measure (score " 0 " or " 1 ", a score of 0 indicating a total score on the positive symptom dimension of the CAPE $<90^{\text {th }}$ centile; a score $1 \geq 90^{\text {th }}$ percentile).

\section{Statistical analyses}

In order to replicate our previous association between hearing impairment and positive psychotic-like experiences, expressed as the CAPE positive dimension mean frequency score, multivariate linear regression analyses were carried out using STATA version 9 (StataCorp, 2005). The main effect of HI_19 was tested. In order to examine whether any association with HI_19 was conditional on longer duration of the hearing impairment, an interaction between HI_19 and HI_7 was fitted with no hearing problems ("0") at age 7 as the reference category. Estimation of HI_19 effect sizes with and without additional presence of HI_7 were calculated from the model with the interactions by calculating the appropriate linear combinations using the STATA LINCOM routine. Main effects and interaction were assessed by Wald test.

The model was adjusted for the following a priori selected possible confounding effects of sex, average school grade obtained (score from " 0 " to " 20 ", a higher score indicating a better grade), socioeconomic status (based on the question "how would you describe your family's financial situation?", ranging from " 1 " lots of financial problems to " 4 " very good), T2 lifetime cannabis use (ranging from " 0 " never used to " 4 " systematic use), and T2 depression (score " 0 " or " 1 ", a score of 0 indicating a mean frequency score on the depressive symptom dimension of the CAPE $<90^{\text {th }}$ percentile; a score of $1 \geq 90^{\text {th }}$ percentile). We also included T1 visual impairment and T2 visual impairment. T1 visual impairment was rated by teachers and parents (present " 1 " or absent "0"). T1 visual impairment was rated present when both teachers and parents had indicated that they suspected that the child could not see very well. For measuring T2 visual impairment, 
participants were asked "How would you define your vision?". They could indicate the following answers: normal or normal with glasses or contact lenses ("1"), impaired or blind ("2"). We also included the possible confounding effect of tinnitus, as this inner ear disorder has been associated with psychotic experiences (Gordon, 1997, 2003). In order to assess tinnitus, participants were asked "Have you ever experienced tinnitus (continuous buzzing/ringing in your ears) after spending time in a place with loud music?". They could indicate the following answers separately for each ear: no ("0"), occasionally for a few seconds or minutes ("1"), occasionally for over one hour (" 2 "), continually (" 3 ”), and cannot say. Tinnitus was expressed as a categorical outcome measure, calculated as the mean of the two ears and recoded as follows: $0=0 ; 0.5=1 ; 1$ $=2 ; 1.5$ to $3.0=3$. Individuals who gave the answer 'cannot say' for both ears constituted a separate group that was coded " 4 ". Individuals who gave the answer 'cannot say' for only one ear, were assigned to the category of the other ear.

\section{RESULTS}

\section{Sample}

After exclusion of individuals with missing values at T1 and T2 hearing impairment, T2 psychotic-like experiences, and any of the confounding variables, the risk set consisted of 1411 adolescents (45.6\% male). At T1, a total of 28 (2.0\%) children displayed hearing problems according to both teachers and parents. Five out of these 28 children $(17.9 \%)$ reported positive psychotic-like experiences at age 19 years. Out of the 1383 children who did not display hearing problems at $\mathrm{T} 1,127$ (9.2\%) reported positive psychotic-like experiences at age 19 years. At T2, a total of 79 (5.6\%) adolescents indicated that they had hearing difficulties. Sixteen out of these 79 adolescents $(20.3 \%)$ reported positive psychotic-like experiences. Out of the 1332 adolescents who did not indicate that they had hearing difficulties, $116(8.7 \%)$ showed psychotic-like experiences at the same age.

\section{T1 and T2 hearing impairment and T2 psychosis}

A significant main effect was found for hearing impairment at age 19 on the presence of positive psychotic-like experiences at this age $(\beta=0.18 \mathrm{SE}=0.02, \mathrm{p}<0.000)$, even after adjustment for hearing problems at age 7 and the $a$ priori selected confounders $(\beta=0.12$ $\mathrm{SE}=0.03, \mathrm{p}<0.000)$. A suggestive but non-significant main effect was found for hearing problems at age 7 on positive psychotic-like experiences at age 19 years $(\beta=0.10$ 
$\mathrm{SE}=0.06, \mathrm{p}=0.085)$, also after adjustment for hearing impairment at age 19 and the $a$ priori selected confounders $(\beta=0.05 \mathrm{SE}=0.03, \mathrm{p}=0.109)$. The association between hearing impairment at age 19 and positive psychotic-like experiences was modified by hearing impairment at age 7 (unadjusted interaction term: $\beta=0.40 \mathrm{SE}=0.18, \mathrm{p}=0.022$ ), indicating that the association in those with previous hearing impairment at age 7 years $(\beta=0.56$; 95\% CI: $0.23-0.90 ; p=0.001)$ was significantly stronger than the association in those without hearing difficulties at age 7 years $(\beta=0.16$ CI $0.09-0.23, \mathrm{p}<0.000)$ (Table 6.1). The interaction effect remained significant after adjustment of the a priori selected confounders $(\beta=0.33 \mathrm{SE}=0.16, \mathrm{p}=0.038)$.

Table 6.1 Interaction between childhood hearing problems (HI_7) and hearing impairment at adolescence (HI_19)

Exposure level

T2 Psychosis

Scores $^{\mathrm{a}} \quad \beta^{\mathrm{b}}(95 \% \mathrm{CI} ; p) \quad \beta^{\mathrm{c}}(95 \% \mathrm{CI} ; p)$

$0 \quad$ No hearing problems age $7 /$ no hearing impairment age 19

1 No hearing problems age 7 / hearing impairment age 19

2 Hearing problems age 7 / no hearing impairment age 19

3 Hearing problems age $7 /$ hearing impairment age 19

$$
1.62
$$

$$
0.16 \text { (0.09-0.23; }
$$$$
p<0.000)
$$

0.11 (0.04-0.18; $p=0.002$ )

1.66

$$
\begin{array}{ll}
0.56(0.23-0.90 ; & 0.44(0.13-0.75 \\
p=0.001) & p=0.005)
\end{array}
$$

\footnotetext{
2-way interaction ${ }^{\mathrm{d}}$

$\mathrm{F}(1,1448)=5.22, p=0.022$

2-way interaction ${ }^{\mathrm{e}}$ $\mathrm{F}(1,1396)=4.31, p=0.038$

${ }^{a}$ represents raw score of the dependent variable (mean frequency score on positive dimension of CAPE)

${ }^{\mathrm{b}}$ unadjusted regression coefficient, indicates change in mean CAPE frequency scores associated with hearing impairment at age 19 years

${ }^{c}$ regression coefficient adjusted for sex, average school grade obtained, socioeconomic status, T2 lifetime cannabis use, T2 depression, tinnitus, visual impairment at age 19, visual impairment at age 7

${ }^{\mathrm{d}}$ HI_7 X HI_19 interaction

${ }^{\text {e }}$ HI_7 X HI_19 interaction adjusted for sex, average school grade obtained, socioeconomic status, T2 lifetime cannabis use, T2 depression, tinnitus, visual impairment at age 19, visual impairment at age 7
} 


\section{Discussion}

The data demonstrate an association between hearing impairment at age 19 years and positive psychotic-like experiences in a general population sample. This is consistent with previous results (Thewissen et al., 2005) and extends the findings to a sample of young adults. In addition, longer duration with onset early in childhood was associated with a stronger risk. Although consistent, the association between hearing impairment and positive psychotic-like experiences may in the first instance be considered as a nonspecific association between positive psychotic-like experiences and a general deficit in brain functioning. On the other hand, the association may represent a causal relationship between hearing impairment and the onset of positive psychotic-like experiences. There is cognitive plausibility to the hypothesis of causality in terms of recent accounts of cognitive mechanisms for psychotic symptoms (Bentall, 2003; Frith, 1992; Garety, Kuipers, Fowler, Freeman, \& Bebbington, 2001). A number of cognitive biases have been demonstrated in patients suffering from psychosis. The current data suggest that the earliest expression of these biases can be captured in the form of early psychotic-like experiences before the onset of clinical illness.

Delusions or delusional beliefs may be best understood as a result of an underlying cognitive misinterpretation of one's own and other's mental states (beliefs, thoughts and intentions), in other words an impaired 'theory of mind' (ToM) (Brüne, 2005; Corcoran, 2000; Frith, 1992). Several studies have shown that hearing impaired or deaf (signing) children show a delay in theory of mind development (Jackson, 2001; Peterson \& Siegal, 1995; Woolfe, Want, \& Siegal, 2002), which is due to the fact that most of these children have been growing up in hearing families and therefore have had limited exposure to social interaction and experience and accordingly limited opportunities for learning about mental states (Peterson, Wellman, \& Liu, 2005; Russell et al., 1998). Since persons with long lasting hearing impairments have more difficulty inferring the mental states of others, they are at risk of developing impairments in their ToM and consequently at risk to develop delusional experiences. The fact that no significant main effect of childhood hearing impairment on psychosis was found, fits with this explanation, because the lack of a strong association is likely due to the fact that in the early hearing-impaired group, a proportion of children will experience a change in exposure status (i.e. have their hearing problems cured) and therefore have an opportunity to catch up and overcome their ToM deficits when their hearing problems disappear. A significant association between hearing problems at age 19 and presence of 
positive psychotic-like experiences was found. To the extent that these persons had not suffered from hearing impairment before and had learned to use all information available to infer the mental states of others, the onset of psychotic experiences can be explained by the fact that when a large part of this information (i.e. the auditory context) is lost or reduced, the person will have more difficulties to construct or understand the mental states of others. Therefore, hearing impairments that develop after childhood may also put people at risk of developing deficits in their ToM and accordingly at risk to develop delusional experiences. Our data nevertheless suggest that longer duration, with onset early in childhood and persistence over critical stages of social development, is associated with the highest risks.

Hallucinations or hallucinatory experiences are often associated with impairments in source monitoring (Bentall, 1990; Brebion, Gorman, Amador, Malaspina, \& Sharif, 2002; Henquet, Krabbendam, Dautzenberg, Jolles, \& Merckelbach, 2005; Johns et al., 2001), which is the capacity to discriminate between mental events and events in the world. Hallucinating individuals may make hasty and overconfident judgements about the source of their perceptual experiences. As a result, they can make an incorrect attribution of internally generated stimuli (especially speech) to an external source. Accurate source monitoring is an ability or skill that depends on several sources of information (Bentall, 2003; Johnson, Hashtroudi, \& Lindsay, 1993). Since subjects with long lasting hearing impairments have limited access to auditory information, they are at risk to develop source monitoring failures and, by consequence, at risk to develop psychotic experiences. Individuals with recent hearing impairments, on the other hand, lose an important source of information and may become less skilled in differentiating between internally and externally generated stimuli due to the lack of external information, which increases the risk of source monitoring failures. This fits with data suggesting that source monitoring failures are more likely to occur during conditions of sensory restriction and meaningless auditory input (Gallagher, Dinan, \& Baker, 1994; Margo, Hemsley, \& Slade, 1981).

The findings of the current study are based on self-report. One could argue that subjective measures of hearing impairment and psychosis are less reliable. However, self-reported hearing loss by one single question may yield reasonable sensitivity and specificity for hearing impairment, at least in an older population (Sindhusake et al., 2001). A self-report questionnaire for psychotic symptoms may be a less sensitive measure. However, we do not expect that that individuals with hearing impairment would respond differently than individuals without hearing impairment. Significant 
results were found, despite the fact that a less sensitive measure (subjective report) was used. A limitation of current study was the limited number of individuals with hearing problems. For that reason it was not possible to investigate a dose-response relationship between the degree of hearing impairment and the gravity of psychotic symptoms. Future research requires a larger sample of individuals.

\section{References}

Almeida, O. P., Howard, R. J., Levy, R., \& David, A. S. (1995). Psychotic states arising in late life (late paraphrenia). The role of risk factors. British Journal of Psychiatry, 166(2), 215-228.

Bentall, R. P. (1990). The illusion of reality: a review and integration of psychological research on hallucinations. Psychological Bulletin, 107(1), 82-95.

Bentall, R. P. (2003). Madness explained: psychosis and human nature. London: Penguin.

Brebion, G., Gorman, J. M., Amador, X., Malaspina, D., \& Sharif, Z. (2002). Source monitoring impairments in schizophrenia: characterisation and associations with positive and negative symptomatology. Psychiatry Research, 112(1), 27-39.

Brüne, M. (2005). "Theory of mind" in schizophrenia: a review of the literature. Schizophrenia Bulletin, 31(1), 21-42.

Chapman, L. J., Chapman, J. P., Kwapil, T. R., Eckblad, M., \& Zinser, M. C. (1994). Putatively psychosis-prone subjects 10 years later. Journal of Abnormal Psychology, 103(2), 171-183.

Cooper, A. F. (1976). Deafness and psychiatric illness. British Journal of Psychiatry, 129, 216-226.

Cooper, A. F., \& Curry, A. R. (1976). The pathology of deafness in the paranoid and affective psychoses of later life. Journal of Psychosomatic Research, 20(2), 97-105.

Cooper, A. F., Curry, A. R., Kay, D. W., Garside, R. F., \& Roth, M. (1974). Hearing loss in paranoid and affective psychoses of the elderly. Lancet, 2(7885), 851-854.

Corcoran, R. (2000). Theory of mind in other clinical conditions: is a selective 'theory of mind' deficit exclusive to autism? In S. Baron-Cohen, H. Tager-Flusberg \& D. J. Cohen (Eds.), Understanding other minds: perspectives from developmental cognitive neuroscience (2nd ed., pp. 391-421). Oxford ; New York: Oxford University Press.

David, A., Malmberg, A., Lewis, G., Brandt, L., \& Allebeck, P. (1995). Are there neurological and sensory risk factors for schizophrenia? Schizophrenia Research, 14(3), 247-251.

Eastwood, M. R., Corbin, S. L., Reed, M., Nobbs, H., \& Kedward, H. B. (1985). Acquired hearing loss and psychiatric illness: an estimate of prevalence and co-morbidity in a geriatric setting. British Journal of Psychiatry, 147, 552-556. 
Frith, C. D. (1992). The Cognitive Neuropsychology of Schizophrenia. Hove: Lawrence Erlbaum Associates.

Gallagher, A. G., Dinan, T. G., \& Baker, L. J. (1994). The effects of varying auditory input on schizophrenic hallucinations: a replication. British Journal of Medical Psychology, 67(1), 67-75.

Garety, P. A., Kuipers, E., Fowler, D., Freeman, D., \& Bebbington, P. E. (2001). A cognitive model of the positive symptoms of psychosis. Psychological Medicine, 31(2), 189-195.

Gordon, A. G. (1997). Insight into auditory hallucinations and psychosis. International Journal of Geriatric Psychiatry, 12(3), 410-411.

Gordon, A. G. (2003). Auditory susceptibility in hallucinating schizophrenic patients. Journal of Nervous and Mental Disease, 191(6), 410-411.

Hanssen, M., Bak, M., Bijl, R., Vollebergh, W., \& van Os, J. (2005). The incidence and outcome of subclinical psychotic experiences in the general population. British Journal of Clinical Psychology, 44(2), 181191.

Hanssen, M., Peeters, F., Krabbendam, L., Radstake, S., Verdoux, H., \& van Os, J. (2003). How psychotic are individuals with non-psychotic disorders? Social Psychiatry and Psychiatric Epidemiology, 38(3), 149-154.

Henquet, C., Krabbendam, L., Dautzenberg, J., Jolles, J., \& Merckelbach, H. (2005). Confusing thoughts and speech: source monitoring and psychosis. Psychiatry Research, 133(1), 57-63.

Jackson, A. L. (2001). Language facility and theory of mind development in deaf children. Journal of Deaf Studies and Deaf Education, 6(3), 161-176.

Johns, L. C., Rossell, S., Frith, C., Ahmad, F., Hemsley, D., Kuipers, E., et al. (2001). Verbal self-monitoring and auditory verbal hallucinations in patients with schizophrenia. Psychological Medicine, 31(4), 705-715.

Johns, L. C., \& van Os, J. (2001). The continuity of psychotic experiences in the general population. Clinical Psychology Review, 21(8), 1125-1141.

Johnson, M. K., Hashtroudi, S., \& Lindsay, D. S. (1993). Source monitoring. Psychological Bulletin, 114(1), 3 28.

Margo, A., Hemsley, D. R., \& Slade, P. D. (1981). The effects of varying auditory input on schizophrenic hallucinations. British Journal of Psychiatry, 139, 122-127.

McGorry, P. D. (2000). The nature of schizophrenia: signposts to prevention. Australian and New Zealand Journal of Psychiatry, 34 Suppl, S14-21.

Peters, E. R., Joseph, S. A., \& Garety, P. A. (1999). Measurement of delusional ideation in the normal population: introducing the PDI (Peters et al. Delusions Inventory). Schizophrenia Bulletin, 25(3), 553-576.

Peterson, C. C., \& Siegal, M. (1995). Deafness, conversation and theory of mind. Journal of Child Psychology and Psychiatry, 36(3), 459-474. 
Peterson, C. C., Wellman, H. M., \& Liu, D. (2005). Steps in theory-of-mind development for children with deafness or autism. Child Development, 76(2), 502-517.

Poulton, R., Caspi, A., Moffitt, T. E., Cannon, M., Murray, R., \& Harrington, H. (2000). Children's selfreported psychotic symptoms and adult schizophreniform disorder: a 15-year longitudinal study. Archives of General Psychiatry, 57(11), 1053-1058.

Rodriguez-Ferrera, S., Vassilas, C. A., \& Haque, S. (2004). Older people with schizophrenia: a community study in a rural catchment area. International Journal of Geriatric Psychiatry, 19(12), 1181-1187.

Russell, P. A., Hosie, J. A., Gray, C. D., Scott, C., Hunter, N., Banks, J. S., et al. (1998). The development of theory of mind in deaf children. Journal of Child Psychology and Psychiatry, 39(6), 903-910.

Sindhusake, D., Mitchell, P., Smith, W., Golding, M., Newall, P., Hartley, D., et al. (2001). Validation of selfreported hearing loss. The Blue Mountains Hearing Study. International Journal of Epidemiology, 30(6), 1371-1378.

StataCorp. (2005). Stata Statistical Software: Release 9.0. TX: Stata Corporation, College Station.

Stefanis, N. C., Delespaul, P., Henquet, C., Bakoula, C., Stefanis, C. N., \& Van Os, J. (2004). Early adolescent cannabis exposure and positive and negative dimensions of psychosis. Addiction, 99(10), 13331341.

Stefanis, N. C., Hanssen, M., Smirnis, N. K., Avramopoulos, D. A., Evdokimidis, I. K., Stefanis, C. N., et al. (2002). Evidence that three dimensions of psychosis have a distribution in the general population. Psychological Medicine, 32(2), 347-358.

Stein, L. M., \& Thienhaus, O. J. (1993). Hearing impairment and psychosis. International Psychogeriatrics, 5(1), 49-56.

Thewissen, V., Myin-Germeys, I., Bentall, R., de Graaf, R., Vollebergh, W., \& van Os, J. (2005). Hearing impairment and psychosis revisited. Schizophrenia Research, 76(1), 99-103.

Tzoumaka-Bakoula, C. (1987). The Greek national perinatal survey: I: Design, methodology, case ascertainment. Paediatric and Perinatal Epidemiology, 1(1), 43-55.

Woolfe, T., Want, S. C., \& Siegal, M. (2002). Signposts to development: theory of mind in deaf children. Child Development, 73(3), 768-778. 


\section{Chapter 7}

\section{EPILOGUE}


Over the last two decades, the psychological understanding of positive psychotic symptoms has developed greatly as a result of significant advances in both theory and research on psychosis. Single-symptom research into psychosis has received substantial attention and has facilitated greater understanding of the psychological mechanisms underlying specific symptoms, especially paranoid symptoms (Bentall, Corcoran, Howard, Blackwood, \& Kinderman, 2001; Freeman, Garety, Kuipers, Fowler, \& Bebbington, 2002). In addition, an increasing number of studies demonstrate evidence of a continuum of psychosis, by showing psychotic symptoms to be prevalent in a proportion of individuals from the general population who do not develop distress and need for care (e.g. Peters, Joseph, \& Garety, 1999; van Os, Hanssen, Bijl, \& Ravelli, 2000). The studies presented in this current thesis have built on these advances in understanding psychosis using an epidemiological and momentary assessment approach. This final chapter will recapitulate the main findings of the studies, provides clinical implications and suggests directions for further research. An integrative overview of the main aspects discussed in the chapters is offered in Figure 7.1.

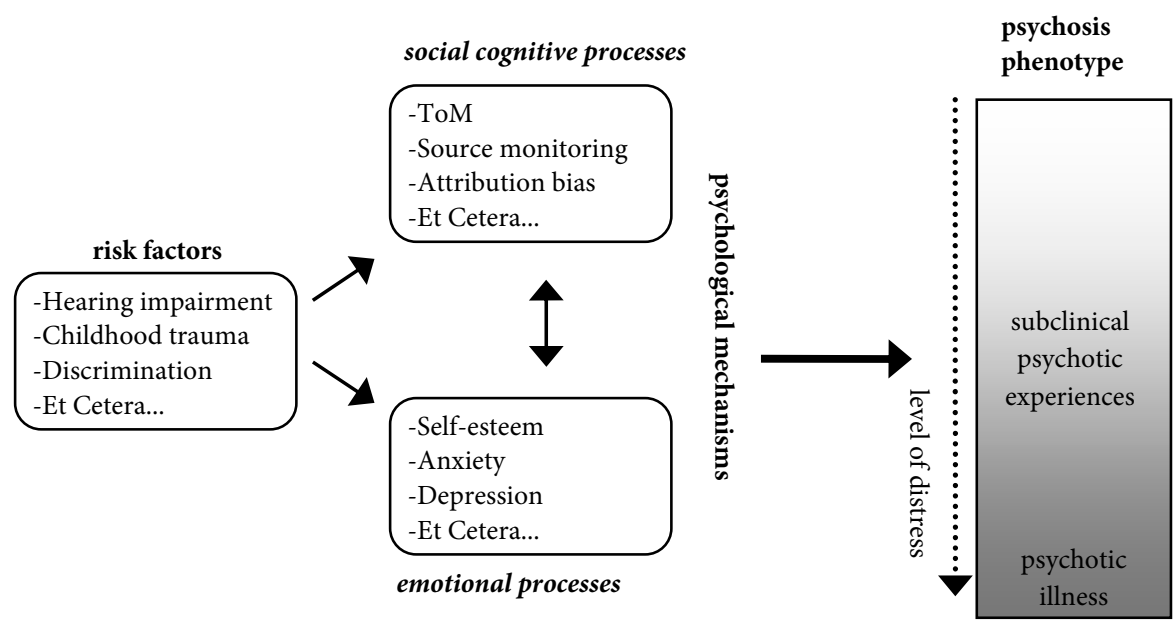

Figure 7.1 Integrative overview of the chapters

There is a reciprocal relationship between social cognitive and emotional processes (Part 1; chapters 2, 3 and 5), which can together be conceived as psychological mechanisms underlying the psychosis phenotype. Risk factors, such as deafness or hearing impairment (Part 2; chapter 5 and 6), may impact on these mechanisms. 


\section{The psychological understanding of positive psychotic symptoms}

In this thesis, an attempt was made to understand the genesis of positive psychotic symptoms from within a cognitive psychological framework. An increasing body of research has demonstrated that psychotic symptoms are not merely the product of a genetic predisposition or (neuro) biological defects, but also understandable in terms of social cognitive and psychological processes. As has become evident in the previous chapters, psychotic symptoms are likely to arise from a complex series of interactions between the individual and the environment. Environmental influences may affect the development of psychological processes underlying psychotic symptoms. Moreover, the underlying psychological processes of psychotic symptoms are subject to contextual influences in everyday life. Psychotic symptoms consequently rarely stay constant. As "change is the hallmark of psychopathology", an adequate psychological model should explain how symptoms may vary over time (Bentall, Corcoran, Howard, Blackwood, \& Kinderman, 2001).

Several cognitive psychological models on positive psychotic symptoms have been proposed during the past few years (e.g. Bentall, Corcoran, Howard, Blackwood, \& Kinderman, 2001; Freeman, Garety, Kuipers, Fowler, \& Bebbington, 2002; Garety, Kuipers, Fowler, Freeman, \& Bebbington, 2001). One influential psychological model of paranoia put forward by Bentall and colleagues (2001) is the 'attribution - selfrepresentation model'. This explanatory model accurately captures dynamic relationships between psychological processes and paranoid symptoms. According to the model, paranoid individuals harbour latent negative beliefs about themselves. They unremittingly attempt to avoid the activation of these beliefs into consciousness by attributing self-threatening events to intentional actions of other people. Since the attempts to avoid negative beliefs are not always effective, the prediction was that selfesteem would be highly fluctuating in paranoid persons. Chapter 2 and 3 addressed the prediction that paranoia is associated with self-esteem instability.

\section{Is paranoia associated with fluctuations in self-esteem?}

In chapter 2, an epidemiological approach was used to investigate the hypothesized association between paranoia and self-esteem instability. Investigating large-scale samples may constitute a useful first approach to elucidate elusive psychological processes underlying the psychosis phenotype. A large sample of individuals from the general population was interviewed for the presence of positive psychotic symptoms at three distant points in time using the Composite International Diagnostic Interview. 
The participants also filled in the Rosenberg Self-Esteem Scale at all three measure moments. Results demonstrated that individuals with paranoid symptoms showed a significantly lower mean self-esteem level compared to individuals with other positive psychotic symptoms. This is consistent with the idea that paranoid persons harbour latent negative beliefs about themselves (Bentall, Corcoran, Howard, Blackwood, \& Kinderman, 2001). Low levels of self-esteem in relation to paranoid symptoms have been demonstrated before in both clinical (Drake et al., 2004; Freeman et al., 1998) and non-clinical populations (Combs \& Penn, 2004; Ellett, Lopes, \& Chadwick, 2003; Martin $\&$ Penn, 2001). A second and more interesting finding was that paranoid symptoms, and not positive psychotic symptoms in general, were indeed associated with (long-term) self-esteem instability, as predicted by the 'attribution - self-representation model' (Bentall, Corcoran, Howard, Blackwood, \& Kinderman, 2001). The association between paranoid symptoms and unstable self-esteem remained significant after controlling for self-esteem level (and a range of other confounding factors), which indicates that selfesteem instability is not constrained by self-esteem level. These results are, to our knowledge, the first evidence of self-esteem instability in relation to paranoid symptoms.

In order to investigate the prediction into further detail, a more refined methodology was required. Therefore, a second study used a momentary assessment approach - the Experience Sampling Method (ESM) - to investigate the association between self-esteem and paranoia in daily life (chapter 3). This method is particularly suitable for investigating all kind of dynamic predictions. Self-esteem was assessed at ten random times a day for six consecutive days in the daily life of individuals who ranged across the continuum from subclinical to clinical levels of current paranoia. Results showed that trait paranoia, measured with the Paranoia Scale, was significantly associated with higher instability in daily life self-esteem. Fluctuations in self-esteem were consistently demonstrated at two different levels: momentary level (fluctuation from moment-to-moment) and participant level (standardised fluctuation as a subject characteristic). These results are consistent with the findings described in chapter 2 and broaden these findings to the context of daily life in individuals with paranoia ranging from non-pathological to pathological levels.

Global measures of self-esteem were also obtained for each individual using the Rosenberg Self-Esteem Scale (which was completed at the end of each day) and the SelfEsteem Rating Scale. Results showed that trait paranoia was associated with a lower general level of self-esteem at two different levels: momentary level (mean level of ESM 
self-esteem) and participant level (total score on the Self-Esteem Rating Scale). However, after controlling for the constraining effect of self-esteem instability, the association disappeared at momentary level. This suggests that instability of self-esteem plays a more important role in the association with paranoia than level of self-esteem, which was already implied by the prediction of a dysfunctional strategy of self-esteem regulation (Bentall, Corcoran, Howard, Blackwood, \& Kinderman, 2001).

In summary, the findings reported in chapters 2 and 3 clearly show that selfesteem is not rigidly fixed but fluctuates over time in paranoid individuals.

\section{What role do emotional processes play in relation to paranoia?}

Apart from self-esteem, there are some other aspects of emotional experience which are suggested to be implicated in the development of paranoid symptoms. Emotional processes play an essential theoretical role in the aforementioned 'attribution - selfrepresentation model', since it suggests that paranoid beliefs prevent the activation of negative beliefs about the self. This suggestion is similar to the hypothesis that paranoia may be a form of hidden depression (Zigler \& Glick, 1988). Another influential cognitive psychological model of paranoia is put forward by Freeman and colleagues (2002). According to this model, persecutory delusions arise from an interaction between internal unusual experiences and cognitive psychological and emotional processes. Emotions are assumed to have a central and direct role in the formation and maintenance of paranoid symptoms. Especially anxiety is postulated as being important, since both anxiety and paranoia involve the anticipation of danger. The evidence to date for a causal role of emotions in the generation of paranoid symptoms is scarce, mainly because of a lack of studies investigating the longitudinal association between emotional processes and paranoia. Chapter 4 addressed the involvement of dynamic emotional processes in the generation and maintenance of paranoia.

In chapter 4, a momentary assessment approach was used to examine the temporal association between state emotional experiences (emotions highly influenced by daily life experiences and circumstances) and momentary paranoia in a sample of patients with positive psychotic symptoms. Paranoia and three key negative emotional experiences (depression, anxiety and anger) were assessed randomly ten times a day for six consecutive days. It was demonstrated that changes in negative emotional experiences were associated with a subsequent development of paranoid symptoms. Increases in feeling down, anxious or angry independently led to the generation of paranoid experiences. Paranoia itself led to a further increase in negative emotional 
experiences and was found to have the largest effect on subsequent anxiety. On the whole, the findings are in line with previous evidence of an association between paranoia on the one hand and anxiety (Freeman et al., 2005) or negative emotional experiences in general (e.g. Appelbaum, Robbins, \& Roth, 1999; Combs \& Penn, 2004; Smith et al., 2006) on the other. It seems that negative emotional processes, particularly anxiety, have a direct role in the initiation and maintenance of paranoid beliefs.

As predicted by the 'attribution - self-representation model' (Bentall, Corcoran, Howard, Blackwood, \& Kinderman, 2001), the findings reported in chapter 2 and 3 of this thesis clearly show that paranoia is associated with fluctuations in selfesteem. According to this model, paranoid thoughts are constructed defensively against negative affective processes, including low self-esteem. Whether or not paranoia indeed serves a defensive function, is difficult to conclude from current findings. It could be argued that paranoid thoughts serve as a defence, but the mechanism is not working properly since self-esteem is highly fluctuating. As Bentall and colleagues state, paranoid individuals "might be locked into an intense struggle to maintain positive selfrepresentations that often fails" (Bentall, Corcoran, Howard, Blackwood, \& Kinderman, 2001, p. 1166). The finding that a decrease in self-esteem immediately leads to an increase in momentary paranoia (chapter 3), may also be suggestive of a defensive mechanism. On the other hand, it could be argued that current findings do not favour the paranoia-as-defence theory, since paranoia is associated with a lower general level of overt self-esteem (chapter 2 and 3) and momentary paranoia predicts an increase in subsequent negative emotional experiences (chapter 4). This would not be expected if paranoid thoughts serve a defensive function (e.g. Freeman, 2007; Freeman et al., 1998). According to Garety and Freeman (1999), a 'weaker' formulation of the paranoia-asdefence theory (i.e. paranoia only partially fulfils its defensive function) predicts a discrepancy between overt and covert self-esteem in paranoid individuals. Covert selfesteem is thereby expected to be lower in paranoid individuals. In this case, studies need to employ methods which can penetrate the defence in order to measure covert selfesteem. A recent study has successfully demonstrated a discrepancy between overt and covert self-esteem in paranoid patients, thereby showing evidence in favour of this weaker formulation of the paranoia-as-defence hypothesis (McKay, Langdon, \& Coltheart, 2007). McKay and colleagues (2007) mention that the fact that paranoia is associated with a lower general level of overt self-esteem does not militate against the paranoia-as-defence theory. It may be likely that overt self-esteem would even be lower 
without the (defensive) paranoid thoughts. Apart from this recent study, the evidence for the weaker formulation of the paranoia-as-defence hypothesis is equivocal and previous studies suffer from methodological difficulties (Garety \& Freeman, 1999).

In summary, taken all the findings together it is hard to prove whether or not paranoia indeed serves a defensive function against low self-esteem and other negative affective processes. However, it may be clear that self-esteem is an important concept when considering paranoia, especially the dynamics of self-esteem. In addition, negative emotional processes, particularly anxiety, have been demonstrated to be important in the development of paranoid beliefs. It may be likely that there is a circular relationship between self-esteem, negative emotional processes and paranoia (Freeman, 2007). Low self-esteem level, high self-esteem instability and negative emotional processes may therefore act as vulnerability, maintaining and consequential factors of paranoia.

The findings reported in the first part of this thesis underline the importance to account for dynamic interactions when modelling positive psychotic symptoms. As has been mentioned earlier, environmental risk factors may impinge on psychological processes underlying psychotic symptoms. The second part of this thesis concentrated on one specific potential risk factor; the presence of deafness or hearing impairment. It was hypothesised that problems in the domain of hearing may constitute a vulnerability to develop delusions and/or hallucinations by impacting on social cognitive and psychological mechanisms. This hypothesis was addressed in chapter 5 and 6.

\section{Does hearing impairment constitute a vulnerability to develop positive psychotic} symptoms?

In chapter 5, the association between hearing impairment and positive psychotic experiences was investigated prospectively in a large-scale epidemiological sample of adults between 18-64 years of age, drawn from the Dutch general population. Hearing impairment was measured subjectively at baseline by asking the participants whether they had experienced deafness or serious hearing impairment in the past 12 months. Three years after enrolment, positive psychotic experiences (hallucinations and/or delusional ideation) were assessed using the Composite International Diagnostic Interview. Results indicated that individuals with baseline deafness or hearing impairment had a threefold increased risk to develop positive psychotic experiences three years later compared to individuals without hearing defects. Reverse causality (psychosis provokes the idea of being hearing impaired) may be unlikely as the results 
remained significant after controlling for baseline psychosis (and a range of other confounders). In addition, similar results were found for individuals who indicated that they were under treatment or medical supervision for their hearing impairment. The current results add to previous reports associating deafness with psychotic illness (e.g. Cooper, 1976; Cooper \& Curry, 1976; Cooper, Curry, Kay, Garside, \& Roth, 1974; Stein \& Thienhaus, 1993) and extend these findings to the subclinical expression of psychosis in the general population.

Since age of onset and duration of hearing impairment are important predictors of possible consequences of deafness (Cooper, 1976; Cooper \& Curry, 1976), it was investigated to what degree any association between hearing impairment and psychosis was conditional on the duration of hearing impairment (chapter 6). The alleged association was investigated using a longitudinal epidemiological Greek birth cohort in which individuals were followed up from birth to late adolescence. Hearing impairment was determined subjectively at age 7 years (reported by parents and teachers of the participant) and age 19 years (participant self-report). Positive psychotic experiences were measured at age 19 years using the Community Assessment of Psychic Experiences. A significant main effect was found for hearing impairment at age 19 on the presence of positive psychotic experiences at this age after adjusting for a range of confounders. However, no significant main effect was found for hearing problems at age 7 on positive psychotic experiences at age 19 years after adjusting for possible confounders. Yet, the results showed a significant interaction effect, which indicated that the association was significantly stronger in individuals with previous hearing impairment at age 7 years than individuals without previous hearing impairment at age 7 years. Therefore, longer duration of hearing impairment with onset early in childhood is associated with a stronger risk to develop positive psychotic symptoms. The current results are consistent with those reported in chapter 5 and extend the findings to a sample of young adults.

The association between hearing impairment and psychosis can be interpreted in terms of psychological models which focus on social cognitive biases as an essential element in the generation of positive psychotic symptoms (e.g. Bentall, 1990; Frith, 1992; Garety, Kuipers, Fowler, Freeman, \& Bebbington, 2001). Since hearing impairment has a profound influence on interaction with the social environment, it can be argued that hearing impaired individuals are at increased risk of developing disturbances in social cognition, the ability to construe the social environment (e.g. Bentall, 1990; Frith, 1992; Garety, Kuipers, Fowler, Freeman, \& Bebbington, 2001). 
Theory of mind and source monitoring are social cognitive processes which are most clearly related to the interaction with the social environment. While deficits in theory of mind have been related to the development of delusions (Frith, 1992), source monitoring impairments have been associated with hallucinations (Bentall, 1990). In order to correctly perceive and interpret the social environment, it is necessary to have access to various sources of information. Individuals with long lasting hearing impairment and onset before the critical stages of social development are at risk of developing a delay in their theory of mind and impairments in source monitoring, since they have limited access to an important source of information (the auditory context). Individuals with acquired hearing loss later in life, such as in late adolescence or adulthood, are at risk of developing positive psychotic symptoms, because of the loss or reduction of the auditory context. Since these individuals have learned to use all information available to infer the mental states of others and to discriminate between internal and external sources of information, they are put at risk of developing impairments in their social cognitive skills.

Chapters 5 and 6 have shown that symptom-specific psychological models may also be useful in understanding the association between specific risk factors and psychosis as these models may represent the final common pathways that lead to experiences such as hallucinations and delusions (Bentall, 2006).

\section{Clinical implications}

The present findings have several implications for clinical practice. Psychological models may serve as a useful theoretical framework upon which specific therapeutic interventions for psychosis can be tailored. The studies presented in this thesis are placed within a framework of a continuum-based and symptom-oriented approach to psychosis. Further evidence for continuity of psychotic symptoms with normal experiences may encourage the use of Cognitive-Behavioral Therapy (CBT) techniques such as the 'normalizing rationale' (Kingdon \& Turkington, 1994). The symptomoriented approach promotes the development and application of therapeutic interventions which are directed to the underlying mechanisms of specific symptoms (Bentall, 2006).

CBT has proven to be effective in dealing with persistent positive psychotic symptoms (Tarrier et al., 1998; Valmaggia, van der Gaag, Tarrier, Pijnenborg, \& Slooff, 2005) and is nowadays officially recommended in the Netherlands by the Multidisciplinary Guideline for the Treatment of Schizophrenia (Brandt-Dominicus, 
2005). CBT techniques are increasingly applied to manage specific complaints. Paranoid and suspicious thoughts can be effectively managed by modifying dysfunctional cognitions (Freeman, Freeman, \& Garety, 2006). The findings presented in this thesis show that negative emotions, especially anxiety, play an important role in the cause, consequence and maintenance of paranoid symptoms. It is therefore important to recognise that $\mathrm{CBT}$, next to primarily addressing dysfunctional cognitions, should complementary focus on the associated negative emotional disturbances which often precede paranoid symptoms (Birchwood, 2003; Birchwood \& Trower, 2006; Freeman, Freeman, \& Garety, 2006). Trying to interrupt cycles of anxiety or low mood may be helpful in this (Kuipers et al., 2006). Freeman and colleagues (2006) have already shown that paranoid and suspicious thoughts can be managed by addressing low self-esteem, one aspect of emotional experience. The current findings of highly fluctuating selfesteem in paranoid individuals suggest that psychological treatments should not only target improvement of self-esteem, but also focus on self-esteem regulation.

The effectiveness of psychotherapeutic interventions shows that psychological mechanisms may be amenable to treatment. Identification of risk factors, such as deafness or hearing impairment, which may impact on these mechanisms is therefore of high significance. Early detection of hearing impairment is important as longer duration of hearing impairment was found to be associated with a greater risk of developing psychosis. Especially individuals with a high vulnerability to develop psychosis may benefit from early detection of risk factors. A considerable part of hearing impairment is often medically treatable and even 50 percent is avoidable through prevention and management (WHO, 2006).

\section{Concluding word}

The work presented in this thesis contributes to a fuller understanding of the psychology behind positive psychotic symptoms and may guide further development of psychological explanatory models. It has become apparent that an epidemiological approach is useful for broadly investigating theoretical premises on elusive psychological processes. These processes can be further explored into greater detail by using more refined and dynamic approaches, such as the Experience Sampling Method.

Research into the etiology and underlying mechanisms of psychosis has been narrowed down from a syndrome-oriented approach to a more specific symptomoriented approach. The findings presented in the first part of this thesis have shown that paranoid symptoms are related to dynamic psychological processes. It is important for 
future explanatory models to acknowledge these dynamic processes. Recent research has further narrowed down the investigation into paranoia by specifically focussing on the content of paranoid beliefs. Evidence has been proposed for two different types of paranoia which represent beliefs about the deservedness of paranoia; persecution / 'poor-me' paranoia and punishment / 'bad-me' paranoia (Chadwick, Trower, JuustiButler, \& Maguire, 2005). The latter type, in which malevolence of others is seen as deserved, is typically associated with lower self-esteem, anxiety and guilt. The former type, in which malevolence of others is seen as undeserved, is associated with anger (Chadwick, Birchwood, \& Trower, 2005). Recent evidence has demonstrated that these two types may alternate over time within the same person (Melo, Taylor, \& Bentall, 2006). It would therefore be valuable for future studies to take into account these two dynamic types of paranoia, especially when investigating the relationship with selfesteem and negative emotions. It may even be likely that this conceptual distinction leads to a reformulation of existing psychological models of paranoia (Chadwick et al. , 2005).

The findings presented in the second part of this thesis show that hearing impairment may impact on social cognitive and psychological processes underlying positive psychotic symptoms. As multiple causal and maintaining factors are implicated in the generation and maintenance of psychotic symptoms, it will eventually be essential to formulate an integrative model which bridges explanations from different fields so that psychological, social and (neuro) biological factors can be jointly studied.

\section{References}

Appelbaum, P. S., Robbins, P. C., \& Roth, L. H. (1999). Dimensional approach to delusions: comparison across types and diagnoses. American Journal of Psychiatry, 156(12), 1938-1943.

Bentall, R. (2006). Madness explained: Why we must reject the Kraepelinian paradigm and replace it with a 'complaint-orientated' approach to understanding mental illness. Medical Hypotheses, 66(2), 220233.

Bentall, R. P. (1990). The illusion of reality: a review and integration of psychological research on hallucinations. Psychological Bulletin, 107(1), 82-95.

Bentall, R. P., Corcoran, R., Howard, R., Blackwood, N., \& Kinderman, P. (2001). Persecutory delusions: a review and theoretical integration. Clinical Psychology Review, 21(8), 1143-1192. 
Birchwood, M. (2003). Pathways to emotional dysfunction in first-episode psychosis. British Journal of Psychiatry, 182, 373-375.

Birchwood, M., \& Trower, P. (2006). The future of cognitive-behavioural therapy for psychosis: not a quasineuroleptic. British Journal of Psychiatry, 188, 107-108.

Brandt-Dominicus, J. C. (2005). Multidisciplinaire Richtlijn Schizofrenie: Richtlijn voor de diagnostiek, zorgorganisatie en behandeling van volwassen cliënten met schizofrenie. Utrecht: Trimbos Instituut.

Chadwick, P., Birchwood, M., \& Trower, P. (2005). Cognitive therapy for delusions, voices, and paranoia. Chichester ; New York: Wiley.

Chadwick, P. D., Trower, P., Juusti-Butler, T. M., \& Maguire, N. (2005). Phenomenological evidence for two types of paranoia. Psychopathology, 38(6), 327-333.

Combs, D. R., \& Penn, D. L. (2004). The role of subclinical paranoia on social perception and behavior. Schizophrenia Research, 69(1), 93-104.

Cooper, A. F. (1976). Deafness and psychiatric illness. British Journal of Psychiatry, 129, 216-226.

Cooper, A. F., \& Curry, A. R. (1976). The pathology of deafness in the paranoid and affective psychoses of later life. Journal of Psychosomatic Research, 20(2), 97-105.

Cooper, A. F., Curry, A. R., Kay, D. W., Garside, R. F., \& Roth, M. (1974). Hearing loss in paranoid and affective psychoses of the elderly. Lancet, 2(7885), 851-854.

Drake, R. J., Pickles, A., Bentall, R. P., Kinderman, P., Haddock, G., Tarrier, N., et al. (2004). The evolution of insight, paranoia and depression during early schizophrenia. Psychological Medicine, 34(2), 285 292.

Ellett, L., Lopes, B., \& Chadwick, P. (2003). Paranoia in a nonclinical population of college students. Journal of Nervous and Mental Disease, 191(7), 425-430.

Freeman, D. (2007). Suspicious minds: The psychology of persecutory delusions. Clinical Psychology Review, 27(4), 425-457.

Freeman, D., Freeman, J., \& Garety, P. (2006). Overcoming paranoid \& suspicious thoughts: A self-help guide using Cognitive Behavioral Techniques. London: Constable \& Robinson Ltd.

Freeman, D., Garety, P., Fowler, D., Kuipers, E., Dunn, G., Bebbington, P., et al. (1998). The London-East Anglia randomized controlled trial of cognitive-behaviour therapy for psychosis. IV: Self-esteem and persecutory delusions. British Journal of Clinical Psychology, 37(Pt 4), 415-430.

Freeman, D., Garety, P. A., Bebbington, P., Slater, M., Kuipers, E., Fowler, D., et al. (2005). The psychology of persecutory ideation II: a virtual reality experimental study. Journal of Nervous and Mental Disease, 193(5), 309-315.

Freeman, D., Garety, P. A., Kuipers, E., Fowler, D., \& Bebbington, P. E. (2002). A cognitive model of persecutory delusions. British Journal of Clinical Psychology, 41(Pt 4), 331-347.

Frith, C. D. (1992). The Cognitive Neuropsychology of Schizophrenia. Hove: Lawrence Erlbaum Associates. 
Garety, P. A., \& Freeman, D. (1999). Cognitive approaches to delusions: a critical review of theories and evidence. British Journal of Clinical Psychology, 38(Pt 2), 113-154.

Garety, P. A., Kuipers, E., Fowler, D., Freeman, D., \& Bebbington, P. E. (2001). A cognitive model of the positive symptoms of psychosis. Psychological Medicine, 31(2), 189-195.

Kingdon, D. G., \& Turkington, D. (1994). Cognitive-behavioral therapy of schizophrenia. New York: Guiford Press.

Kuipers, E., Garety, P., Fowler, D., Freeman, D., Dunn, G., \& Bebbington, P. (2006). Cognitive, emotional, and social processes in psychosis: refining cognitive behavioral therapy for persistent positive symptoms. Schizophrenia Bulletin, 32(1 Suppl), S24-31.

Martin, J. A., \& Penn, D. L. (2001). Social cognition and subclinical paranoid ideation. British Journal of Clinical Psychology, 40(Pt 3), 261-265.

McKay, R., Langdon, R., \& Coltheart, M. (2007). The defensive function of persecutory delusions: an investigation using the Implicit Association Test. Cognitive Neuropsychiatry, 12(1), 1-24.

Melo, S. S., Taylor, J. L., \& Bentall, R. P. (2006). Poor me versus bad me paranoia and the instability of persecutory ideation. Psychology and Psychotherapy, 79(Pt 2), 271-287.

Peters, E. R., Joseph, S. A., \& Garety, P. A. (1999). Measurement of delusional ideation in the normal population: introducing the PDI (Peters et al. Delusions Inventory). Schizophrenia Bulletin, 25(3), 553-576.

Smith, B., Fowler, D. G., Freeman, D., Bebbington, P., Bashforth, H., Garety, P., et al. (2006). Emotion and psychosis: links between depression, self-esteem, negative schematic beliefs and delusions and hallucinations. Schizophrenia Research, 86(1-3), 181-188.

Stein, L. M., \& Thienhaus, O. J. (1993). Hearing impairment and psychosis. International Psychogeriatrics, 5(1), 49-56.

Tarrier, N., Yusupoff, L., Kinney, C., McCarthy, E., Gledhill, A., Haddock, G., et al. (1998). Randomised controlled trial of intensive cognitive behaviour therapy for patients with chronic schizophrenia. British Medical Journal, 317(7154), 303-307.

Valmaggia, L. R., van der Gaag, M., Tarrier, N., Pijnenborg, M., \& Slooff, C. J. (2005). Cognitive-behavioural therapy for refractory psychotic symptoms of schizophrenia resistant to atypical antipsychotic medication. Randomised controlled trial. British Journal of Psychiatry, 186, 324-330.

van Os, J., Hanssen, M., Bijl, R. V., \& Ravelli, A. (2000). Strauss (1969) revisited: a psychosis continuum in the general population? Schizophrenia Research, 45(1-2), 11-20.

WHO. (2006). Deafness and hearing impairment. Fact sheet no 300 (May 2006). Geneva: Switzerland: World Health Organisation.

Zigler, E., \& Glick, M. (1988). Is paranoid schizophrenia really camouflaged depression? American Psychologist, 43(4), 284-290. 
SUMMARY

SAMENVATTING 
In recent years, a big advance has been made in elucidating the psychological processes underlying psychotic symptoms. It has been convincingly demonstrated that psychotic symptoms are not merely the result of a genetic predisposition or (neuro) biological defects, but also understandable in terms of psychological factors. The specific psychological mechanisms, however, which are implicated in the aetiology and maintenance of psychosis remained fairly unclear.

This thesis, UNDERSTANDING THE PSYCHOLOGY OF POSITIVE PSYCHOTIC SYMPTOMS, offers a comprehensive and integrative approach to the psychological understanding of the positive symptoms of psychosis.

Chapter 1 outlines the phenomenology and concept of psychosis and discusses the continuum view, which implies that psychotic symptoms are not only prevalent in individuals with a psychotic disorder but also in a considerable part of the general population. The chapter further provides a general introduction to the psychology of paranoia, a common positive psychotic symptom. Two influential psychological models of paranoia are briefly discussed: the 'attribution - self-representation model' and the 'multifactorial model'. According to the first model, paranoia has a defensive function and is the consequence of a coherent set of cognitive biases to maintain the self-concept. Since these cognitive biases to avoid negative beliefs about the self are often dysfunctional, an important prediction from this model is that self-esteem will act dynamically across time in paranoid individuals. The 'multifactorial model' presents a different view on the development of paranoia. Persecutory delusions are hypothesised to arise from an interaction between several factors. In this model, a more central and direct role is claimed for emotional factors and self-esteem in the development and maintenance of paranoia. Further on in the chapter, the Experience Sampling Method (ESM) is introduced as a feasible, valid and reliable method to investigate dynamic psychological processes in daily life. An array of (environmental) risk factors for psychosis is described, including the presence of deafness or hearing impairment. Since hearing impairment has a profound influence on interaction with the social environment, it is suggested that problems in the domain of hearing may constitute a vulnerability to psychosis by impacting on social cognitive and psychological mechanisms. The chapter finishes with the aims and outline of the thesis.

The present thesis consists of two parts. The first part (chapters 2, 3 and 4) specifically focuses on the underlying psychological mechanisms of paranoid symptoms. 
Chapter 2 reports a study on the association between self-esteem and paranoia. In the literature, paranoia has been associated with high as well as low, or even normal, levels of self-esteem. While previous studies have mainly concentrated on self-esteem level, the current study also focused on self-esteem instability. Starting from a continuum view of psychosis, an epidemiological approach was chosen to investigate whether self-esteem instability was specifically related to sub-clinical paranoid symptoms in a general population sample. A risk set of 4636 individuals from the Dutch general population was interviewed at three distant points in time for the presence of positive psychotic symptoms. The participants also completed the Rosenberg Self-Esteem scale at all three measure moments. The results demonstrated that individuals with sub-clinical paranoid symptoms showed a significantly lower mean self-esteem level compared to individuals with other positive psychotic symptoms (e.g. thought interference and auditory hallucinations). However, more interestingly, the results also demonstrated that the presence of sub-clinical paranoid symptoms, and not other positive sub-clinical psychotic symptoms, was significantly associated with self-esteem instability over a three year period. This association remained significant after controlling for level of selfesteem, which indicates that self-esteem instability is not constrained by self-esteem level. This finding of a specific association between sub-clinical paranoid symptoms and self-esteem instability is in line with the 'attribution - self-representation model', which was introduced in chapter 1 . It is possible that paranoid beliefs arise partly as a consequence of dysfunctional efforts to regulate self-esteem.

Chapter 3 presents a study in which a momentary assessment approach was used to investigate short-term instability in self-esteem and paranoia. The goal of this chapter was twofold. First, the association between trait paranoia and level and instability of self-esteem was investigated in 154 individuals who ranged across the continuum in level of paranoia. Trait paranoia was measured using the Paranoia Scale. Level and instability of self-esteem were examined in daily life using ESM. The results showed that trait paranoia was associated with both a lower level and higher instability in selfesteem. Instability in self-esteem was consistently demonstrated using two different approaches to measure fluctuations in self-esteem: 1) at momentary level, fluctuations from moment to moment and 2) at participant level, in which the fluctuations reflected the variance in self-esteem over the study period. A second purpose of this chapter was to examine the temporal relationship between state paranoia and changes in self-esteem in these individuals. The results showed that a decrease in self-esteem was associated 
with an immediate increase in state paranoia. Overall, the findings in this chapter provide further support for the 'attribution - self-representation model', which suggests that paranoid beliefs have a defensive function.

Chapter 4 reports a study in which a momentary assessment approach was used to examine state paranoia and negative emotional processes in the daily life of patients with positive psychotic symptoms. Emotional processes are considered to play an important role in the development of paranoia. The 'attribution - self-representation model' and the 'multifactorial model', both introduced in chapter 1, suggest a different role for emotional processes in the generation of paranoid symptoms: paranoia as a protection against negative emotions and paranoia as a direct reflection of negative emotions. State paranoia and three key negative emotions, including depression, anxiety and anger, were examined in the daily life of 79 patients with a clinical diagnosis of psychotic disorder using ESM. The results showed that paranoia was independently and significantly cross-sectionally associated with feelings of anxiety, anger and depression. More interestingly, longitudinal analyses showed that paranoia was predicted by increases in feeling anxious, angry and down. Paranoia in its turn was a significant predictor of an increase in all three emotional processes. The strongest association was demonstrated between paranoia and anxiety, both longitudinally and cross-sectionally. The findings presented in this chapter imply that paranoid beliefs both generate and arise from changes in negative emotional processes. It therefore seems that paranoid beliefs do not serve an immediate defensive function against depressive or other negative emotions, as suggested by the 'attribution - self-representation model'. Paranoia seems to be a direct reflection of negative emotions, particularly anxiety, as suggested by the 'multifactorial model'.

The second part of this thesis (chapters 5 and 6) concentrates on hearing impairment, which may constitute a vulnerability to psychosis by impacting on social cognitive and psychological mechanisms.

Chapter 4 describes a study in which an epidemiological approach was used to investigate the presence of deafness or hearing impairment as a risk factor for positive psychotic symptoms. The association between hearing impairment and psychosis has previously been reported, but poorly investigated. In the current study, the alleged association was investigated prospectively in a general population sample of 4845 adults. 
Hearing impairment was measured subjectively at baseline of the study by asking the participants whether they had experienced deafness or serious hearing impairment in the past 12 months. Positive psychotic experiences were assessed by an interview three years later. The results indicated that individuals with baseline deafness or hearing impairment had a threefold increased risk to develop positive psychotic experiences compared to individuals without hearing problems. Hearing impairment has a profound influence on interaction with the social environment. Therefore, the association between hearing impairment and positive psychotic experiences can be understood in terms of psychological models which focus on social cognitive biases as an essential element in the generation of positive psychotic symptoms.

Chapter 6 elaborates further on the link between deafness or hearing impairment and positive psychotic symptoms. Again, an epidemiological approach was used to investigate the association and to examine to what degree any association was conditional on the duration of hearing impairment. In the current study, a risk set of 1411 adolescents, who were followed up from birth, was investigated. Hearing impairment was determined subjectively at age 7 years (reported by parents and teachers of the participant) and age 19 years (participant self-report). Positive psychoticlike experiences were assessed at age 19 years using a questionnaire which measures the frequency of attenuated psychotic experiences. The results showed that hearing problems at age 7 were not associated with positive psychotic-like experiences at age 19 . However, hearing problems at age 19 were significantly associated with positive psychotic-like experiences at this age. Interestingly, there was a significant interaction effect, which indicated that the association was significantly stronger in those individuals with previous hearing impairment at age 7 compared to individuals without hearing impairment at this young age. These findings indicate that individuals with a longer period of hearing impairment and onset early in childhood are at greater risk to develop positive psychotic symptoms.

Chapter 7 recapitulates the main findings from part 1 and part 2 of this thesis. The first part of this thesis shows that self-esteem is an important concept when considering paranoia, especially the dynamics of self-esteem. Negative emotional processes, particularly anxiety, have been demonstrated to be important in the development of paranoia as well. The 'attribution - self-representation model' and the 'multifactorial model' are critically discussed. It may be likely that there is a circular relationship 
between self-esteem, negative emotional processes and paranoia. Low self-esteem level, high self-esteem instability and negative emotional processes may act as vulnerability, maintaining and consequential factors of paranoia. The second part of this thesis concentrates on the presence of deafness or hearing impairment as a risk factor for psychosis. Findings showed that hearing impairment constitutes a vulnerability to develop positive psychotic symptoms. In addition, it was demonstrated that this vulnerability was conditional upon the duration and onset of the hearing problems. Since individuals with problems in the domain of hearing might be at risk of developing impairments in their social cognitive skills, the association can be understood in terms of psychological models in which social cognitive biases are considered as an essential element in the generation of positive psychotic symptoms. Deficits in theory of mind have been related to the development of delusions and source monitoring impairments have been associated with hallucinations. In summary, both parts of this thesis show that there is a reciprocal relationship between social cognitive and emotional processes, which can together be conceived as psychological mechanisms underlying the psychosis phenotype. Risk factors, such as deafness or hearing impairment may impact on these mechanisms (see Figure 7.1). The chapter finishes with a brief overview of the clinical implications as well as some directions for future research. 
In de afgelopen jaren is er een significante vooruitgang geboekt in onderzoek naar psychologische processen die ten grondslag liggen aan psychotische symptomen. Er is overtuigend bewijs geleverd dat psychotische symptomen niet louter voortvloeien uit een genetische predispositie of (neuro)biologische afwijkingen, maar ook te verklaren zijn in termen van psychologische factoren. De specifieke psychologische mechanismen die betrokken zijn in de etiologie en het voortbestaan van psychose bleven echter relatief onduidelijk.

Het voorliggende proefschrift, UNDERSTANDING THE PSYCHOLOGY OF POSITIVE PSYCHOTIC SYMPTOMS, biedt een uitgebreide en complete benadering van positieve psychotische symptomen, geplaatst vanuit een psychologisch perspectief.

Hoofdstuk 1 schetst de fenomenologie en concept van psychose en behandelt de continuüm opvatting. Volgens deze opvatting komen psychotische symptomen niet alleen voor in individuen met een psychotische stoornis, maar ook in een aanzienlijk deel van de algemene bevolking. Het hoofdstuk biedt verder een algemene introductie in de psychologie van paranoia, een veel voorkomend positief psychotisch symptoom. Twee invloedrijke psychologische modellen van paranoia worden kort besproken: het 'attributie - zelf-representatie model' en het 'multifactorieel model'. Volgens het eerste model heeft paranoia een defensieve functie en is het een gevolg van een samenhangend geheel van cognitieve biases om negatieve opvattingen over het zelf te vermijden en dus zelfwaardering te beschermen. Deze cognitieve biases zijn echter vaak disfunctioneel. Een belangrijke voorspelling van het model is dan ook dat zelfwaardering zich dynamisch presenteert door de tijd heen. Het 'multifactorieel model' vertoont een andere visie op de ontwikkeling van paranoia. Paranoïde of vervolgingswanen worden verondersteld voort te komen uit een interactie tussen verschillende factoren. Binnen dit model wordt een meer centrale en directe rol toegeschreven aan emotionele factoren en zelfwaardering bij de ontwikkeling en het voortbestaan van paranoia. Verderop in het hoofdstuk wordt de Experience Sampling Methode (ESM) geïntroduceerd als een geschikte, valide en betrouwbare methode om dynamische psychologische processen in het dagelijkse leven te onderzoeken. Een reeks risicofactoren voor psychose wordt beschreven, waaronder de aanwezigheid van doofheid of slechthorendheid. Aangezien slechthorendheid een diepgaande invloed heeft op interactie met de sociale omgeving, wordt verondersteld dat problemen op het gebied van horen een kwetsbaarheid vormen voor psychose door sociaal cognitieve en psychologische mechanismen te beïnvloeden. Het hoofdstuk eindigt met de doelstellingen en een uiteenzetting van het proefschrift. 
Het huidige proefschrift bestaat uit twee delen. Het eerste deel (hoofdstukken 2, 3 en 4) richt zich in het bijzonder op de onderliggende psychologische mechanismen van paranoïde symptomen.

Hoofdstuk 2 beschrijft een studie naar de associatie tussen zelfwaardering en paranoia. In de literatuur wordt paranoia geassocieerd met zowel hoge als lage, en zelfs normale, niveaus van zelfwaardering. Terwijl eerdere studies zich voornamelijk gericht hebben op niveau van zelfwaardering, focust de huidige studie zich ook op instabiliteit van zelfwaardering. Uitgaande van een continuüm opvatting van psychose, is gekozen voor een epidemiologische benadering om te onderzoeken of instabiliteit van zelfwaardering specifiek gerelateerd is aan subklinische paranoïde symptomen. Een steekproef van 4636 personen uit de algemene Nederlandse bevolking werd tijdens drie aparte meetmomenten geïnterviewd voor de aanwezigheid van positieve psychotische symptomen. De deelnemers vulden tijdens deze meetmomenten ook de Rosenberg SelfEsteem Scale in. De resultaten lieten zien dat individuen met subklinische paranoïde symptomen een significant lager gemiddeld niveau van zelfwaardering vertoonden ten opzichte van individuen met overige positieve psychotische symptomen (zoals gedachte interferentie en auditieve hallucinaties). Echter, meer interessant was dat de aanwezigheid van subklinische paranoïde symptomen, en niet overige positieve subklinische psychotische symptomen, significant geassocieerd was met instabiliteit van zelfwaardering over een periode van drie jaar. Deze associatie bleef significant na controle voor niveau van zelfwaardering, wat aangeeft dat instabiliteit van zelfwaardering niet begrensd wordt door niveau van zelfwaardering. De bevinding van een specifieke associatie tussen subklinische paranoïde symptomen en instabiliteit van zelfwaardering is in overeenstemming met het 'attributie - zelf-representatie model' dat werd geïntroduceerd in hoofdstuk 1. Mogelijk ontstaan paranoïde opvattingen deels als gevolg van disfunctionele pogingen om zelfwaardering te reguleren.

Hoofdstuk 3 presenteert een studie waarbij de Experience Sampling Methode werd gebruikt om korte termijn instabiliteit in zelfwaardering en paranoia te onderzoeken. Het doel van dit hoofdstuk was tweeledig. Allereerst werd de associatie tussen trait paranoia en niveau en instabiliteit van zelfwaardering onderzocht in 154 personen die zich op verschillende plaatsen van het paranoia continuüm bevonden. Trait paranoia werd gemeten aan de hand van de Paranoia Scale. Niveau en instabiliteit van zelfwaardering werden in het dagelijkse leven onderzicht aan de hand van de Experience 
Sampling Methode. De resultaten toonden aan dat trait paranoia geassocieerd was met zowel een lager niveau als hogere instabiliteit in zelfwaardering. Instabiliteit in zelfwaardering werd consistent aangetoond door middel van drie verschillende methoden om fluctuaties in zelfwaardering te meten: 1) op momentaan niveau, fluctuaties van moment tot moment, 2) op dagniveau, de maximum fluctuatie binnen de dag, en 3) op participant niveau, waarin de fluctuaties de variantie in zelfwaardering over de studieperiode reflecteert. Het tweede doel van dit hoofdstuk was om de temporele relatie tussen state paranoia en veranderingen in zelfwaardering te onderzoeken bij dezelfde personen. De resultaten toonden aan dat een afname in zelfwaardering geassocieerd was met een onmiddellijke toename in state paranoia. Over het geheel genomen leveren de bevindingen in dit hoofdstuk nader bewijs voor het 'attributie - zelf-representatie model', dat een defensieve functie voor paranoïde wanen suggereert.

Hoofdstuk 4 rapporteert een studie waarin de Experience Sampling Methode werd gebruikt om state paranoia en negatieve emotionele processen te onderzoeken in het dagelijkse leven van patiënten met positieve psychotische symptomen. Emotionele processen worden verondersteld een belangrijke rol te spelen in de ontwikkeling van paranoia. Het 'attributie - zelf-representatie model' en het 'multifactorieel model', beiden geïntroduceerd in hoofdstuk 1, postuleren een verschillende rol voor emotionele processen in de ontwikkeling van paranoïde symptomen: paranoia als protectie tegen negatieve emoties en paranoia als directe reflectie van negatieve emoties. State paranoia en drie voorname negatieve emoties, depressie, angst en boosheid, werden door middel van de Experience Sampling Methode onderzocht in het dagelijkse leven van 79 patiënten met een klinische diagnose van psychotische stoornis. De resultaten toonden aan dat paranoia onafhankelijk en significant cross-sectioneel geassocieerd was met gevoelens van angst, boosheid en depressie. Nog interessanter was dat longitudinale analyses aantoonden dat paranoia voorspeld werd door een toename in gevoelens van angst, boosheid en depressie. Paranoia was vervolgens een significante voorspeller van een toename in de drie emotionele processen. Tussen paranoia en angst werd de sterkste associatie aangetoond, zowel longitudinaal als cross-sectioneel. De bevindingen in dit hoofdstuk impliceren dat paranoïde opvattingen zowel resulteren uit als zorgen voor veranderingen in negatieve emotionele processen. Het lijkt er daarom op dat paranoïde opvattingen geen onmiddellijke defensieve functie vervullen tegen depressieve of andere negatieve emoties, zoals verondersteld door het 'attributie - zelf-representatie model'. 
Paranoia lijkt een directe reflectie van negatieve emoties, met name angst, zoals verondersteld door het 'multifactorieel model'.

Het tweede deel van dit proefschrift (hoofdstukken 5 en 6) concentreert zich op slechthorendheid, dat een kwetsbaarheid voor psychose vormt door in te grijpen op sociaal cognitieve en psychologische mechanismen.

Hoofdstuk 5 beschrijft een studie waarin een epidemiologische benadering is gebruikt om te onderzoeken of doofheid een risicofactor vormt voor positieve psychotische symptomen. De associatie tussen slechthorendheid en psychose is eerder beschreven, maar nog slecht onderzocht. In de huidige studie werd de veronderstelde associatie prospectief onderzocht in een steekproef van 4845 volwassenen uit de algemene bevolking. Slechthorendheid werd subjectief gemeten bij aanvang van de studie door deelnemers te vragen of ze doofheid of serieuze gehoorproblemen hadden ervaren in de afgelopen 12 maanden. Drie jaar later werden positieve psychotische ervaringen gemeten door middel van een interview. De resultaten toonden aan dat personen met doofheid of gehoorproblemen bij aanvang van de studie een drievoudig toegenomen risico hadden op het ontwikkelen van positieve psychotische symptomen ten opzichte van personen zonder gehoorproblemen. Slechthorendheid heeft een fundamentele invloed op interactie met de sociale omgeving. De associatie tussen slechthorendheid en positieve psychotische ervaringen kan daarom worden begrepen in termen van psychologische modellen die zich richten op sociaal cognitieve biases als een essentieel element in de ontwikkeling van positieve psychotische symptomen.

Hoofdstuk 6 borduurt verder op de link tussen doofheid of slechthorendheid en positieve psychotische symptomen. Weer werd een epidemiologische benadering gebruikt om de associatie te onderzoeken en om na te gaan in welke mate de associatie afhankelijk was van de duur van slechthorendheid. In de huidige studie werden 1411 adolescenten onderzocht, die allen reeds werden gevolgd vanaf hun geboorte. Slechthorendheid was subjectief bepaald op 7-jarige leeftijd (gerapporteerd door ouders en leerkrachten van de deelnemer) en op 19-jarige leeftijd (zelfrapportage). Positieve psychoseachtige ervaringen werden op 19-jarige leeftijd gemeten aan de hand van een vragenlijst die de frequentie van lichte psychotische ervaringen meet. De resultaten toonden aan dat gehoorproblemen op 7-jarige leeftijd niet geassocieerd waren met positieve psychoseachtige ervaringen op 19-jarige leeftijd. Gehoorproblemen op 19- 
jarige leeftijd waren echter wel geassocieerd met positieve psychoseachtige ervaringen op deze leeftijd. Interessant was dat er een significant interactie effect was, wat indiceerde dat de associatie significant sterker was in de individuen die al gehoorproblemen hadden op 7-jarige leeftijd vergeleken met mensen zonder slechthorendheid op deze jonge leeftijd. Deze bevindingen duiden erop dat personen met een langere periode van slechthorendheid en met aanvang vroeg in de kindertijd een groter risico hebben op het ontwikkelen van positieve psychotische symptomen.

Hoofdstuk 7 biedt een samenvatting van de belangrijkste bevindingen uit deel 1 en deel 2 van dit proefschrift. Het eerste deel van dit proefschrift toont aan dat zelfwaardering een belangrijk concept is bij paranoia, met name de dynamiek van zelfwaardering. Verder is aangetoond dat ook negatieve emotionele processen, met name angst, belangrijk zijn in de ontwikkeling van paranoia. Het 'attributie - zelf-representatie model' en het 'multifactorieel model' worden kritisch besproken. Het is duidelijk dat er een circulaire relatie is tussen zelfwaardering, negatieve emotionele processen en paranoia. Een laag niveau van zelfwaardering, hoge instabiliteit van zelfwaardering en negatieve emotionele processen fungeren mogelijk als kwetsbaarheidfactoren en handhavende factoren van paranoia, maar mogelijk ook als uit paranoia voortvloeiende factoren. Het tweede deel van dit proefschrift richt zich op de aanwezigheid van doofheid of slechthorendheid als risicofactor voor psychose. De bevindingen tonen aan dat slechthorendheid een kwetsbaarheid vormt voor het ontwikkelen van positieve psychotische symptomen. Daarnaast is aangetoond dat deze kwetsbaarheid afhankelijk is van de duur en aanvang van gehoorproblemen. Aangezien personen met gehoorproblemen een risico lopen op het ontwikkelen van sociaal cognitieve vaardigheden, kan de associatie verklaard worden in termen van psychologische modellen die zich richten op sociaal cognitieve biases als een essentieel element in de ontwikkeling van positieve psychotische symptomen. Gebreken in Theory of Mind zijn gerelateerd aan de ontwikkeling van wanen en bronmonitoring problemen zijn geassocieerd met hallucinaties. Kortom, beide delen van dit proefschrift laten zien dat er een wederzijdse relatie is tussen sociaal cognitieve en emotionele processen, welke beide kunnen worden opgevat als psychologische mechanismen die ten grondslag liggen aan het psychose fenotype. Risicofactoren, zoals doofheid of slechthorendheid kunnen ingrijpen op deze mechanismen (zie Figuur 7.1). Het hoofdstuk besluit met een kort overzicht van de klinische implicaties van het onderzoek en enkele aanbevelingen voor toekomstige vervolgstudies. 


\section{DANKWOORD}

Vlak voor mijn AiO-periode raadpleegde ik Het boek met alle antwoorden ${ }^{1}$. Zou ik me de komende vier jaar hélemaal gaan storten op de wetenschap? Het boek viel open op de bladzijde met de tekst "Ga op onderzoek uit en geniet ervan". Ik ben op onderzoek uit gegaan en heb er in ieder geval erg van genoten! Dit dankzij een groot aantal mensen, die ik hiervoor graag wil bedanken.

\section{Promotoren en copromotor}

In het bijzonder dank ik mijn promotor, Prof. dr. Jim van Os. Beste Jim, ik heb erg veel van je geleerd en heb veel bewondering voor jouw manier van werken. Jouw geestdrift, jouw vlotte - binnen 24 uur(!) - feedback, maar ook jouw wekelijks terugkomende vraag "Is je volgende artikel al af?" heeft er voor gezorgd dat ik gemotiveerd bleef en op tijd kon promoveren. Ook dank ik jou voor de mogelijkheden die je creëerde om binnen mijn AiO-schap ervaring op de doen in de klinische praktijk.

Mijn copromotor, Dr. Inez Myin-Germeys. Beste Inez, bij jou kon ik dagelijks binnen vallen met al mijn prangende vragen. Jouw enthousiasme en gedrevenheid in het doen van onderzoek heeft ervoor gezorgd dat ik met veel plezier aan mijn proefschrift heb gewerkt en ook enorm veel geleerd heb!

I would also like to thank my second supervisor, Prof. dr. Richard Bentall from the University of Manchester. Dear Richard, thank you for the very pleasant and fruitful collaboration during the past four years. I'm very grateful to you for inviting me over to the University of Manchester last year and for all the other opportunities for useful working visits. I'm very pleased to continue our collaboration now you are working at Bangor University in Wales.

\section{Beoordelingscommissie}

Graag wil ik de leden van de beoordelingscommissie bedanken voor de tijd en energie die zij gestoken hebben in het lezen en beoordelen van mijn manuscript: Prof. dr. M. de Vries (voorzitter), Prof. dr. A. Aleman, Dr. D. Freeman, Prof. dr. H. Merckelbach en Prof. dr. R. Wiers.

\footnotetext{
${ }^{1}$ Bolt, C. (2003). Het boek met alle antwoorden. BZZTôH: 's-Gravenhage.
} 


\section{Proefpersonen}

Mijn oprechte dank gaat uit naar alle proefpersonen die een week lang bereid waren om rond te lopen met het ESM-horloge. Zonder hen was dit proefschrift er helemaal niet geweest. Medewerkers van Mondriaan Zorggroep Heerlen (in het bijzonder Dr. Joost à Campo en Drs. Thom van Lierop), PMS Vijverdal, Psycope Maastricht en RIAGG Maastricht: dank voor jullie hulp bij de werving van proefpersonen.

\section{Co-auteurs en collegae}

Alle co-auteurs wil ik bedanken voor de fijne samenwerking. Het Trimbos instituut, en in het bijzonder Dr. Ron de Graaf en Dr. Wilma Vollebergh, dank ik voor het bieden van de mogelijkheid om met de NEMESIS data te werken. Dr. Nikos Stefanis, thank you for the interesting Greek birth cohort data. Many thanks go to all the staff from the psychopathology research group at Manchester University who have made my threemonth visit to Manchester a valuable experience.

De volgende personen zijn in verschillende stadia van het onderzoek van grote hulp geweest. Dr. Philippe Delespaul, dank voor je expertise bij het samenstellen van de ESMboekjes. Ron, dank voor je 24/7 computerondersteuning. Anouk, dankzij jouw punctualiteit en wervend vermogen op het gebied van proefpersoneninstroom hebben we de dataverzameling binnen de vastgestelde tijd kunnen afronden. Truda, Frieda, Inge en Miriam, bedankt voor de onderzoeksondersteuning en het coderen en invoeren van de enorme berg vragenlijsten en boekjes. Ook de stagiaires Ilona, Roos, Ingrid en Eefje wil ik bedanken voor hun inzet. Johan, dank voor het opnieuw benaderen van alle proefpersonen voor het vervolgonderzoek. Thanks to Judith for the (non-Jockifying!) linguistic advice.

Cécile, mijn kamergenoot, dank voor al jouw advies en belangstelling. Maar vooral bedankt voor de gezelligheid de afgelopen jaren! Ik ben blij dat we in de toekomst op vrijdag onze kamer kunnen blijven delen. Nicole, mijn paranimf, wij hebben samen de laatste loodjes voor ons proefschrift mogen delen. Ik vind het leuk dat we binnen twee weken tijd de rollen mogen omdraaien. Graag wil ik ook alle mede-AiO's en overige collegae van SP (Sociale Psychiatrie) en KP (Klinische Psychiatrie) bedanken voor alle leuke momenten op de afdeling tijdens lunchtijd of op congressen, terrasjes, etentjes, carnaval etc. Het was fijn om jullie collega te mogen zijn! 
Dankzij Psycope Maastricht kon ik de afgelopen jaren naast het doen van onderzoek ook meedraaien in een multidisciplinair team dat speciaal gericht is op de behandeling van psychotische aandoeningen. Alle leden van team II: bedankt voor de fijne tijd. Ik heb veel van jullie geleerd!

Mijn collegae van de Open Universiteit, veel dank voor jullie hartelijkheid en interesse in de afronding van het proefschrift! Sandra en Annette, bedankt voor het mooie ontwerp van de omslag van dit proefschrift.

\section{Vrienden en familie}

Graag wil ik mijn vrienden en vriendinnen bedanken. Jullie stonden altijd klaar om te helpen, al vanaf het begin van mijn onderzoek met het deelnemen aan de pilotstudie tot aan het eind met het poseren voor een foto voor op de kaft. Anne-Claire, mijn tweede paranimf, jij past perfect onder dit kopje. Niet alleen zijn we familie maar ook goede vriendinnen. Ik vind het fijn dat je mij als paranimf terzijde wilt staan.

Een speciaal woord van dank aan mijn familie en schoonfamilie. Lieve papa en mama, dank voor jullie steun, advies, betrokkenheid, aanmoediging en altijd aanwezige interesse in mijn proefschrift en alles wat ik doe in mijn leven. Dankzij jullie heb ik deze mijlpaal bereikt. Mijn lieve zus Eveline, in de afgelopen vier jaar liep mijn AiO-periode parallel aan de periode waarin jij gezondheidswetenschappen hebt gestudeerd en hebben we regelmatig informatie op het gebied van 'mental health' uitgewisseld. Ik wens je veel succes met je carrière! Het is een ongeschreven regel dat men de belangrijkste persoon als laatste noemt. Lieve Ken, ik wil jou bedanken voor je belangstelling, support, geduld, begrip, vriendschap en liefde in de afgelopen jaren. 


\section{CURRICULUM VITAE}

Viviane Thewissen werd geboren op 20 maart 1980 in Heerlen. Nadat zij in 1998 haar VWO diploma behaalde aan het Jeanne d'Arc College te Maastricht, ging zij Psychologie studeren aan de Universiteit Maastricht. In 2002 studeerde zij af in de richting biologische psychologie (neuropsychologie), waarna ze aansluitend ging werken als onderzoeksmedewerker aan de Universiteit Maastricht bij het Instituut Hersenen \& Gedrag (vakgroep Psychiatrie en Neuropsychologie) van de Faculteit der Geneeskunde. In april 2003 werd ze bij de sectie Sociale Psychiatrie en Psychiatrische Epidemiologie aangesteld als Assistent in Opleiding ( $\mathrm{AiO}$ ) om gedurende vier jaar onderzoek te doen naar psychologische mechanismen bij psychose in samenwerking met de Universiteit van Manchester, Engeland. Haar onderzoek is grotendeels uitgevoerd binnen het 'Sociaal Cognitie Lab' van Mondriaan Zorggroep Heerlen. In 2006 verbleef zij drie maanden aan de 'School of Psychological Sciences' van de Universiteit van Manchester. Naast haar promotieonderzoek werkte zij als psycholoog binnen een 'Assertive Community Treatment' team van Psycope Maastricht (een transmuraal zorgprogramma voor mensen met een psychotische aandoening) en verzorgde ze onderwijs aan de faculteiten Geneeskunde en Psychologie. Per 1 maart 2007 is ze werkzaam aan de Open Universiteit te Heerlen als Universitair Docent klinische psychologie. Ook blifft ze verbonden aan de Universiteit Maastricht in de functie van honorair post-doc onderzoeker. 


\section{Publications}

\section{International journals}

Thewissen, V., Bentall, R., Lecomte, T., van Os., J., \& Myin-Germeys, I. (in press). Paranoia and fluctuations in self-esteem in the context of daily life. Journal of Abnormal Psychology.

van der Werf, M., van Boxtel, M., Thewissen, V., \& van Os, J. (2007). Mild hearing impairment and psychotic experiences in a normal aging population. Schizophrenia Research, 94, 180-186.

Thewissen, V., Myin-Germeys, I., Bentall, R., de Graaf, R., Vollebergh, W., \& van Os., J. (2007). Fluctuations in self-esteem and subclinical paranoia. Social Psychiatry and Psychiatric Epidemiology, 42(1), 1-5.

Thewissen, V., Stefanis, N., van Os, J. and Myin-Germeys, I. (2006). Hearing impairment and psychosis: An association in a cohort of young adults. Schizophrenia Research, 85, 266-272.

Thewissen, V., Myin-Germeys, I., Bentall, R., de Graaf, R., Vollebergh, W., \& van Os, J. (2005). Hearing impairment and psychosis revisited. Schizophrenia Research, 76(1), 99-103.

\section{National journal}

Thewissen, V. (2006). Slecht horen: een risicofactor voor psychose. Psychiatrie Centraal, voorjaar 2006, 8-9.

\section{Abstracts}

Thewissen, V., Bentall, R., Lecomte, T., van Os, J., \& Myin-Germeys, I. (2007). Shortterm instability of self-esteem across the paranoia continuum. Schizophrenia Bulletin, 33(2), 224.

Thewissen, V., Bentall, R., à Campo, J., van Lierop, T., van Os, J., \& Myin-Germeys, I. (2007). Psychologische processen bij paranoia: Een Experience Sampling onderzoek. Tijdschrift voor Psychiatrie, 49(suppl. 1), S65-S66. 
Thewissen, V., van Os, J., Bentall, R., \& Myin-Germeys, I. (2006). Paranoia and fluctuations in self-esteem: An Experience Sampling Study. 13th AEP Symposium (Association of European Psychiatrists), Bordeaux, France, pp 172.

Thewissen, V., van Os, J., Bentall, R., \& Myin-Germeys, I. (2006). Paranoia and fluctuations in self-esteem in the context of daily life. Schizophrenia Research, 81, 130.

Thewissen, V., Myin-Germeys, I., Bentall, R., de Graaf, R., Vollebergh, W., \& van Os., J. (2005). Fluctuation in self-esteem as a mediator in the development of paranoid beliefs. Schizophrenia Bulletin, 31(2), 240.

Thewissen, V., Myin-Germeys, I., Bentall, R., de Graaf., R., Vollebergh, W., \& van Os., J. (2004). Deafness or hearing impairment: A risk factor for psychosis. Acta Psychiatrica Scandinavica, 421(110), 30.

Thewissen, V., Myin-Germeys, I., Bentall, R., de Graaf., R., Vollebergh, W., \& van Os., J. (2004). Deafness or hearing impairment: A risk factor for psychosis. Schizophrenia Research, 67(1), 49. 
